GILVAN PRADA ROSSI

\title{
ESTUDO DE CORRELAÇÃO DO COMPORTAMENTO DE PONTOS DE SOLDA EM CORPOS DE PROVA PELO MÉTODO DOS ELEMENTOS FINITOS
}

Dissertação apresentada à Escola Politécnica da
Universidade de São Paulo para obtenção do título de

Mestre em Engenharia

Área de Concentração: Engenharia Mecânica

Orientador: Prof. Dr. Marcelo Augusto Leal Alves 
GILVAN PRADA ROSSI

\section{ESTUDO DE CORRELAÇÃO DO COMPORTAMENTO DE PONTOS DE SOLDA EM CORPOS DE PROVA PELO MÉTODO DOS ELEMENTOS FINITOS}


A meus pais e minha avó, meus primeiros professores, cujo exemplo de conduta sempre foi e será um guia para a minha vida. 


\section{Agradecimentos}

Em primeiro lugar agradeço a Deus, por esta oportunidade que muitos gostariam de ter.

À minha família, pelo suporte nos momentos difíceis e pelo constante incentivo.

À minha esposa Angélica, que compreendeu a importância da realização deste trabalho e me ajudou com carinho e dedicação.

Ao meu orientador, Prof. Dr. Marcelo A. L. Alves, por toda ajuda e orientação no desenvolvimento deste estudo.

À General Motors do Brasil, representada pelo gerente do departamento de Cálculo Estrutural Roberto P. Ramos, pela oportunidade da realização deste estudo e pelos conselhos na fase final do trabalho.

Aos amigos Juan e Melissa, companheiros de estudo nas primeiras matérias do mestrado, Nelson Quim, Kathy Wang, José Castillo e Eduardo Almeida, pelas discussões sobre o tema, Haroldo, Flávio Costa e Bisaio pela ajuda na fabricação dos corpos de prova e realização dos testes. 
"Tende o mesmo sentimento uns para com os outros; em lugar de serdes orgulhosos, condescendei com o que é humilde; não sejais sábios aos vossos próprios olhos." (Romanos 12, 16) 


\section{Resumo}

A soldagem a ponto por resistência é o processo de união de partes mais comum utilizado na indústria automobilística. Vários métodos de representação de pontos de solda estão disponíveis, e este trabalho se propõe comparar dois métodos de modelagem de pontos de solda através de um estudo de correlação, em termos da força máxima suportada pela junta soldada, entre os resultados de testes virtuais e de laboratório. Estes métodos de representação dos pontos de solda são os elementos de viga e os elementos sólidos.

Os testes utilizados neste estudo de correlação carregam o corpo de provas sob ação de forças de cisalhamento e normal aplicadas diretamente no ponto de solda. E para completar este estudo de correlação, o entendimento dos modos e critérios de falha de juntas soldadas também é necessário.

Os modelos de elementos finitos dos corpos de prova gerados para serem testados sob condições de cisalhamento e de força normal são detalhados pela apresentação dos tipos de materiais, elementos, formulações de contato e carregamento utilizados. Estes modelos foram analisados pelo LS-DYNA, que é um código de elementos finitos de propósito geral para análise de respostas dinâmicas provenientes de grandes deformações de estruturas. Da mesma forma, os testes físicos e os corpos de prova utilizados são detalhados, e os resultados provenientes dos testes são comparados aos obtidos nas simulações.

Dos resultados obtidos, a melhor correlação se deu com a utilização do elemento sólido para representar o ponto de solda, com diferenças entre os resultados físicos e virtuais em torno de $4 \%$. Uma representação simples do ponto de solda é indicada no caso de modelos completos e para aplicações na indústria, alguns fatores, tais como a modelagem da ZTA, podem ser suprimidos.

Uma breve descrição do processo de soldagem a ponto, alguns tópicos da análise de elementos finitos não-linear e algumas características do LS-DYNA, além das conclusões e recomendações para trabalhos posteriores, completam este estudo.

Palavras-chave: Soldagem a ponto por resistência, ponto de solda, método dos elementos finitos, estudo de correlação. 


\begin{abstract}
Resistance spot welding is the most common jointing process of parts used in automotive industry. Several methods to represent spot welds are available, and the purpose of this work is to compare two different methods of spot weld modeling through a correlation study, taking into consideration the maximum force withstood by the welded joint, between virtual and lab test results. These spot weld representation methods are beam and solid elements.

The tests used in this correlation study load the specimens under pure shear and pure normal forces. And in order to complete this correlation study, the understanding of the failure modes and criteria is also necessary.

The specimens' finite element models generated to be tested under pure shear and normal conditions are detailed by the presentation of materials, elements, contact formulations and loading types used. These models were analyzed by the LS-DYNA, which is general purpose finite element code for analyzing the large deformation dynamic response of structures. As well, the physical tests and used specimens are detailed, and the results from the tests are compared to the results obtained in the simulations.

Taking the obtained results, the best correlation was found using solid elements to represent the spot weld, due to differences between the physical and the virtual results about 4\%. A simple representation of the spot weld is indicated in case of a complete model, and for the industry application, some factors such as the HAZ, may be suppressed.

A brief description of the spot welding process, some topics of the non-linear finite element analysis and some features of the LS-DYNA, and also the conclusions and recommendations for future works, complete this study.
\end{abstract}

Keywords: Resistance spot welding, spot weld, finite element method, correlation study. 


\section{LISTA DE ILUSTRAÇÕES}

Figura 1.1: 1997 Geo Metro (National Crash Analysis Center apud NIMBALKAR, 2003)

Figura 1.2: Processo da Análise de Elementos Finitos (BATHE, 1996)........................3 Figura 2.1: (a) viga elástica delgada carregada pela carga $P$. (b) viga elasto-plástica carregada por uma carga $P$ de direção fixa. (c) tensão de contato em um rolamento. (COOK, 1995).

Figura 2.2: Sistema de 1 grau de liberdade amortecido. (LS-DYNA theory manual, 1998)

Figura 2.3: Esquema de forças agindo na massa m. (LS-DYNA theory manual, 1998)

Figura 2.4: Método das Diferenças Centrais (ANSYS/LS-DYNA user's guide, 1998 apud SANCHES, 2001)

Figura 2.5: Esquema do Processo Iterativo de Integração no Tempo do LS-DYNA.. 19 (LS-DYNA Theory Manual, 1998).

Figura 2.6 - Exemplo gráfico de integração explícita no tempo (HALLQUIST, 2002)24

Figura 2.7 - Exemplo gráfico de integração implícita no tempo (HALLQUIST, 2002)26

Figura 2.8 - Corpos em contato no instante de tempo "t" (BATHE, 1996) .................29

Figura 2.9 - Nós da superfície Master deslizante designados com "x" são tratados como Nós de Superfície Livre no Método de Restrição Nodal (HALLQUIST, 1998). 32 Figura 2.10 - Esquema do contato *CONTACT_SLIDING_ONLY

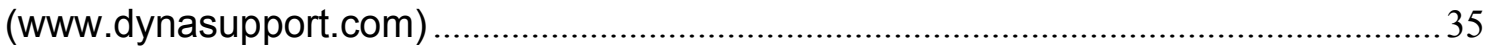

Figura 2.11 - Esquema do contato *CONTACT_TIED_SURFACE_TO_SURFACE

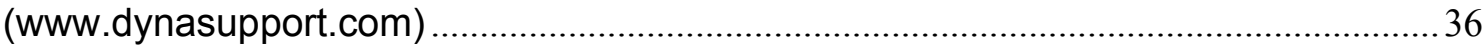

Figura 2.12 - Esquema do contato *CONTACT_SURFACE_TO_SURFACE

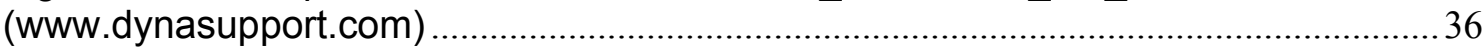

Figura 2.13 - Esquema do contato

*CONTACT_AUTOMATIC_GENERAL_INTERIOR (www.dynasupport.com)..............37

Figura 2.14 - Esquema do contato *CONTACT_NODES_TO_SURFACE

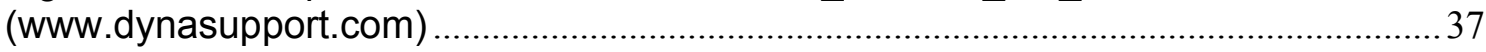

Figura 2.15 - Esquema do contato *CONTACT_TIED_NODES_TO_SURFACE

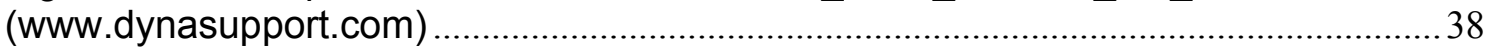

Figura 2.16 - Esquema do contato

${ }^{*}$ CONTACT_TIED_SHELL_EDGE_TO_SURFACE (www.dynasupport.com) .............38

Figura 2.17 - Esquema do contato *CONTACT_TIEBREAK_NODES_ONLY

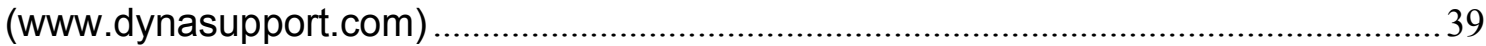

Figura 2.18 - Esquema do contato

*CONTACT_ONE_WAY_SURFACE_TO_SURFACE (www.dynasupport.com) ........40

Figura 3.1 - Diagrama simplificado dos processos básicos de solda por resistência (AWS apud RUIZ, 2005).

Figura 3.2 - Temperaturas no ponto de solda e demais regiões na máxima

temperatura (SSAB TUNNPLÅT, 1996)....

Figura 3.3 - Diagrama de Força e Tempo para Soldagem a Ponto (SSAB

TUNNPLÅT, 1996)

Figura 3.4 - Causas da Diminuição da Área de Contato dos Eletrodos (GMB apud RUIZ, 2005) 
Figura 3.5 - Lóbulo de Soldabilidade, Diagrama Generalizado (SSAB TUNNPLÅT, 1996)

Figura 3.6 - Esquematização das Regiões do Ponto de Solda (RUIZ, 2005)..............49

Figura 3.7 - Atributos Geométricos da solda mostrados esquematicamente em uma seção transversal de um Ponto de Solda (ZHOU et al., 2003) ...................................50 Figura 3.8 - Defeitos da Solda a Ponto e respectivas causas (SSAB TUNNPLÅT,

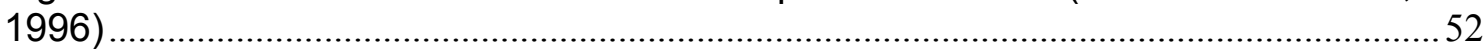
Figura 3.9 - Resistência ao Cisalhamento de Pontos de Solda em relação à Tensão de Ruptura do Material Base (SSAB TUNNPLÅT, 1996) .............................................54 Figura 3.10 - Redução de Custo/Peso em relação à Tensão de Escoamento do material (SSAB TUNNPLÅT, 1996) ......................................................................5

Figura 4.1: Equipamento de Testes Instron série 4480 (www.instron.us)...................56 Figura 4.2: Dimensões do corpo de provas de espessura 0,8 $\mathrm{mm}$ utilizado no teste

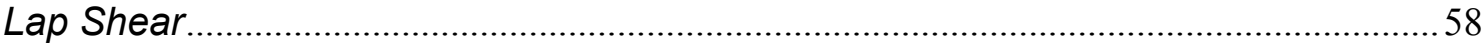
Figura 4.3: Dimensões do corpo de provas de espessura 1,2 mm utilizado no teste Lap Shear.

Figura 4.4: Imagem dos corpos de prova utilizado no teste Lap Shear (superior - 0,8

$\mathrm{mm}$; inferior - 1,2 mm) ..................................................................................... 58

Figura 4.5: Dimensões dos corpos de prova utilizados no teste de força normal

aplicada diretamente no ponto de solda ......................................................................5

Figura 4.6: Imagem dos corpos de prova utilizados no teste de força normal aplicada

diretamente no ponto de solda ..................................................................................5

Figura 4.7: Detalhe da fixação do corpo de prova Lap Shear.......................................61

Figura 4.8: Detalhe da fixação do corpo de prova de tração (normal) aplicada diretamente no ponto de solda.

Figura 5.1: Efeito da Localização do Elemento de Viga no teste Lap Shear (Wang, 2000)

Figura 5.2: Efeito da Localização do Elemento de Viga no teste Cross Tension (Wang, 2000) 68

Figura 5.3: Sistema de Coordenadas Locais do Elemento de Viga (Wang, 2000).....69 Figura 5.4: Modelo de elementos finitos do corpo de prova do ensaio Lap Shear, com representação da solda por elemento de viga..... .71 Figura 5.5: Modelo de elementos finitos do corpo de prova do ensaio de força normal aplicada diretamente no ponto de solda, com representação da solda por elemento sólido

Figura 5.6: Resultados dos Testes Lap Shear (3 amostras) com espessura 0,8 $\mathrm{mm} 72$ Figura 5.7: Resultados dos Testes Lap Shear (3 amostras) com espessura 1,2 mm73 Figura 5.8: Imagens do Teste Lap Shear - Corpo de prova com espessura de 1,2 $\mathrm{mm}$

Figura 5.9: Resultados de Simulação do Teste Lap Shear usando elementos de barra e sólido na representação do ponto de solda - espessuras de 0,8 e 1,2 mm..74 Figura 5.10: Evolução da deformação do corpo de prova com espessura de 1,2 mm - elemento de viga . .74

Figura 5.11: Resultados de Simulação do Teste Lap Shear usando elementos de barra e sólido na representação do ponto de solda com diferentes tamanhos de malha- espessura de $1,2 \mathrm{~mm}$

Figura 5.12: Resultados dos Testes de Força Normal Aplicada diretamente no ponto de solda ( 3 amostras) com espessura $0,8 \mathrm{~mm}$ .76 Figura 5.13: Imagens do Teste de Força Normal Aplicada diretamente no ponto de solda - Corpo de prova com espessura de $0,8 \mathrm{~mm}$ 
Figura 5.14: Resultados dos Testes de Força Normal Aplicada diretamente no ponto de solda (3 amostras) com espessura 1,2 mm

Figura 5.15: Resultados de Simulação dos Testes de Força Normal Aplicada diretamente no ponto de solda com espessura 0,8 $\mathrm{mm}$ .78

Figura 5.16: Evolução da deformação do corpo de prova com espessura de $0,8 \mathrm{~mm}-$ elemento sólido 78

Figura 5.17: Resultados de Simulação dos Testes de Tração (Normal) Aplicada diretamente no ponto de solda com espessura $1,2 \mathrm{~mm}$

Figura 6.1: Curva Força x Deslocamento - Modos de falha A e B (Zhou; Hu; Zhang, 1999)

Figura 6.2: Curva Força x Deslocamento - Modos de falha C, D e E (Zhou; Hu; Zhang, 1999)

Figura 6.3: Corpo de Prova tipo "Square-cup" (Lin et al. 2002)

Figura 6.4: Fratura na interface do ponto de solda - vista lateral e superior (Marya; Wang; Hector e Gayden, 2006)

Figura 6.5a: Fratura por destacamento do ponto de solda - vista lateral e superior (Marya; Wang; Hector e Gayden, 2006)

Figura 6.5b: Fratura por destacamento do ponto de solda - vista lateral e superior (Marya; Wang; Hector e Gayden, 2006).

Figura 6.6: Corpo de Prova para ensaio misto de carga normal $\left(P_{N}\right)$ e cisalhamento $\left(P_{S}\right)($ Chao, 2003).

Figura 6.7: Modo geral de deformação de uma junta soldada a ponto submetida ao ensaio Lap Shear - (a) configuração inicial, (b) rotação do ponto, alinhando-o com a linha de carga, (c) estiramento, afinamento e estricção, e (d) fratura devido a estricção (Chao, 2003) .88

Figura 6.8: Início da fratura no corpo de prova no ensaio Lap Shear (Chao, 2003) .. 88 Figura 6.9: Modo geral de deformação de uma junta soldada a ponto submetida ao ensaio Cross Tension - (a) configuração inicial, (b) deformação do corpo de prova, (c) fratura por destacamento do ponto (Chao, 2003).

Figura 6.10: Esquema geral das curvas Carga vs. Deslocamento para os ensaios Lap Shear e Cross Tension (Chao, 2003)

Figura 6.11: Corpo de Prova para ensaio do tipo Coach Peel (Zhang, 1998).............90 Figura 6.12: Corpos de Prova para falha por cisalhamento (a), rotação no plano (b), descascamento (c), e normal (d) (Wung, 2001)

Figura 6.13: Distribuição de Tensões Normais ao redor do ponto de solda no teste Lap Shear (Chao, 2003)

Figura 6.14: Distribuição de Tensões de Cisalhamento ao redor do ponto de solda no teste Cross Tension (Chao, 2003)....

Figura 6.15: Esquema da Rótula Plástica com ação da força aplicada $F_{P}$ (VandenBossche, 1977) .95

Figura 6.16: Diagrama de Corpo Livre no ponto de máxima rotação da solda (VandenBossche, 1977)

6.17: Distribuição de tensões na ZTA (VandenBossche, 1977)

Figura 2.6: Esquema do Processo Iterativo de Integração no Tempo do LS-DYNA 110 (LS-DYNA Theory Manual, 1998) 


\section{LISTA DE TABELAS}

Tabela 2.2: Procedimentos Alternativos de Integração. 13

Tabela 2.3: Vantagens dos Algoritmos Explícito e Implícito ............................................2

Tabela 2.4: Desvantagens dos Algoritmos Explícito e Implícito ....................................27

Tabela 3.1 - Atribuições das classes de segurança e dos critérios de qualidade incluindo definições complementares (DIN 8524 apud RUIZ, 2005)

Tabela 4.1 - Parâmetros de soldagem utilizados na fabricação dos corpos de prova 


\section{LISTA DE ABREVIATURAS E SIGLAS}

$\begin{array}{ll}\text { MPa } & \text { Mega Pascal } \\ \text { FMVSS } & \text { Federal Motors Vehicle Safety Standard } \\ \text { GMW } & \text { General Motors Worldwide Material Specifications Metals } \\ \text { GM } & \text { General Motors Corporation } \\ \text { GMB } & \text { General Motors do Brasil } \\ \text { ABS } & \text { Anti-lock Brake System } \\ \text { IIHS } & \text { Insurance Institute for Highway Safety } \\ \text { NCAP } & \text { New Car Assessment Programme } \\ \text { MNO } & \text { Materially-nonlinear-only } \\ \text { ID } & \text { Identificação de partes no modelo de elementos finitos } \\ \text { ZTA } & \text { Zona termicamente afetada } \\ \text { HAZ } & \text { Heat Affected Zone } \\ \text { RWMA } & \text { Resistance Welders Manufacturers' Association } \\ \text { TSF } & \text { Força Tensão-Cisalhamento } \\ \text { ASTM } & \text { American Society for Testing and Materials } \\ \text { NBR } & \text { Normas Brasileiras } \\ \text { ABNT } & \text { Associação Brasileira de Normas Técnicas } \\ \text { DIN } & \text { Deutsches Institut für Normung } \\ \text { ISO } & \text { International Organization for Standardization }\end{array}$




\section{LISTA DE SÍMBOLOS}

\{F\} Vetor de forças nodais

[K] Matriz de rigidez do sistema

\{u\} Vetor de deslocamentos nodais

[M] Matriz de massa

[C] Matriz de amortecimento

[K] Matriz de rigidez

$\{i i\} \quad$ Vetor de acelerações

$\{\dot{u}\} \quad$ Vetor de velocidades

$\{u\} \quad$ Vetor de deslocamentos

$\left\{F^{a}\right\} \quad$ Vetor de forças aplicadas

$\Delta \mathrm{t} \quad$ Incremento de tempo

c Coeficiente de amortecimento

k Rigidez linear

m Massa

$u_{0} \quad$ Deslocamento inicial

$\dot{u}_{0} \quad$ Velocidade inicial

$\phi \quad$ Matriz modal dos autovalores

L Comprimento característico do elemento

c Velocidade do som no material deformável

$\mathrm{A}_{\mathrm{c}} \quad$ Área do elemento de casca

$A_{s} \quad$ Área de lado do elemento sólido

$\checkmark \quad$ Volume do elemento sólido

$d_{\mathrm{P}} \quad$ Máxima Profundidade de Penetração no Contato

$\mathrm{T}_{1} \quad$ Tempo de aperto no processo de solda a ponto

T Tempo de soldagem

$\mathrm{T}_{2} \quad$ Tempo de espera no processo de solda a ponto

d Diâmetro do ponto de solda

w Largura do corpo de prova Lap Shear

$\mathrm{Sy}_{\mathrm{MB}} \quad$ Limite de escoamento do metal base

Sy $\quad$ Limite de escoamento do metal da solda 


$\begin{array}{ll}\text { SyzTA } & \text { Limite de escoamento da ZTA } \\ \sigma & \text { Tensão aplicada } \\ \sigma_{\mathrm{el}} & \text { Tensão equivalente na interface da solda } \\ \sigma_{\mathrm{eZTA}} & \text { Tensão equivalente na ZTA } \\ \mathrm{t} & \text { Espessura da chapa } \\ \mathrm{E} & \text { Módulo de Elasticidade } \\ \text { PR } & \text { Coeficiente de Poisson } \\ \text { SIGY } & \text { Tensão de Escoamento do material da solda } \\ \mathrm{E}_{\mathrm{t}} & \text { Módulo de Endurecimento do material da solda }\end{array}$




\section{SUMÁRIO}

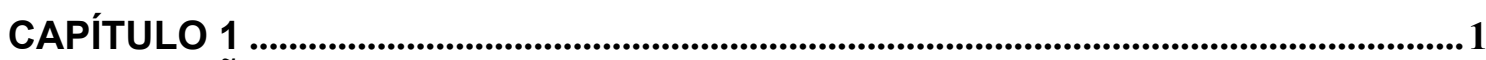

INTRODUÇÃO ................................................................................................................................... 1

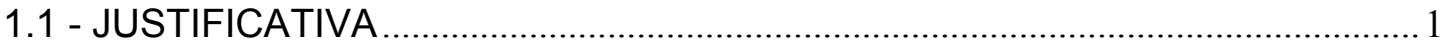

1.2 - OBJETIVOS

1.3 - MOTIVAÇÃO

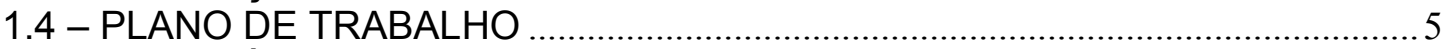

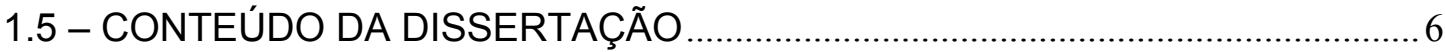

1.6 - RECURSOS COMPUTACIONAIS ...............................................................

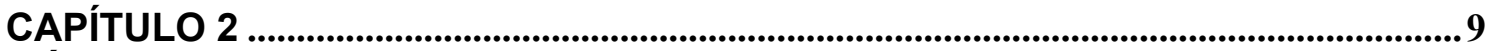

MÉTODOS COMPUTACIONAIS ..............................................................................9

2.1 - TÓPICOS DE ANÁLISE NÃO-LINEAR .........................................................

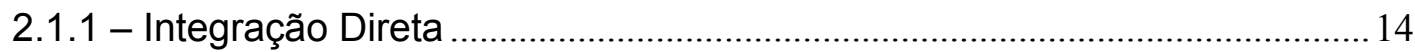

2.1.2 - Integração no Tempo ................................................................................. 14

2.1.3 - Integração no Tempo pelo Método das Diferenças Centrais...................... 18

2.1.4 - Estabilidade do Método das Diferenças Centrais .......................................2

2.2 - LS-DYNA - HISTÓRICO ……………………………………………….......2 22

2.3 - ANÁLISE IMPLÍCITA E ANÁLISE EXPLÍCITA - BREVE COMPARAÇÃO ...24

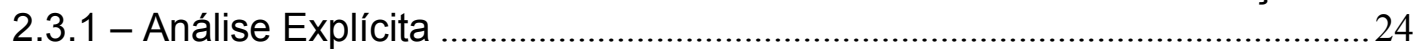

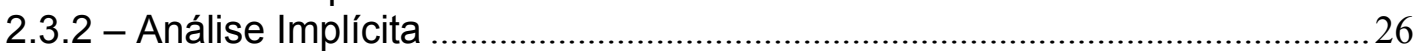

2.4 - COMPARATIVO DAS VANTAGENS E DESVANTAGENS DOS

ALGORÍTMOS DINÂMICOS EXPLÍCITO E IMPLÍCITO .............................................27

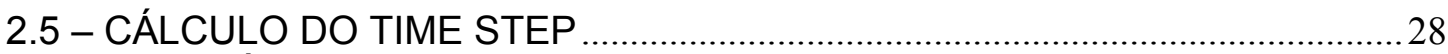

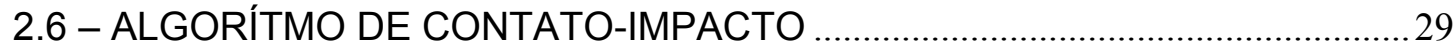

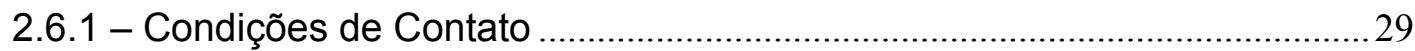

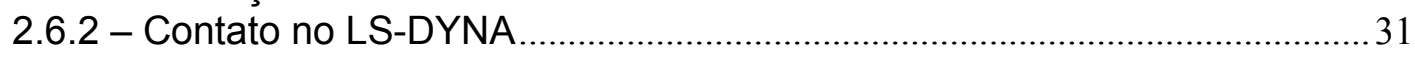

2.6.3 - Como o contato funciona no LS-DYNA ………………....................................

2.6.4 - Principais Tipos de Contato do LS-DYNA .......................................................

2.6.5 - Contatos de Superfície Simples (Single Surface) .........................................4 40

2.6.6 - Contatos Tied .......................................................................................... 41

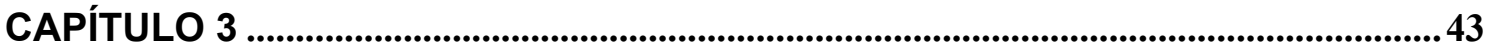

DESCRIÇÃO DO PROCESSO DE SOLDAGEM POR RESISTÊNCIA ELÉTRICA...43

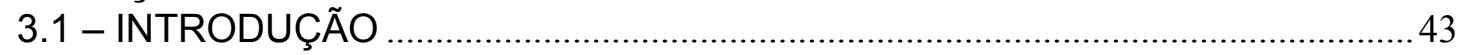

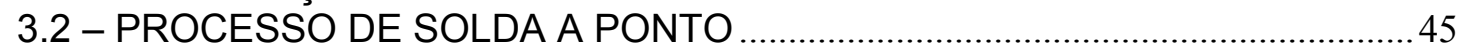

3.2.1 - Ajuste dos Parâmetros do Processo de Soldagem a Ponto ........................46

3.2.2 - Características do Ponto de Solda ...............................................................49

3.3 - SOLDA A PONTO EM AÇOS DE BAIXO CARBONO.........................................52

3.4 - SOLDA A PONTO EM AÇOS DE ALTA RESISTÊNCIA ……………………......53

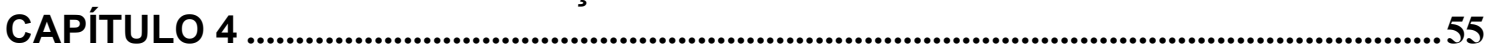

ESTUDO DO COMPORTAMENTO DE PONTOS DE SOLDA EM CORPOS DE

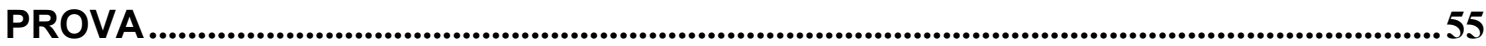

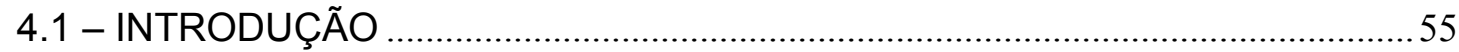

4.2 - PROCEDIMENTOS EXPERIMENTAIS …………………………………….........

4.2.1 - Parâmetros de Soldagem Utilizados …………………………………….......57

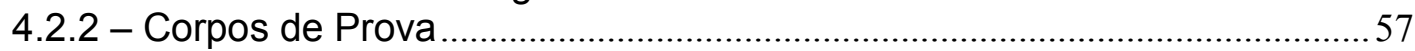

4.2.3 - Fixação dos Corpos de Prova .......................................................................6

CAPÍTULO 5 .....................................................................................................................................62 
CORRELAÇÃO DOS RESULTADOS DE TESTE E SIMULAÇÃO DO COMPORTAMENTO DE PONTOS DE SOLDA EM CORPOS DE PROVA ................62

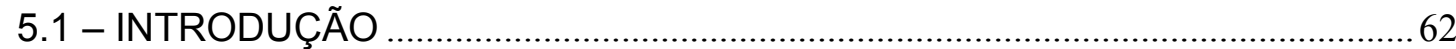

5.2 - REVISÃO BIBLIOGRÁFICA DOS ESTUDOS DE CORRELAÇÃO TESTE vs.

SIMULAÇÃO. 62

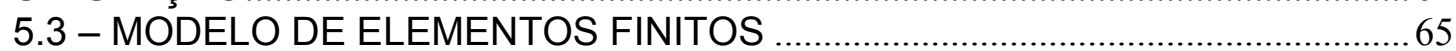

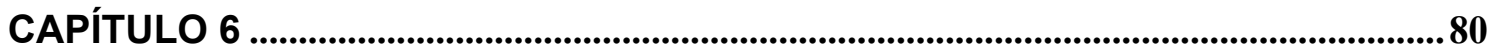

AVALIAÇÃO DA FALHA DE PONTOS DE SOLDA ….............................................80

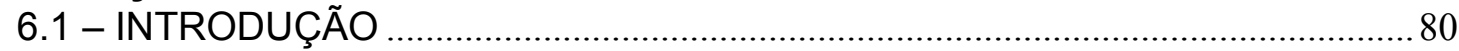

6.2 - TIPOS DE FRATURA DE JUNTAS SOLDADAS A PONTO ……………….....81

6.3 - CRITÉRIOS DE FALHA DE UMA JUNTA SOLDADA ..................................... 89

6.4 - APLICAÇÃO DO CRITÉRIO DE DETERMINAÇÃO DO DIÂMETRO CRÍTICO

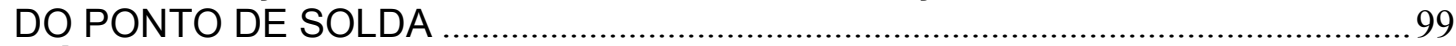

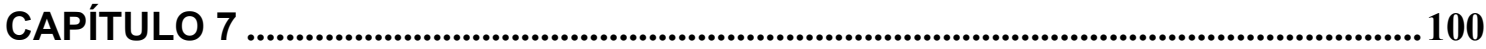

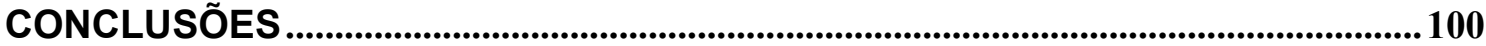

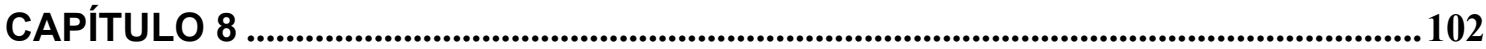

RECOMENDAÇÃO PARA TRABALHOS POSTERIORES ….....................................102

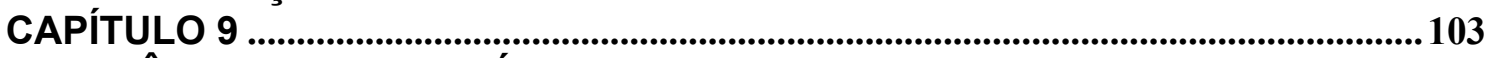

REFERÊNCIAS BIBLIOGRÁFICAS ................................................................103

ANEXO I.............................................................................................................................. 107

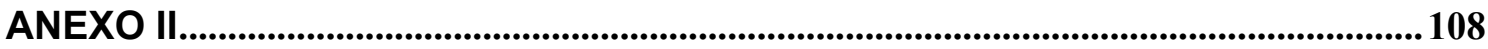

ANEXO III ................................................................................................................................... 109

CONSIDERAÇÕES PRELIMINARES E EQUAÇÕES GOVERNANTES

UTILIZADAS PELO LS-DYNA 


\section{CAPÍTULO 1 \\ INTRODUÇÃO}

\section{1 - JUSTIFICATIVA}

Com a crescente preocupação pela melhoria da segurança oferecida por veículos automotores, seja por conta da legislação, nacional ou internacional, que é constantemente aprimorada, ou até mesmo por meio de testes realizados por órgãos não-governamentais especializados e que influenciam a escolha do consumidor deste produto, o projeto de veículos deve ser planejado e executado desde o seu início tendo em vista atender não somente os requisitos legais de certificação, mas também corresponder às expectativas de um mercado que se torna cada vez mais exigente no que se refere à segurança. A prática de consultar órgãos especializados que classificam os veículos disponíveis no mercado quanto à segurança que eles oferecem é muito comum por consumidores na Europa (EuroNCAP - European New Car Assessment Programme) e nos Estados Unidos (IIHS - Insurance Institute for Highway Safety), e tem espaço para crescimento no Brasil, onde o fator preponderante na escolha de compra de um veículo é no momento o aspecto econômico.

Mas ao mesmo tempo em que as empresas fabricantes de automóveis precisam projetar veículos que sejam seguros, elas devem atender uma meta de execução em tempo e custo mínimos para que assim atinjam progresso financeiro. Para isso, essas empresas, mas não limitando esta prática às empresas apenas deste segmento, maximizam o emprego de ferramentas que permitem o desenvolvimento virtual do produto em todas as fases do projeto, da concepção à produção.

Estas ferramentas permitem avaliações também do processo, como a estampagem de peças metálicas ou a injeção de peças plásticas. Mas no que dizem respeito ao projeto do produto, as ferramentas de desenvolvimento virtual permitem avaliações de durabilidade, ruído e vibração, avaliações fluido-térmicas, crashworthiness, que define a capacidade da estrutura do veículo em prover proteção adequada aos seus ocupantes e à sua carga no evento de uma colisão (PALUSZNY, 1992), elétrica, entre outras. Especificamente em relação às 
avaliações estruturais do veículo, as ferramentas virtuais de desenvolvimento estão baseadas na teoria dos Elementos Finitos.

O método dos elementos finitos considera a região (contínuo) de solução do problema formada por pequenos elementos interligados entre si. A região em estudo é modelada, ou em termos práticos discretizada, por um conjunto de elementos prédefinidos, escolhidos de acordo com o tipo de simulação a ser executada. Uma vez que estes elementos podem ser colocados juntos em diferentes configurações, é possível a discretização de geometrias bastante complexas. Esse método também permite que o engenheiro analista possa aplicar no modelo diversos tipos de condição de contorno, que são restrições aplicadas aos graus de liberdade do modelo, e cargas, tais como forças, momentos, acelerações, pressão, tornando o método largamente utilizado em análises estruturais (SÁNCHEZ, 2001). Um veículo e seu respectivo modelo de elementos finitos é apresentado como exemplo de utilização do método na figura 1.1 .
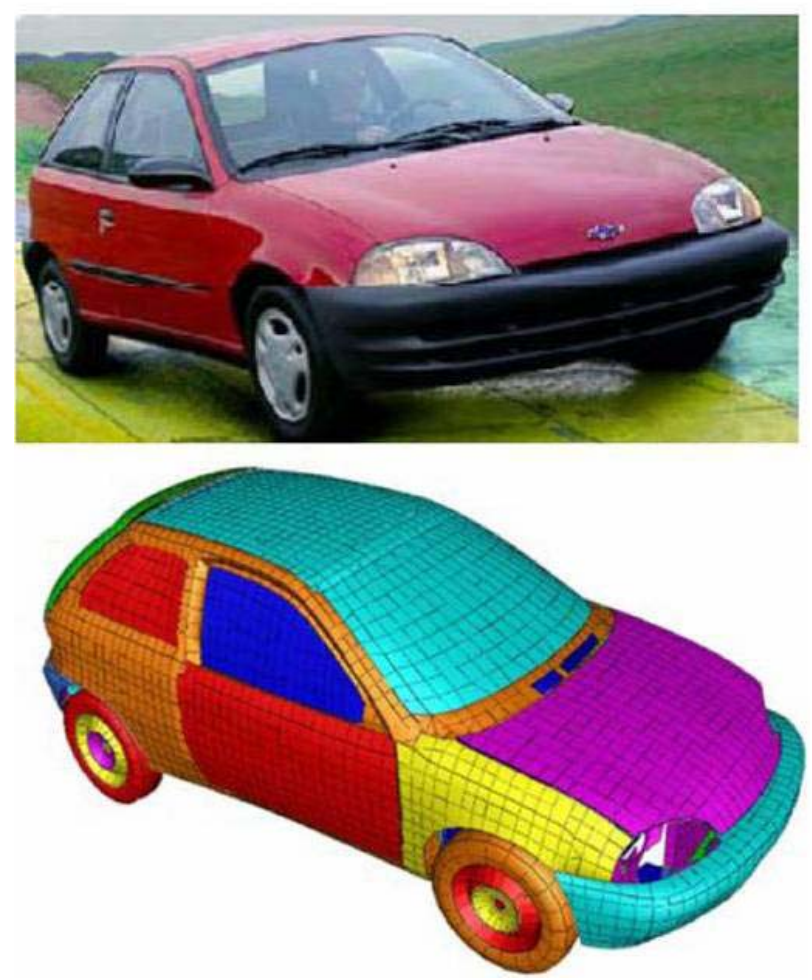

Figura 1.1: 1997 Geo Metro (National Crash Analysis Center apud NIMBALKAR, 2003) 
De maneira geral, o método dos elementos finitos é utilizado para solucionar problemas estruturais de análise e projeto em engenharia. O problema físico tipicamente envolve uma estrutura ou um componente estrutural sujeito a um determinado carregamento. A idealização do problema físico em um modelo matemático requer que algumas suposições sejam adotadas, que juntas levarão a um conjunto de equações diferenciais que governarão o modelo matemático. Esse modelo será solucionado pela análise de elementos finitos, que é uma aproximação do modelo real e sendo solucionado por uma técnica matemática. E como uma aproximação, deve atender a um critério de precisão a ser previamente estabelecido. Se o critério de precisão não é atendido, a solução numérica deve ser repetida como parâmetros mais refinados de solução, como por exemplo, a utilização de malhas mais finas ou refinadas, até que uma precisão suficiente é atingida.

Está claro que a solução dos elementos finitos resolverá apenas o modelo matemático solucionado e que todas as suposições adotadas no modelo se refletirão sobre a resposta. Portanto, uma escolha adequada do modelo matemático com todas as suas suposições é fundamental e determina completamente o quão bem será representado o problema físico pela análise.

A figura 1.2 mostra de maneira sumarizada o processo de uma análise de elementos finitos (BATHE, 1996).

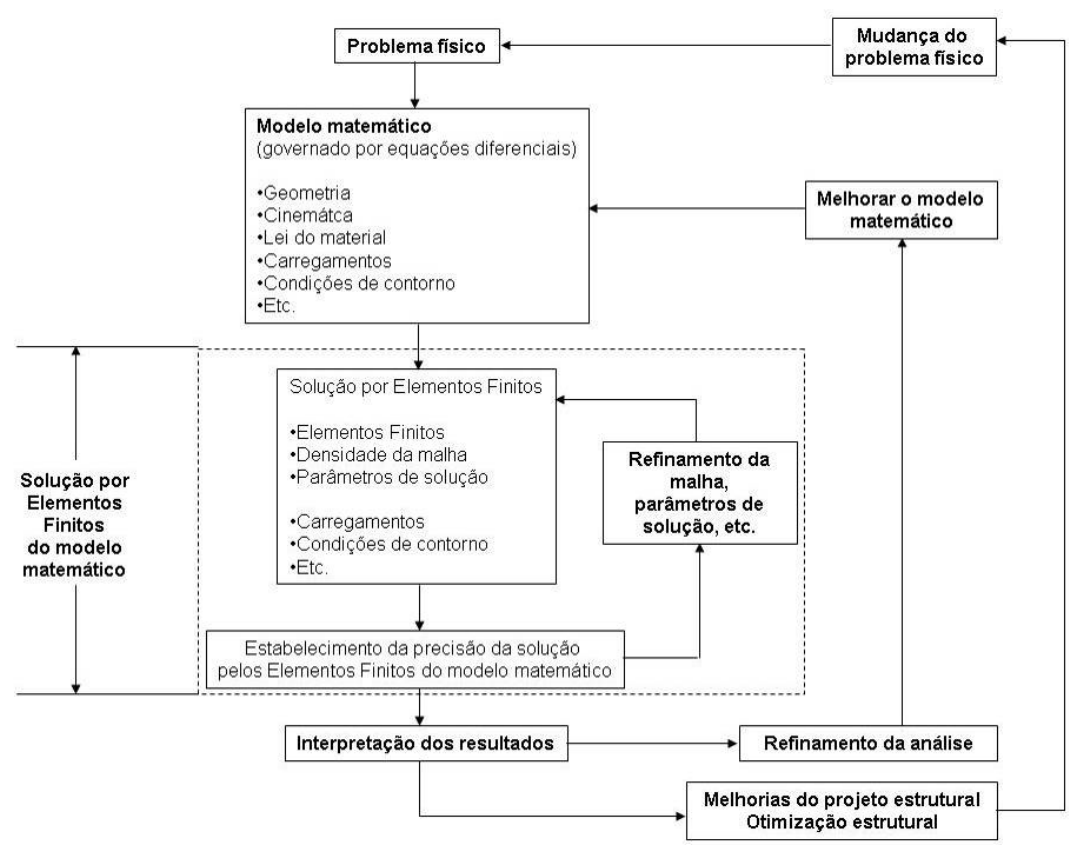

Figura 1.2: Processo da Análise de Elementos Finitos (BATHE, 1996) 
As simulações computacionais realizadas com base nesta teoria permitem estudos avançados e grande agilidade durante o desenvolvimento do produto por conta da quantidade de propostas que podem ser avaliadas sem que exista qualquer peça física. Com isso o número de protótipos para testes reais fica bastante reduzido e o custo do desenvolvimento é otimizado.

Contudo, para que haja a redução do número de protótipos durante a fase de desenvolvimento do veículo, os modelos de elementos finitos devem apresentar a precisão necessária para que exista confiança suficiente na substituição de um teste físico por uma simulação.

Além dos benefícios econômicos a serem conseguidos através da redução do número de protótipos e da diminuição do tempo de execução do projeto do veículo, poder estudar um possível aumento da confiabilidade do projeto no que diz respeito à segurança dos ocupantes também é uma justificativa deste trabalho. Apenas não se pode esquecer que a segurança não depende somente de um bom projeto estrutural, embora este seja de fundamental importância. A segurança veicular depende também de equipamentos presentes no veículo tais como freios $A B S^{1}$ para aumentar a eficiência nas frenagens, bolsas infláveis e cintos de segurança trabalhando que em ação conjunta desaceleram o ocupante e reduzem o risco de ferimentos na cabeça e tórax, e até mesmo o comportamento dos motoristas.

\section{2 - OBJETIVOS}

Este trabalho se propõe a estudar a correlação de dois tipos de modelagem de pontos de solda através de um estudo paramétrico: modelagem através de elementos de barra e de elementos sólidos.

O estudo se baseia na avaliação de modelos mais simples, no nível de corpos de prova, para familiarização das técnicas de modelagem dos pontos de solda no software escolhido, o LS-DYNA (Livemore Software Technology Corporation, 2001). Os resultados obtidos na simulação serão comparados com valores de testes físicos com o objetivo de avaliar qual tipo de elemento apresenta melhor correlação.

\footnotetext{
${ }^{1}$ Anti-lock Brake System (Sistema de Freios Anti-Travamento)
} 
Outros objetivos deste estudo são apresentar de maneira abreviada uma descrição do processo de soldagem a ponto, que é um processo de custo baixo e largamente empregado na indústria automobilística, e do comportamento de uma junta soldada a ponto sob tração, gerando cargas de cisalhamento e normal aplicada diretamente no ponto de solda, bem como os respectivos modos e critérios de falha.

\section{3 - MOTIVAÇÃO}

A correlação entre simulação e teste físico foi escolhida como tema central deste trabalho porque desta forma poderá ser apresentado de maneira prática o uso do Método dos Elementos Finitos em relação direta com o comportamento estrutural de pontos de solda objetivando a aplicação em segurança veicular. E a correlação é o principal objetivo da área de simulação, que utiliza o Método dos Elementos Finitos para a realização de seus estudos.

\section{4 - PLANO DE TRABALHO}

Após o desenvolvimento do estudo teórico que envolve o tema em questão, um plano de trabalho foi elaborado para facilitar a continuidade da pesquisa. Abaixo está a lista de tarefas que permitiu a organização do trabalho, agrupando pesquisa teórica e o estudo de correlação:

- revisão da literatura para desenvolvimento teórico do método dos elementos finitos não-linear, entendimento das características do software escolhido para o cálculo e estudo do histórico de simulações envolvendo pontos de solda;

- escolha dos modelos de elementos finitos que representarão os pontos de solda;

- definição das características dos corpos de prova a serem avaliados, tais como espessura e tipo de material;

- definição do carregamento a ser avaliado;

- obtenção dos resultados experimentais - testes realizados no Laboratório da área de Qualidade de Peças de Fornecedor da GMB; 
- criação e simulação dos modelos de elementos finitos paramétricos, reproduzindo os testes físicos;

- comparação dos resultados virtuais $\mathrm{x}$ experimentais obtendo qual modelo melhor representou o ponto de solda;

- conclusões do estudo.

\section{5 - CONTEÚDO DA DISSERTAÇÃO}

Esta dissertação está estruturada da seguinte maneira:

CAPÍTULO 1 - Introdução. Uma breve descrição dos objetivos, justificativa e motivação da realização deste estudo está apresentada neste capítulo. O plano de trabalho, o conteúdo da dissertação e os recursos computacionais utilizados no desenvolvimento do trabalho também estão aqui apresentados.

CAPÍTULO 2 - Métodos Computacionais. O método dos elementos finitos nãolinear, a descrição das técnicas de integração direta que permitem a solução dos problemas não-lineares e um resumo da teoria utilizada pelo LS-DYNA, que inclui os métodos de análise implícitos e explícitos, cálculo do incremento de tempo (time steps), algoritmo de contato, estão descritos neste capitulo.

CAPÍTULO 3 - Descrição do Processo de Soldagem por Resistência Elétrica. As características do processo de soldagem por resistência elétrica, também conhecida por solda a ponto, bem como suas vantagens e desvantagens, histórico e emprego na indústria podem ser encontrados no capítulo 3. A correlação do comportamento do ponto de solda sob diversos carregamentos é o principal objetivo deste estudo.

CAPÍTULO 4 - Estudo do Comportamento de Pontos de Solda em Corpos de Prova. O capítulo 4 descreve os ensaios realizados em corpos de prova soldados a ponto e os respectivos modelos de elementos finitos usados no estudo de correlação.

CAPÍTULO 5 - Correlação Teste vs. Simulação do Comportamento de Pontos de Solda em Corpos de Prova. Neste capítulo, os resultados obtidos pelos ensaios e 
pela simulação das juntas soldadas são comparados, identificando a correlação do comportamento dos corpos de prova.

CAPÍTULO 6 - Estudo de modos de falha de juntas soldadas e avaliação de modelos analíticos e critérios de falha de pontos de solda.

CAPÍTULO 7 - Conclusões.

CAPÍTULO 8 - Recomendação para Trabalhos Posteriores.

CAPÍTULO 9 - Referências Bibliográficas. Os livros, papers, dissertações e web sites utilizados como referência neste trabalho estão listados no capítulo 9.

ANEXOS - Os anexos contêm as seguintes informações: modelos de elementos finitos, gráficos de resultados e informações complementares.

\section{6 - RECURSOS COMPUTACIONAIS}

No pré-processamento ${ }^{2}$ do modelo de elementos finitos, o software utilizado foi o Altair Hypermesh v7.0 (Altair Computing Inc., 2005a). Sua principal característica é a compatibilidade com diversos solvers ${ }^{3}$ de elementos finitos, além de possuir uma interface bastante amigável, facilitando a construção do modelo.

\footnotetext{
${ }^{2}$ Entende-se por pré-processamento a fase de construção do modelo de elementos finitos incluindo escolha dos tipos de elementos, definição das propriedades dos materiais, carregamentos, condições iniciais e de contorno, e simplificações que possam ajudar o processamento computacional sem que o resultado final seja prejudicado.

${ }^{3}$ Solvers de elementos finitos são os programas que realizarão os cálculos e que estão baseados em um algoritmo numérico que tem por objetivo solucionar eficientemente o sistema de equações gerado a partir de todas as definições realizadas na fase de pré-processamento.
} 
Como este trabalho estuda resultados gerados a partir do impacto de estruturas, a teoria de elementos finitos a ser usada é a teoria não-linear, pois esta vai estudar as grandes deformações. O LS-DYNA (Livemore Software Technology Corporation, 2001), código de elementos finitos de propósito geral para análise de respostas dinâmicas provenientes de grandes deformações de estruturas foi escolhido para realizar estes cálculos.

Já o pós-processamento ${ }^{4}$ dos resultados foi feito pelo Altair Hypergraph módulo Crashworthiness (Altair Computing Inc., 2005b) para a geração de gráficos e pelo Altair Hyperview módulo Crashworthiness (Altair Computing Inc., 2005c) para a visualização da dinâmica das deformações.

Todos os softwares foram rodados no sistema operacional UNIX, caracterizado pela estabilidade, rapidez e melhor aproveitamento da memória disponível quando comparado ao Windows. Os cálculos foram realizados em servidoras do tipo CRAY, e o pré e pós-processamento foi realizado em estações de trabalho HP J2240.

\footnotetext{
${ }^{4}$ Pós-processamento é a etapa em que os resultados obtidos durante o processamento do modelo pelo solver de elementos finitos são analisados pelo engenheiro. Entre os resultados que se pode obter estão deslocamentos nodais, tensões, gradientes de temperatura, freqüências naturais e seus respectivos modos de vibrar, deformações, etc.
} 


\section{CAPÍTULO 2 MÉTODOS COMPUTACIONAIS}

\section{1 - TÓPICOS DE ANÁLISE NÃO-LINEAR}

A base teórica que envolve a análise de elementos finitos linear assume que os deslocamentos decorrentes dos carregamentos a qual a estrutura está sujeita são infinitesimalmente pequenos e as propriedades mecânicas dos materiais da estrutura em estudo apresenta apenas as características lineares elásticas. Além disso, assume-se que as condições de contorno permanecem inalteradas durante a aplicação das cargas no modelo de elementos finitos da estrutura. Com estas hipóteses, as equações de equilíbrio dos elementos finitos levam à:

$$
\{F\}=[K]\{u\}
$$

onde $\{F\}$ é o vetor de forças nodais, $[K]$ é a matriz de rigidez do sistema e $\{\mathbf{u}\}$ é o vetor deslocamentos nodais. As equações de equilíbrio que derivam da relação acima correspondem a uma análise linear de um problema estrutural pois o vetor $\{\mathbf{u}\}$ é uma função linear do vetor de forças $\{F\}$, e analogamente se o vetor de forças fosse $\alpha\{F\}$ ao invés de $\{F\}$, onde $\alpha$ é uma constante, o correspondente vetor de deslocamentos seria $\alpha\{\mathbf{u}\}$. E se essa relação não for verdadeira, temos um problema que deve ser solucionado por uma análise de elementos finitos não-linear (BATHE, 1996).

Para compreender problemas que envolvem impactos, como por exemplo a colisão de automóveis, uma boa representação dos fenômenos envolvidos dar-se-á através de estudos que levam em consideração o comportamento não-linear da estrutura. A não-linearidade de um fenômeno ocorre por várias causas (plasticidade, grandes deslocamentos, grandes rotações, deformações não-infinitesimais e os efeitos originários do contato e atrito entre chapas) e podem ser divididas de acordo com COOK (1995) em: 
- Não-linearidade geométrica: ocorre, por exemplo, quando as deformações são grandes o suficiente para significativamente alterar o modo com que a carga é aplicada ou o modo com que a carga é resistida pela estrutura (figura 2.1.a);

- Não-linearidade de material: ocorre quando a carga aplicada à estrutura gere tensões acima do limite de escoamento do material e após o descarregamento a estrutura apresenta deformação permanente (figura 2.1.b);

- Não-linearidade de contato: em problemas práticos, duas estruturas (ou duas partes de uma mesma estrutura) entram em contato quando o espaço entre elas deixa de existir, se separam após estarem em contato ou podem deslizar uma sobre a outra com atrito (figura 2.1.c).

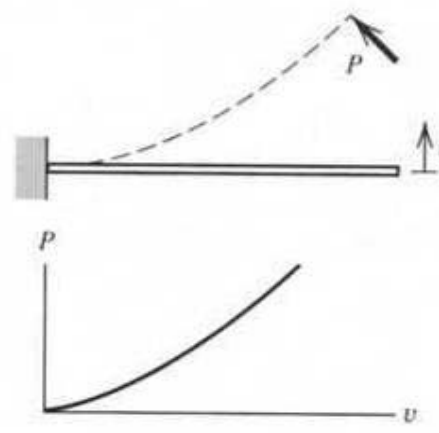

(a)
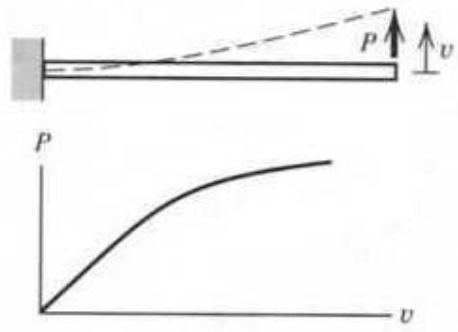

(b)

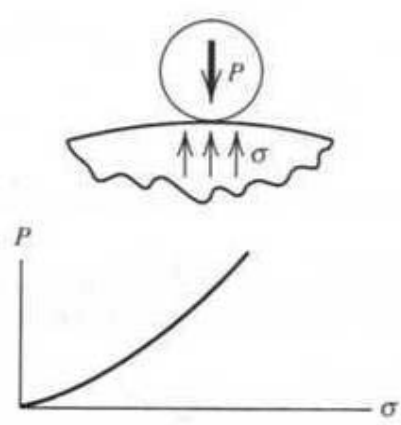

(c)

Figura 2.1: (a) viga elástica delgada carregada pela carga P. (b) viga elasto-plástica carregada por uma carga $P$ de direção fixa. (c) tensão de contato em um rolamento. (COOK, 1995)

Uma classificação dos diferentes tipos de análise não-linear foi proposta por BATHE (1996) e convenientemente separa os efeitos não-lineares de material e cinemáticos. Para cada um dos tipos de análise existe uma formulação diferente que não será apresentada neste trabalho, mas a tabela 2.1 mostra cada tipo de análise não-linear juntamente com as algumas respectivas características. 
Tabela 2.1: Classificação das análises não-lineares (BATHE, 1996)

\begin{tabular}{|c|c|c|c|}
\hline Tipo de análise & Descrição & $\begin{array}{l}\text { Formulação } \\
\text { tipicamente } \\
\text { utilizada }\end{array}$ & $\begin{array}{l}\text { Medições de } \\
\text { tensão e } \\
\text { deformação }\end{array}$ \\
\hline $\begin{array}{l}\text { Não-linearidade } \\
\text { de material }\end{array}$ & $\begin{array}{l}\text { Deslocamentos e } \\
\text { deformações } \\
\text { infinitesimais; a } \\
\text { relação tensão- } \\
\text { deformação é não- } \\
\text { linear. }\end{array}$ & $\begin{array}{l}\text { Não-linearidade } \\
\text { do material } \\
(\mathrm{MNO})\end{array}$ & $\begin{array}{l}\text { Tensão e } \\
\text { deformação de } \\
\text { engenharia }\end{array}$ \\
\hline $\begin{array}{l}\text { Grandes } \\
\text { deslocamentos, } \\
\text { grandes } \\
\text { rotações, mas } \\
\text { pequenas } \\
\text { deformações }\end{array}$ & $\begin{array}{l}\text { Deslocamentos e } \\
\text { rotações das fibras } \\
\text { são grandes, mas as } \\
\text { extensões das fibras e } \\
\text { as mudanças de } \\
\text { ângulos entre elas são } \\
\text { pequenos; a relação } \\
\text { tensão-deformação } \\
\text { pode ser linear ou } \\
\text { não-linear. }\end{array}$ & $\begin{array}{l}\text { Total Lagrangian } \\
(\mathrm{TL}) \\
\text { Updated } \\
\text { Lagrangian (UL) }\end{array}$ & $\begin{array}{l}\text { Tensões } \\
\text { secundárias de } \\
\text { Piola - Kirchhoff, } \\
\text { deformações de } \\
\text { Green - Lagrange } \\
\text { Tensões de } \\
\text { Cauchy, } \\
\text { deformações de } \\
\text { Almansi }\end{array}$ \\
\hline $\begin{array}{l}\text { Grandes } \\
\text { deslocamentos, } \\
\text { grandes } \\
\text { rotações, mas } \\
\text { pequenas } \\
\text { deformações }\end{array}$ & $\begin{array}{l}\text { As extensões das } \\
\text { fibras e as mudanças } \\
\text { de ângulos entre elas } \\
\text { são grandes, } \\
\text { deslocamentos e } \\
\text { rotações das fibras } \\
\text { podem ser grandes; a } \\
\text { relação tensão- } \\
\text { deformação pode ser } \\
\text { linear ou não-linear. }\end{array}$ & $\begin{array}{l}\text { Total Lagrangian } \\
(\mathrm{TL}) \\
\text { Updated } \\
\text { Lagrangian (UL) }\end{array}$ & $\begin{array}{l}\text { Tensões } \\
\text { secundárias de } \\
\text { Piola - Kirchhoff, } \\
\text { deformações de } \\
\text { Green - Lagrange }\end{array}$ \\
\hline
\end{tabular}


Para a solução de problemas dinâmicos, a seguinte equação de movimento é utilizada (BATHE, 1996):

$$
[M]\{\ddot{u}\}+[C]\{\dot{u}\}+[K]\{u\}=\left\{F^{a}\right\}
$$

onde:

$[M]$ é a matriz de massa;

[C] é a matriz de amortecimento;

$[K]$ é a matriz de rigidez;

$\{\ddot{u}\}$ é o vetor de acelerações;

$\{\dot{u}\}$ é o vetor de velocidades;

$\{u\}$ é o vetor de deslocamentos;

$\left\{F^{a}\right\}$ é o vetor de forças aplicadas.

Quando se trata de um problema estático, os vetores de acelerações e de velocidades são nulo e a equação (2.2) fica da seguinte forma:

$$
[K]\{u\}=\left\{F^{a}\right\}
$$

Para que se esteja diante de um problema não-linear, a matriz de rigidez $[\mathrm{K}]$ deve ser dependente do vetor de deslocamentos $\{u\}$ ou de suas derivadas, e dessa forma, as equações (2.2) e (2.3) respectivamente ficam:

$$
\begin{gathered}
{[M]\{\ddot{x}(t)\}+[C]\{\dot{x}(t)\}+[K(x(t))]\{x(t)\}=\{F(t)\}} \\
{[K(x(t))]\{x(t)\}=\{F(t)\}}
\end{gathered}
$$

A equação (2.2) representa matematicamente um sistema de equações lineares de segunda ordem que a princípio, poderiam ser resolvidas através de algum procedimento padrão para solução de equações diferenciais (BATHE, 1996). Entretanto, a solução desse sistema de equações pode se tornar muito trabalhoso se a ordem das matrizes for muito grande, o que é facilmente atingido quanto mais 
complexa for a estrutura em estudo. E neste ponto, alguns procedimentos alternativos de solução podem ser usados.

Esses procedimentos alternativos podem ser divididos em dois grupos, conforme a tabela 2.2 a seguir:

Tabela 2.2: Procedimentos Alternativos de Integração

\begin{tabular}{|l|l|}
\hline Métodos de Integração Direta & Métodos de Superposição Modal \\
\hline - Método de Newmark & - Mudança de base - coordenadas \\
- Método das Diferenças Centrais & generalizadas \\
- Método de Houbolt & - Sistemas sem amortecimento \\
- Método $\theta$ de Wilson & - Sistemas com amortecimento \\
\hline
\end{tabular}

Os métodos de Superposição Modal são largamente empregados em análises de vibrações, quando a geometria básica da estrutura não se altera (SALVAGNI, 2002). Nos problemas não-lineares, que envolvem plasticidade e contato, os modos de vibrar mudam durante o processo e inviabilizam a utilização dos Métodos de Superposição Modal, e desta forma a solução dos sistemas de equações diferenciais se dá pelos Métodos de Integração Direta. Em outras palavras, não se pode simplesmente escalar resultados na mesma proporção das cargas como nos métodos de superposição ou combinar resultados de diferentes casos de carregamento como é feito nas análises lineares. Cada caso de carregamento requer uma análise separada.

Outra característica relevante da não-linearidade é que se a estrutura está sujeita a um carregamento composto por várias cargas que são sequencialmente aplicadas, os resultados podem não ser independentes da ordem em que essas cargas são aplicadas (COOK, 1995). 


\subsection{1 - Integração Direta}

A equação (2.1) é solucionada por um método de integração direta. O termo "direto" significa que anteriormente à integração numérica nenhuma transformação de equações em uma forma diferente é executada. Em sua essência, os métodos numéricos de integração direta são baseados em duas idéias: primeiramente, ao invés de tentar satisfazer a equação (2.1) para qualquer tempo $t$, o objetivo é satisfazê-la somente em intervalos discretos de tempo $\Delta \mathrm{t}$ separadamente. Isto significa basicamente que o equilíbrio estático, o qual inclui o efeito de inércia e efeitos de amortecimento, é procurado em pontos de tempo discretos dentro de um intervalo de solução. Por isso, parece que todas as técnicas de solução empregadas na análise estática podem também ser efetivamente utilizadas na integração direta. A segunda idéia, na qual o método de integração direta é baseado, diz que uma variação dos deslocamentos, velocidades e acelerações dentro de cada intervalo de tempo $\Delta$ t é adotada. E esta suposição determina a precisão, estabilidade e custo (computacional) do procedimento de solução (BATHE, 1996).

\subsection{2 - Integração no Tempo}

A integração no tempo é realizada por time $\operatorname{steps}^{5}$ e pela integração da velocidade obtêm-se os incrementos de deslocamento.

$$
\dot{x}(t)=\frac{\Delta x(t)}{\Delta t}
$$

E a cada passo de integração no tempo o incremento de deslocamento é determinado e o conseqüente contato entre as estruturas ou as partes da estrutura é calculado. E com esse contato é possível encontrar as tensões e deformações.

A matriz de rigidez da estrutura $[K(x(t))]$ também é atualizada a cada passo da integração no tempo nos problemas que envolvem contato.

\footnotetext{
${ }^{5}$ Incrementos de tempo definidos para solução das equações do problema não-linear.
} 
Considerando o sistema amortecido de 1 grau de liberdade (figura 2.2) e as forças agindo na massa m (figura 2.3), obtemos a equação de equilíbrio conforme o princípio de d'Alembert:

$$
f_{1}+f_{D}+f_{\text {int }}=p(t)
$$

Onde:

$$
\begin{aligned}
& f_{1}=m \ddot{u} \quad ; \quad \ddot{u}=\frac{d^{2} u}{d t^{2}} \quad \rightarrow \quad \text { Aceleração } \\
& f_{D}=c \dot{u} \quad ; \quad \dot{u}=\frac{d u}{d t} \quad \rightarrow \quad \text { Velocidade } \\
& f_{\text {int }}=k u \quad ; u \quad \rightarrow \quad \text { Deslocamento }
\end{aligned}
$$

$c=$ coeficiente de amortecimento

$\mathrm{k}=$ rigidez linear

$\mathrm{m}=$ massa

Em notação matricial, a equação 2.7 assume o formato da equação 2.2.

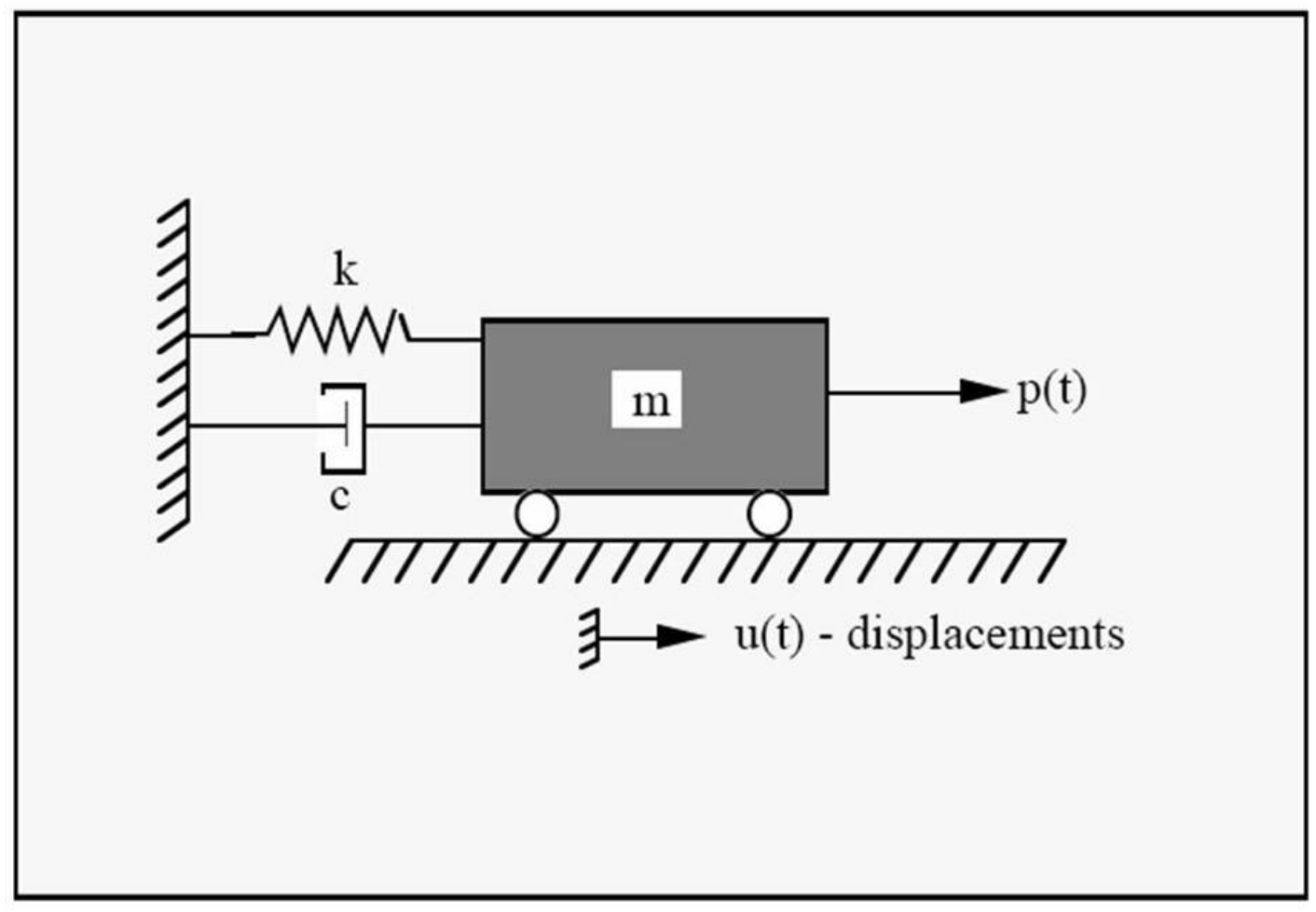

Figura 2.2: Sistema de 1 grau de liberdade amortecido. (LS-DYNA theory manual, 1998) 


\section{$f_{I}$ inertia force}

elastic force

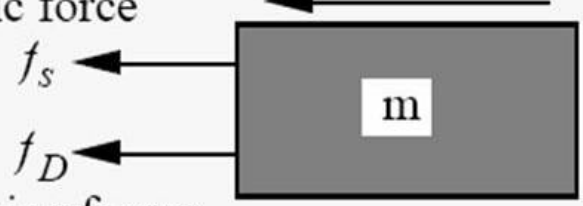

$\mathrm{p}(\mathrm{t})$ external

forces

damping forces

Figura 2.3: Esquema de forças agindo na massa m. (LS-DYNA theory manual, 1998)

A equação de movimento para o comportamento linear da estrutura leva à equação diferencial ordinária:

$$
m \ddot{u}+c \dot{u}+k u=p(t)
$$

Mas para o caso não-linear, as forças internas variam como uma função nãolinear do deslocamento, levando à equação diferencial ordinária:

$$
m \ddot{u}+c \dot{u}+f_{\text {int }}(u)=p(t)
$$

Soluções analíticas das equações diferenciais ordinárias lineares estão disponíveis, mas ao invés da opção por estas soluções, considera-se a resposta dinâmica de um sistema linear sujeito a um carregamento harmônico. Para tanto, é conveniente que se defina alguns termos comumente utilizados: 
Carregamento harmônico:

$$
p(t)=p_{0} \operatorname{sen} \bar{\omega} t
$$

Freqüência circular: $\omega=\sqrt{\frac{k}{m}} \quad$ (para 1 grau de liberdade)

Freqüência natural: $f=\frac{\omega}{2 \pi}=\frac{1}{T} \quad(\mathrm{~T}=$ período $)$

Taxa de amortecimento: $\xi=\frac{c}{c_{c r}}=\frac{c}{2 m \omega}$

Freqüência de vibração amortecida: $\quad \omega_{0}=\omega \sqrt{1-\xi^{2}}$

Freqüência de aplicação da carga: $\quad \beta=\frac{\bar{\omega}}{\omega}$

E assim, a solução fechada assume a seguinte forma:

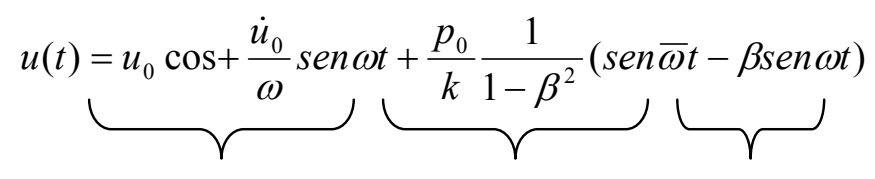

Solução homogênea Estado estacionário Transiente Solução particular

Com as seguintes condições iniciais:

$u_{0}=$ deslocamento inicial

$\dot{u}_{0}=$ velocidade inicial

$\frac{p_{0}}{k}=$ deslocamento estático

Para problemas não-lineares, somente as soluções numéricas são possíveis. O software para cálculos de problemas não-lineares utilizado neste estudo, o LSDYNA, utiliza o método explícito das diferenças centrais para integrar as equações de movimento. 


\subsection{3 - Integração no Tempo pelo Método das Diferenças Centrais}

Tomando a equação do movimento (2.4), no instante $t_{n}$, podemos descrever a velocidade e a aceleração como:

$\begin{array}{ll}\text { Velocidade: } & \{\dot{u}\}=\frac{1}{2 \Delta t}\left\{u_{n+1}-u_{n-1}\right\} \\ \text { Aceleração: } & \{\ddot{u}\}=\frac{1}{(\Delta t)^{2}}\left\{u_{n+1}-2 u_{n}+u_{n-1}\right\}\end{array}$

onde $\Delta$ t é o incremento de tempo ou intervalo dividido em instante futuro $\left(u_{n+1}\right)$, presente $\left(u_{n}\right)$ e passado $\left(u_{n-1}\right)$. Substituindo as equações (2.11) e (2.12) em (2.2), temos:

$$
[M]\left\{\frac{u_{n+1}-2 u_{n}+u_{n-1}}{(\Delta t)^{2}}\right\}+[C]\left\{\frac{u_{n+1}-u_{n-1}}{2 \Delta t}\right\}+[K]\{u\}=\left\{F^{a}\right\}
$$

E rearranjando os termos, teremos:

$$
\left[[M]+\frac{\Delta t}{2}[C]\right] u_{n+1}=\left\{\left(\Delta t^{2}\right)\left(-[K]\left\{u_{n}\right\}+[F]+2[M]\left\{u_{n}\right\}-\left([M]-\frac{\Delta t}{2}[C]\right) u_{n-1}\right\}\right.
$$

Portanto, o instante futuro $\left(u_{n+1}\right)$, presente no primeiro membro da equação (2.14) é a incógnita a ser determinada, pois os termos do segundo membro da equação são todos conhecidos. 


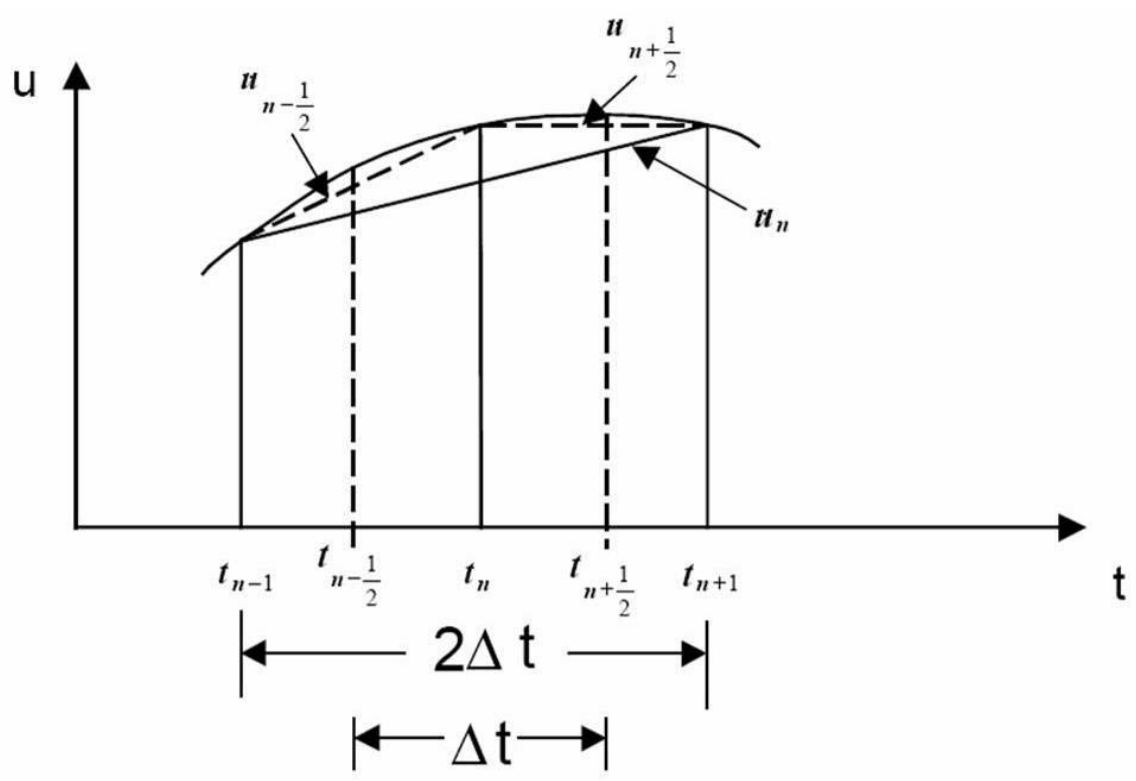

Figura 2.4: Método das Diferenças Centrais (ANSYS/LS-DYNA user's guide, 1998 apud SANCHES, 2001)

E de maneira simplificada, pode-se dizer que o deslocamento no instante $t_{n}+$ $\Delta$ t é dado explicitamente pelos deslocamentos nos instantes $t_{n}$ e $t_{n}-\Delta t$.

A título de informação, a figura 2.5 mostra como o LS-DYNA processa ciclicamente a integração no tempo:

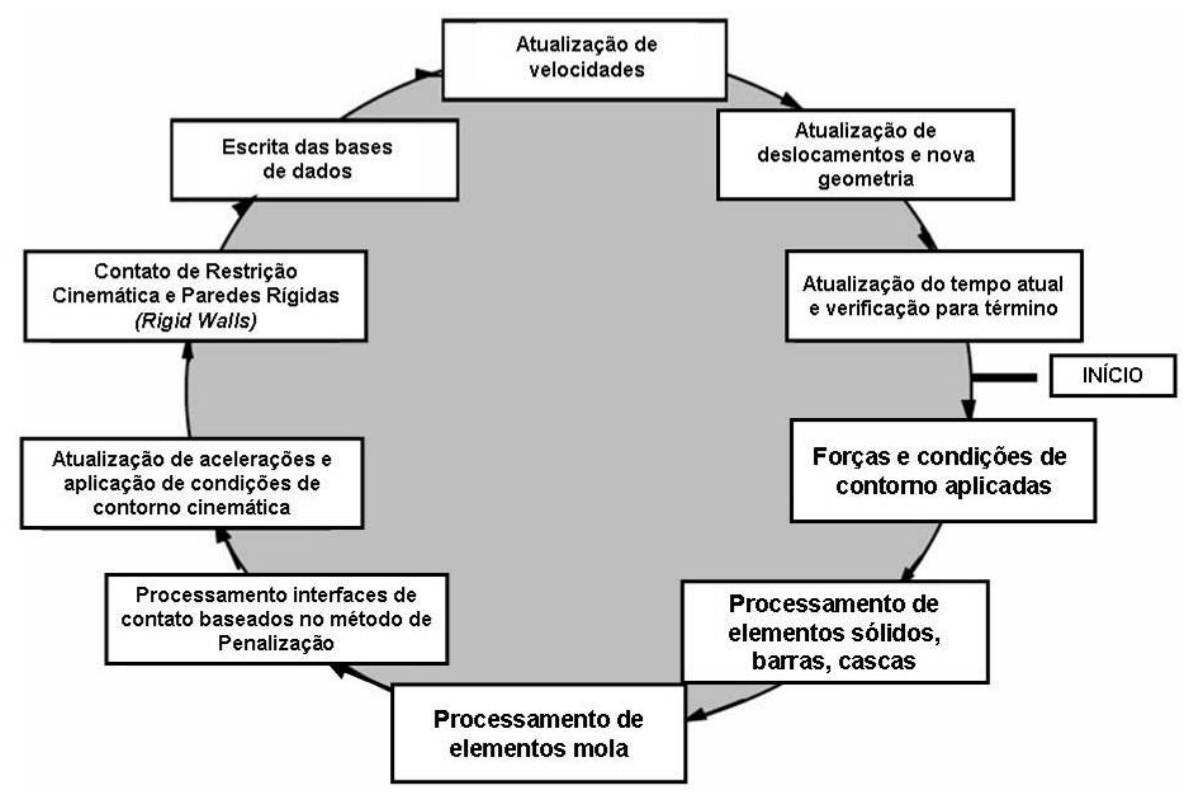

Figura 2.5: Esquema do Processo Iterativo de Integração no Tempo do LS-DYNA (LS-DYNA Theory Manual, 1998) 


\subsection{4 - Estabilidade do Método das Diferenças Centrais}

A estabilidade do Método das Diferenças Centrais é determinada pela busca da estabilidade de um sistema linear. O sistema linear de equações é desacoplado dentro das equações modais onde a matriz modal dos autovalores, $\phi$. é normalizada e as matrizes lineares de rigidez $\mathrm{K}$ e $\mathrm{M}$ respectivamente, tal que:

$$
\begin{aligned}
& \phi^{T} M \phi=I \\
& \phi^{T} K \phi=\omega^{2}
\end{aligned}
$$

Com a normalização, obtêm-se para o amortecimento o desacoplamento da respectiva matriz $\mathrm{C}$ :

$$
\phi^{T} C \phi=2 \xi \omega
$$

As equações de movimento nas coordenadas modais " $x$ " são:

$$
\ddot{x}+2 \xi \omega \dot{x}+\omega^{2} x=\phi^{T} p
$$

$\operatorname{com} Y=\phi^{T} p$

Com a normalização, obtêm-se para a velocidade e a aceleração:

$$
\begin{gathered}
\dot{x}_{n}=\frac{x_{n+1}-x_{n-1}}{2 \Delta t} \\
\ddot{x}_{n}=\frac{x_{n+1}-2 x_{n}+x_{n-1}}{\Delta t^{2}}
\end{gathered}
$$

Substituindo $\dot{x}_{n}$ e $\ddot{x}_{n}$ na equação de movimento no tempo $t^{n}$ teremos:

$$
x_{n+1}=\frac{2-\omega^{2} \Delta t^{2}}{1+2 \xi \omega \Delta t^{2}} x_{n}-\frac{1-2 \xi \omega \Delta t}{1+2 \xi \omega \Delta t} x_{n-1}+\frac{\Delta t^{2}}{1+2 \xi \omega \Delta t^{2}} Y_{n}
$$

que em forma matricial leva a: 
ou

$$
\left[\begin{array}{c}
x_{n+1} \\
x_{n}
\end{array}\right]=\left[\begin{array}{cc}
\frac{2-\omega^{2} \Delta t^{2}}{1+2 \xi \omega \Delta t} & -\frac{1-2 \xi \omega \Delta t}{1+2 \xi \omega \Delta t} \\
1 & 0
\end{array}\right]\left[\begin{array}{c}
x_{n} \\
x_{n-1}
\end{array}\right]+\left[\begin{array}{c}
\frac{\Delta t^{2}}{1+2 \xi \omega \Delta t^{2}} \\
0
\end{array}\right] Y_{n}
$$
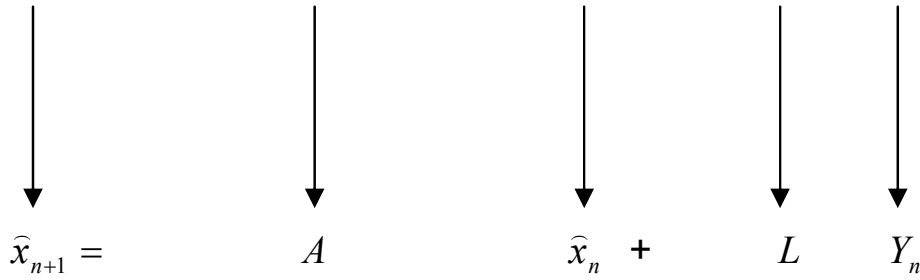

onde A é o operador da integração no tempo para equações discretas de movimento. Após m time steps com $\mathrm{L}=0$, obtêm-se:

$$
\hat{x}_{m}=A^{m} \widehat{x}_{0}
$$

Como $\mathrm{m}$ se aproxima do infinito, $\mathrm{A}$ deve permanecer limitado. Uma decomposição espectral de A nos mostra:

$$
A^{m}=\left(P^{T} J P\right)^{m}=P^{T} J^{m} P
$$

onde $\mathrm{P}$ é a matriz ortogonal que contém os autovetores de $\mathrm{A}$ e $\mathrm{J}$ á a forma de Jordan com os autovalores na diagonal. O raio espectral $(A)$ é o maior valor de $A=\max [\operatorname{diag}$ $(J)]$. Sabe-se que $\mathrm{J}^{\mathrm{m}}$ está limitado se e somente se:

$$
|\rho(A) \leq 1|
$$

Considerando os autovalores de A para a equação de movimento nãoamortecida

$$
\begin{aligned}
\operatorname{Det}\left[\begin{array}{cc}
2-\omega^{2} \Delta t^{2} & -1 \\
1 & 0
\end{array}|-\lambda| \begin{array}{cc}
1 & -1 \\
1 & 0
\end{array} \mid\right] & =0 \\
-\left(2-\omega^{2} \Delta t^{2}-\lambda\right) \cdot \lambda+1 & =0
\end{aligned}
$$




$$
\lambda=\frac{2-\omega^{2} \Delta t^{2}}{2} \pm \sqrt{\frac{\left(2-\omega^{2} \Delta t^{2}\right)^{2}}{4}-1}
$$

Os requisitos para que $|\lambda| \leq 1$ levam a:

$$
\Delta t \leq \frac{2}{\omega_{\max }}
$$

Como o time step crítico. Para as equações de movimento amortecidas, obtêm-se:

$$
\Delta t \leq \frac{2}{\omega_{\max }}\left(\sqrt{1+\xi^{2}}-\xi\right)
$$

Assim, o amortecimento reduz o time step crítico. O tamanho do time step é limitado pela maior freqüência natural da estrutura a qual é por sua vez limitada pela mais alta freqüência de qualquer elemento individual da malha de elementos finitos (HALLQUIST, 1998).

\section{2 - LS-DYNA - HISTÓRICO}

Desde a década de 50 quando o Método dos Elementos Finitos começou a ser utilizado inicialmente em problemas lineares, o método tem sido continuamente desenvolvido e é agora um componente essencial no desenvolvimento virtual de produtos.

A história do Método dos Elementos Finitos Não-Linear está intimamente ligada à evolução dos computadores e está bem representada pelo desenvolvimento dos códigos de elementos finitos. Muitos dos códigos comerciais para cálculo nãolinear foram desenvolvidos em universidades e centros de pesquisa internacionais (BELYTSCHKO, 2000). E um avanço na programação de códigos explícitos de elementos finitos começou em meados dos anos 70 no Lawrence Livermore National Laboratories, nos EUA, por John Hallquist (HALLQUIST, 1998). A primeira versão do código LSTC DYNA foi lançada em 1976 e rapidamente o DYNA-3D, (código com elementos sólidos com 4 ou 8 nós e de tensão constante, elementos sólidos com 16 
ou 20 nós de quadratura Gaussiana 2x2x2, elementos de membrana com 3, 4 ou 8 nós e elemento uniaxial de 2 nós) foi amplamente usado em universidades e laboratórios de pesquisa no mundo todo.

As melhorias feitas por Hallquist nas versões seguintes e que incluíam algoritmos efetivos de contato-impacto, aplicação de elementos de quadratura de um ponto com controle consistente de hourglass ${ }^{6}$ e alto grau de vetorização, abriram novos horizontes para a engenharia de simulação.

De maneira abreviada é possível definir o LS-DYNA como um código de elementos finitos de propósito geral utilizado em análise de repostas dinâmicas de grandes deformações de estruturas incluindo até estruturas acopladas a fluidos. A principal metodologia de solução dos problemas está baseada na integração explícita no tempo e o código contém mais que uma centena de modelos de materiais, mais de quarenta algoritmos de contato-impacto, grande variedade de formulações para cada tipo de elemento, além de elementos especiais como por exemplo os que representam as bolsas infláveis (Airbags) e cintos de segurança (Seat Belts), fazendo do LS-DYNA uma ferramenta analítica líder mundial na indústria automobilística utilizada por empresas como a GM em todos os seus centros de engenharia, a Daimler-Chrysler, Ford-Austrália, Jaguar, entre outras.

No Anexo III estão descritas as equações governantes do LS-DYNA, de acordo com Hallquist (1998).

\footnotetext{
${ }^{6}$ Devido a integração reduzida de um ponto do volume em integração plana, novas deformações artificiais devem ser desenvolvidas, ligadas à modos de energia nula. $\mathrm{O}$ volume de elementos finitos como os de cascas se deformam de acordo com modos de "hourglass" (um exemplo é um quadrado se transformando em trapézio). Para controlar essa deformação artificial, forças de resistência são adicionadas ao elemento. Assim, no balanço de energia mecânica aparece a energia de hourglass que é relacionada às forças de resistência contra a formação desses modos de deformação (http://iamlasun8.mathematik.uni-karlsruhe.de/parallel/skript/node151.html).
} 


\section{3 - ANÁLISE IMPLÍCITA E ANÁLISE EXPLÍCITA - BREVE COMPARAÇÃO}

A principal metodologia de solução do LS-DYNA está baseada na integração explícita do tempo. Este tipo de solução é bastante adequado para as simulações dinâmicas tais como as análises de impacto, mas se torna altamente cara na execução de análises estáticas e de longa duração. Um solver implícito está atualmente disponível com algumas limitações em análises estruturais e transferência de calor, mas para problemas estáticos, tais como análises de spring back ${ }^{7}$ depois de estampagem de chapas metálicas, este tipo de solução é amplamente recomendado (HALLQUIST, 2002).

\subsection{1 - Análise Explícita}

A Análise Explícita se refere ao método numérico usado para representar e resolver as derivadas de tempo nas equações de energia e movimento.

A figura 2.6 abaixo apresenta uma descrição gráfica de uma integração explícita no tempo.

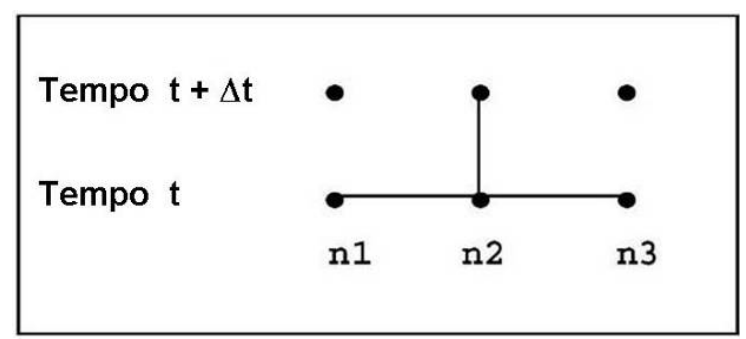

Figura 2.6 - Exemplo gráfico de integração explícita no tempo (HALLQUIST, 2002)

\footnotetext{
7 Termo que identifica o efeito mola comum após processo de estampagem de chapas metálicas onde se observa uma tendência de retorno da chapa ao seu formato original após liberação da força de deformação devido à recuperação elástica do material. O efeito não é apenas influenciado pelas propriedades mecânicas do material, como por exemplo a tensão de escoamento, mas também da espessura da chapa ou características geométricas da peça deformada como raios e ângulos de concordância (http://metals.about.com/library/bldef-Springback.htm).
} 
O deslocamento do nó $\mathrm{n} 2$ no tempo $\mathrm{t}+\Delta \mathrm{t}$ é igual aos valores conhecidos de deslocamento nos nós n1, n2 e n3 no tempo t. Um sistema de equações algébricas explícitas é escrito para todos os nós da malha no tempo $t+\Delta t$. Cada equação é solucionada para um deslocamento nodal desconhecido. Métodos explícitos são, do ponto de vista computacional, bastante rápidos mas são condicionalmente estáveis. O time step $\Delta$ t deve ser menor que um valor crítico ou erros computacionais tomarão enormes proporções, resultando em uma solução ruim. O time step ainda deve ser menor do que o tempo que um sinal leva para viajar na velocidade do som no material entre dois pontos nodais. As considerações sobre o controle serão descritas adiante.

E o valor crítico do time step pode ser calculado por:

$$
\Delta t \leq \frac{\Delta x}{c}=\frac{\Delta x}{\sqrt{\frac{E}{\rho}}}
$$

onde $\Delta$ t é o time step, $\Delta \mathrm{x}$ é a distância entre dois nós, c é uma constante do material que é expressa pela raiz quadrada do módulo de elasticidade (E) sobre a densidade do material $(\rho)$.

Como medida de segurança, o valor de time step utilizado pelo LS-DYNA é 90\% do valor calculado pela expressão acima (HALLQUIST, 2002). 


\subsection{2 - Análise Implícita}

Analogamente à Análise Explícita, a Análise Implícita também se refere a um método numérico usado para representar e resolver as derivadas de tempo nas equações de energia e movimento.

A figura 2.7 abaixo apresenta uma descrição gráfica de uma integração implícita no tempo.

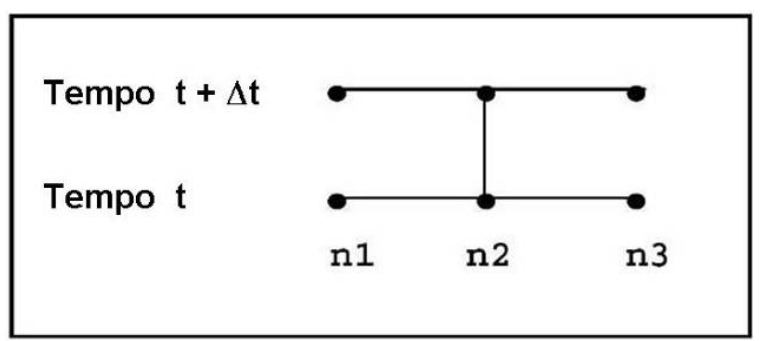

Figura 2.7 - Exemplo gráfico de integração implícita no tempo (HALLQUIST, 2002)

O deslocamento do nó $\mathrm{n} 2$ no tempo $\mathrm{t}+\Delta \mathrm{t}$ é igual ao nível aos valores conhecidos de deslocamento dos nós $n 1$, n2 e n3 no tempo $t$, e também aos desconhecidos valores de deslocamentos dos nós $n 1$ e n3 no tempo $t+\Delta t$. Isto resulta em sistema de equações algébricas simultâneas que são solucionadas utilizando-se Álgebra Matricial (por exemplo, algum método de inversão de matrizes). A vantagem deste método é que ele é incondicionalmente estável (não há tamanho de time step crítico). Em contrapartida, ele apresenta algumas desvantagens tais como o grande esforço computacional requerido para formar, armazenar e inverter o sistema de equações. Simulações que utilizam o método implícito para sua solução, tipicamente envolvem um número pequeno de incrementos para que o cálculo não se torne computacionalmente inviável (HALLQUIST, 2002). 


\section{4 - COMPARATIVO DAS VANTAGENS E DESVANTAGENS DOS ALGORÍTMOS DINÂMICOS EXPLÍCITO E IMPLÍCITO}

Tabela 2.3: Vantagens dos Algoritmos Explícito e Implícito

\begin{tabular}{|l|l|}
\hline \multicolumn{1}{|c|}{ Algoritmo Explícito } & \multicolumn{1}{c|}{ Algoritmo Implícito } \\
\hline - É robusto e mais simples de & É incondicionalmente \\
programar; & convergente: a convergência é \\
- É mais rápido que o algoritmo & garantida independentemente do \\
implícito; & tamanho do time step; \\
- Requer menos memória que o & É a solução natural e completa \\
algoritmo implícito; & do problema: não faz \\
Pode ser paralelizado; & simplificações (matrizes não são \\
Tem bom desempenho para a & diagonais) e a solução tem \\
instabilidade da rigidez. & embutida todo o fenômeno. \\
\hline
\end{tabular}

Tabela 2.4: Desvantagens dos Algoritmos Explícito e Implícito

\begin{tabular}{|l|l|}
\hline \multicolumn{1}{|c|}{ Algoritmo Explícito } & \multicolumn{1}{c|}{ Algoritmo Implícito } \\
\hline É incondicionalmente & - Utiliza mais recursos \\
covergente; & computacionais; \\
- Para se obter uma melhora da & É mais lento; \\
convergência, time steps & É mais sensível que o explícito: a \\
extremamente pequenos são & instabilidade em situações \\
freqüentemente necessários, & especiais pode levar a matriz de \\
denominada Condição de & rigidez à singularidade \\
Courant ${ }^{8}$. & (instabilidade elástica). \\
\end{tabular}

\footnotetext{
${ }^{8}$ A Condição de Courant [Richard Courant (1888-1972)] limita o incremento de tempo para que seja menor que o tempo gasto para uma onda sonora atravessar o elemento de menor comprimento característico no modelo (excluindo os corpos rígidos). Deste modo, garante-se que uma onda de choque que se propaga através de um elemento causará o desenvolvimento de tensões no interior do elemento tal como ocorre na realidade. Se o incremento de tempo é muito grande, o movimento da onda de choque pode "pular" um elemento não detectado (CASTRO, 2005).
} 


\section{5 - CÁLCULO DO TIME STEP}

Conforme mencionado na seção 2.3.1, a equação 2.31 define o time step da simulação, e por medida de segurança, que pode ser entendida pela garantia da estabilidade do cálculo, o LS-DYNA utiliza 90\% deste incremento de tempo calculado.

Para cada iteração, quando é necessário estabelecer o incremento de tempo,

o LS-DYNA verifica todos os elementos. Na fórmula, $\Delta t=0.9 \frac{L}{c}$ o comprimento característico $L$ e a velocidade de propagação da onda c são dependentes do tipo de elemento:

- Elemento de viga:

$L=$ comprimento do elemento

$c=\sqrt{\frac{E}{\rho}}$

- Elemento de casca (shell):

$L=\frac{A_{c}}{\max \left(L_{1}, L_{2}, L_{3}, L_{4}\right)}$ para elementos quadrangulares;

$L=\frac{2 A_{c}}{\max \left(L_{1}, L_{2}, L_{3}\right)}$ para elementos triangulares;

$c=\sqrt{\frac{E}{\rho\left(1-v^{2}\right)}}$

- Elemento sólido:

$L=\frac{V}{\max \left(A_{S 1}, A_{S 2}, A_{S 3}, A_{S 4}, A_{S 5,} A_{S 6}\right)}$ para elementos hexaedros de 8 nós;

$L=$ menor altura para elementos tetraedros de 4 nós;

$c=\sqrt{\frac{E(1-v)}{\rho(1+v)(1-2 v)}}$ 


\section{6 - ALGORÍTMO DE CONTATO-IMPACTO}

\subsection{1 - Condições de Contato}

Segundo BATHE (1996), há uma dificuldade na avaliação do comportamento não-linear de dois ou mais corpos que é o contato entre eles. A não-linearidade do problema não acontece somente pela não-linearidade geométrica ou do material. Ela pode acontecer também devido às condições de contorno do problema em análise. Os problemas de contato vão desde pequenos deslocamentos sem atrito até o contato com atrito em condições de grandes deformações inelásticas. E embora a formulação da condição de contato é a mesma em todos os casos, a avaliação do problema pode se tornar muito complicada em outros casos.

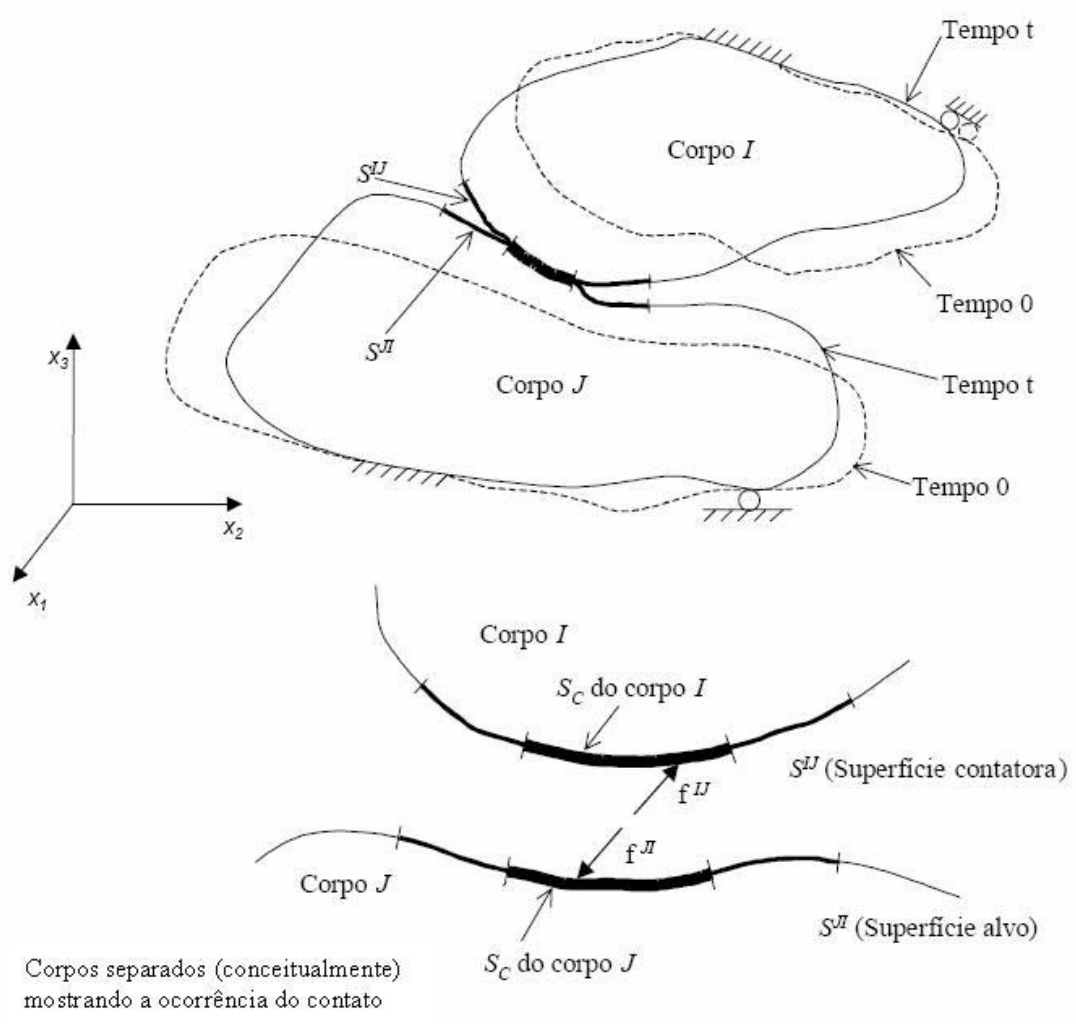

Figura 2.8 - Corpos em contato no instante de tempo " $t$ " (BATHE, 1996) 
Considere-se $N$ os corpos que estão representados na figura 2.8 e estão em contato no tempo $t$. Seja $S_{C}$ a área completa de contato para cada corpo $L, L=1, \ldots$, $N$. O Princípio dos Trabalhos Virtuais para $N$ corpos, fornece no tempo $t$ :

$$
\sum_{L=1}^{N}\left\{\int_{V} \tau_{i j} \delta_{t} e_{i j} d V\right\}=\sum_{L=1}^{N}\left\{\int_{V} \delta u_{i} f_{i}^{B} d V+\int_{S_{f}} \delta u_{i}^{S} f_{i}^{S} d S\right\}+\sum_{L=1}^{N} \int_{S_{C}} \delta u_{i}^{C} f_{i}^{C} d S
$$

onde os termos entre chaves são os termos usuais e o último somatório corresponde à contribuição das forças de contato. O efeito das forças de contato é incluído como uma contribuição às forças de superfície aplicadas externamente.

Seja $f^{I J}$ o vetor contendo as forças devido ao contato no corpo I causado pelo corpo $J$, e $f^{I J}=-f^{J I}$, conforme a notação da figura 2.8. O Trabalho Virtual devido às forças de contato pode ser escrito como:

$$
\int_{S^{I J}} \delta u_{i}^{I} f_{i}^{I J} d S^{I J}+\int_{S^{J I}} \delta u_{i}^{J} f_{i}^{J I} d S^{J I}=\int_{S^{I J}} \delta u_{i}^{I J} d S^{I J}
$$

onde $\delta u_{i}^{I}$ e $\delta u_{i}^{J}$ são os componentes de deslocamento virtual sobre as superfícies de contato dos corpos / e $J$ respectivamente, e

$$
\delta u_{i}^{I J}=\delta u_{i}^{I}-\delta u_{i}^{J}
$$

Pode-se chamar $S^{I J}$ e $S^{J I}$ de par de superfícies em contato e estas superfícies não têm necessariamente o mesmo tamanho. Contudo, a efetiva área de contato em um tempo $t$ para os corpos $/$ e $J$ é $S_{C}$, e em cada caso esta área é parte de $S^{I J}$ e $S^{J I}$, respectivamente chamadas de "superfície contatora" e "superfície alvo". O membro da direita na equação (2.55) pode ser entendido como o Trabalho Virtual que as forças de contato produzem sobre o deslocamento virtual relativo do par de superfícies em contato.

É freqüentemente comum encontrar soluções numéricas de problemas de contato, uma vez que o caráter não-linear das condições de contato superficiais permite que apenas alguns problemas sejam resolvidos analiticamente. Os aspectos 
não-lineares têm um papel muito importante na simulação computacional deste tipo de processo devido às condições de contorno.

\subsection{2 - Contato no LS-DYNA}

O tratamento de deslizamento e impacto ao longo das interfaces das estruturas tem sido uma importante capacidade dos códigos DYNA3D, e para lidar com isso, três métodos distintos foram desenvolvidos: Método de Restrição Cinemática, Método de Penalização e Método de Parâmetro Distribuído (HALLQUIST, 1998).

As interfaces podem ser definidas em três dimensões listando-se uma ordem arbitrária de todos os segmentos quadriláteros e triangulares que compõem cada lado da interface. Um dos lados da interface é denominado como o lado Slave e o outro é denominado Master. E analogamente, os nós que estão em cada uma destas superfícies também recebem as mesmas denominações. No Método de Penalização simétrico, esta distinção entre as superfícies é irrelevante, mas nos outros métodos os nós Slave são restringidos de deslizar na superfície Master depois do impacto e devem permanecer na superfície Master até que uma força seja desenvolvida entre o nó e a superfície.

Hoje, definições automáticas de contato são comumente utilizadas. Com este modo de se definir o contato, as superfícies Master e Slave são geradas internamente pelo LS-DYNA através da numeração, conhecida como $I D$, dada a cada superfície. Em uma simulação de impacto veicular é usual incluir todas as partes do veículo em uma única definição de contato onde todos os elementos e nós dentro da interface interagem.

O Método de Restrição Cinemática consiste em restrições que são impostas nas equações globais pela transformação dos componentes nodais de deslocamento dos nós Slave ao longo da interface de contato. Mas podem aparecer problemas na solução do problema com o uso deste método quando a zona da superfície Master é mais estreita que a zona da superfície Slave, como mostrado na figura 2.9. 


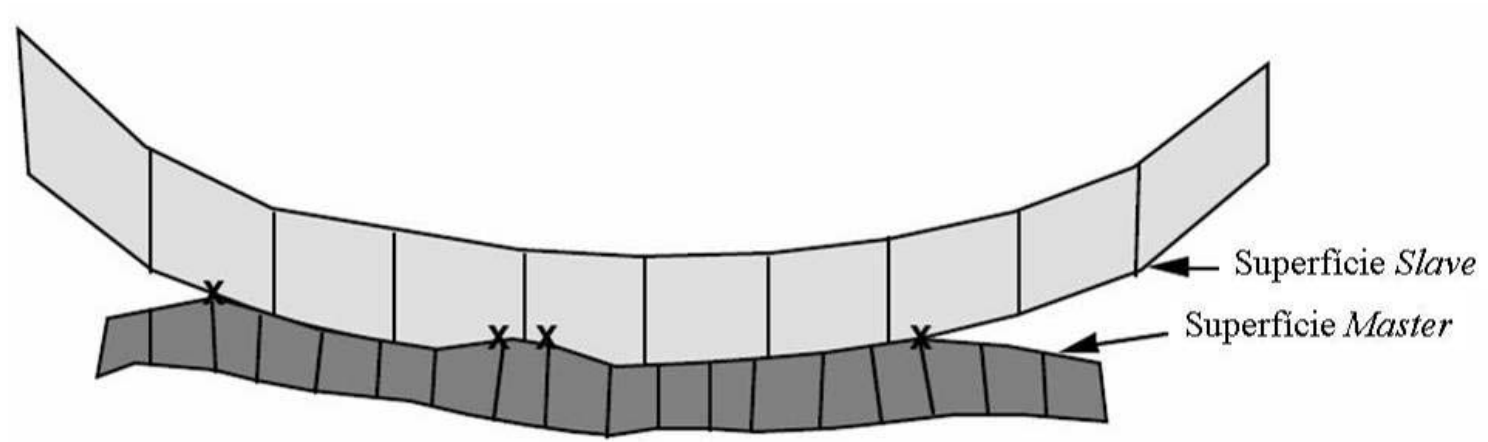

X Indica nós considerados "Nós de Superfície Livre"

Figura 2.9 - Nós da superfície Master deslizante designados com "x" são tratados como Nós de Superfície Livre no Método de Restrição Nodal (HALLQUIST, 1998)

A condição mostrada na figura 2.9 permite concluir que os nós Master podem penetrar através da superfície Slave sem qualquer resistência que seria proveniente do contato e criam uma torção na linha de deslizamento. Estas torções são relativamente comuns com esta formulação, e quando a pressão na interface é alta, estas torções ocorrem se um ou mais pontos de quadratura são usados na integração do elemento. Aparentemente o problema poderia ser resolvido com um modelamento mais cuidadoso que evitasse as penetrações iniciais, mas uma boa condição inicial pode se tornar pobre ao longo da simulação, que é o que ocorre, por exemplo, quando produtos gasosos de um gás altamente explosivo expandem contra a superfície de um membro estrutural.

O Método de Penalização pode ser usado igualmente nos programas implícito e explícito, e ele consiste em posicionar molas, normais à interface, entre todos os nós penetrantes e as superfícies de contato. Com exceção da matriz de rigidez da mola a qual deve ser montada na matriz de rigidez global, os tratamentos dos métodos implícito e explícito são similares. Neste método, uma vez que os momentos são mantidos sem a necessidade de qualquer imposição de condições do impacto e a posterior liberação, nenhum tratamento especial da intersecção das interfaces é necessário, simplificando a implementação.

A rigidez da interface é escolhida para estar aproximadamente na mesma ordem da magnitude da rigidez da interface do elemento normal à interface do contato. Entretanto, se a pressão na interface assume altos valores, podem ocorrer penetrações em níveis inaceitáveis. Uma das possibilidades de resolver o problema 
seria aumentar a rigidez do sistema e diminuir o time step, o que ocasionaria o aumento do número de time steps e o conseqüente aumento do custo computacional, com um maior tempo requerido para solução do problema. Com o aumento do custo computacional, uma opção de contato somente deslizante foi desenvolvido para tratar problemas de interação entre explosivos e estruturas e desse modo evitando a utilização do Método de Penalização. Esta última opção é baseada na especialização do terceiro método descrito abaixo.

$\mathrm{Na}$ formulação do Método de Parâmetro Distribuído, a metade da massa de um elemento Slave de cada elemento em contato é distribuída de modo que cubra a área da superfície Master. Além disso, a tensão interna de cada elemento determina a distribuição de pressão para a área da superfície Master que recebe a massa. Depois de completar a distribuição da massa e pressão, as acelerações e velocidades da superfície Master são atualizadas. Restrições são então impostas nas acelerações e velocidades dos nós Slave para garantir o movimento ao longo da superfície Master. De maneira simples, os cálculos do volume relativo dos elementos Slave ignoram qualquer intrusão da superfície Master.

\subsection{3 - Como o contato funciona no LS-DYNA}

No LS-DYNA, o contato é definido pela identificação por partes, por conjuntos de partes, segmentos e ou conjunto de nós, de quais áreas devem ser verificadas quanto a uma potencial penetração de um nó Slave através de uma superfície Master. Uma busca pelas penetrações, usando uma série de algoritmos, é feita em cada time step. No caso do contato pelo Método de Penalizações, quando a penetração é encontrada, uma força proporcional à profundidade da penetração é aplicada para resistir e ultimamente eliminar a penetração. Elementos rígidos podem ser incluídos no contato por penalização, mas para que a força do contato seja distribuída realisticamente, é recomendado que a malha que define qualquer corpo rígido seja tão refinada quanto as do corpo deformável.

Embora em alguns casos seja conveniente e efetivo definir um contato simples que poderá lidar com qualquer potencial situação de contato no modelo, é permitido no LS-DYNA que se defina qualquer número de contatos em um único modelo. Mas geralmente é recomendado que o contato redundante, i.e., dois ou 
mais contatos produzindo forças devido às mesmas penetrações, seja evitado pelo usuário pois esta condição pode levar a instabilidades numéricas, o que compromete o resultado da simulação.

Para permitir ao usuário certa flexibilidade na modelagem do contato, o LSDYNA apresenta um número de tipos de contato e um número de parâmetros que controlam vários aspectos do tratamento do contato.

\subsection{4 - Principais Tipos de Contato do LS-DYNA}

Em análises de impacto veicular, as deformações podem ser muito grandes e a pré-determinação de onde e como o contato vai ocorrer pode ser difícil. Por esta razão, as opções de contato automático são recomendadas pois estes tipos de contato são não-orientado, significando que eles podem detectar penetrações provenientes também do lado de um elemento de casca. Ainda em relação aos elementos de casca, os tipos automáticos de contato determinam as superfícies de contato projetando na direção normal do plano médio do elemento de casca uma distância igual à metade da "espessura de contato". Além disso, na borda externa da superfície da casca, a superfície de contato envolve a borda da casca com um raio igual à metade da espessura de contato, formando assim uma superfície de contato contínua.

A espessura de contato pode ser especificada diretamente ou definida pelo usuário usando parâmetros opcionais na definição do contato. Se a espessura de contato não é especificada pelo usuário, ela fica então determinada como a espessura da casca (ou no caso de contatos de superfície simples, o mínimo valor da espessura da casca e do comprimento da borda do elemento). Já a superfície de contato para elementos de barra (onde o contato de barras é considerado) é o deslocamento (offset) da linha de centro da barra pelo raio equivalente da seção transversal da barra. Como as superfícies de contato são deslocadas do plano médio da casca e da linha de centro das barras, é de extrema importância que distâncias apropriadas (gaps) sejam modeladas entre cascas e barras para levar em conta as dimensões das espessuras das cascas e das seções transversais das barras. 
A maioria dos contatos no LS-DYNA coloca um limite na máxima profundidade da penetração que é permitida antes do nó Slave ser liberado e as forças de contato são ajustadas para zero, o que é feito principalmente nos tipos automáticos de contato. A máxima profundidade de penetração está tabelada para os vários tipos de contato, e utilizando o contato tipo 4 *CONTACT_SINGLE_SURFACE como exemplo, temos as seguintes fórmulas para a máxima profundidade de penetração, $d_{p}$ :

- Elementos de Casca: $\quad d_{p}=0,4^{*}$ (Espessura Slave + Espessura Master)

- Elemento Sólido: $\quad d_{P}=0,5^{\star}$ Espessura do elemento sólido

Em alguns casos, as interfaces de contato automático parece não funcionar adequadamente pelo fato do limite do contato ser atingido nos estágios iniciais da simulação. Isto ocorre com certa freqüência se elementos de casca extremamente finos são incluídos na superfície de contato. Nestes casos, a falha do contato pode geralmente ser prevenida aumentando a espessura padrão do contato ou ajustando a espessura de contato para valores maiores que as espessuras das cascas.

Abaixo estão descritos alguns dos principais tipos de contato disponíveis no LS-DYNA, que embora na sua maioria não são utilizados neste trabalho, mas estão descritos nesta seção como referência:

- Tipo 1: *CONTACT_SLIDING_ONLY

Característica: somente deslizamento, sem separação.

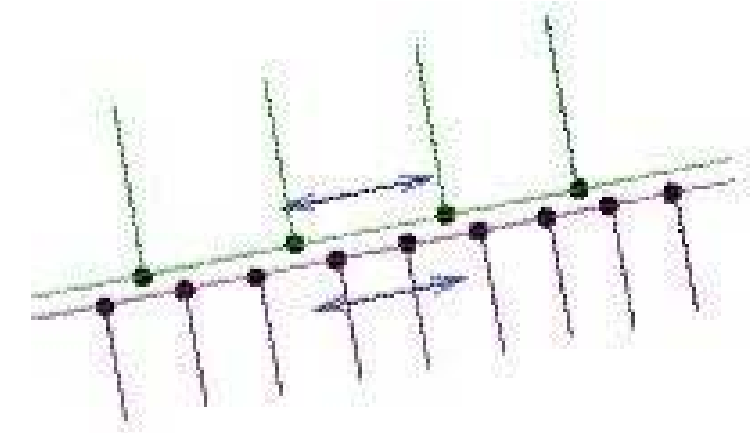

Figura 2.10 - Esquema do contato *CONTACT_SLIDING_ONLY (www.dynasupport.com) 
- Tipo 2: *CONTACT_TIED_SURFACE_TO_SURFACE

Característica: superfícies amarradas por graus de liberdade de translação. A distância entre nós e superfícies é preservada com a opção Offset.

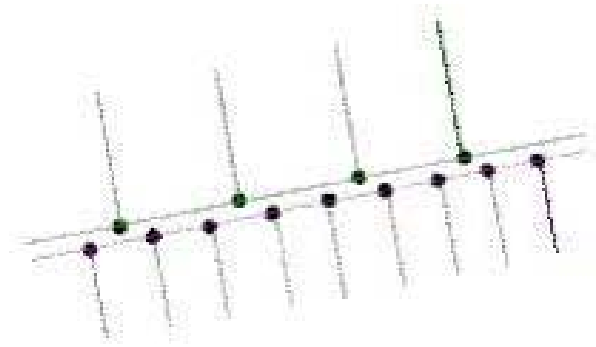

Figura 2.11 - Esquema do contato *CONTACT_TIED_SURFACE_TO_SURFACE (www.dynasupport.com)

- Tipo 3: *CONTACT_SURFACE_TO_SURFACE

Característica: cada nó Slave é verificado pela penetração através da superfície Master. Para superfícies de casca, a orientação da normal do elemento é importante.

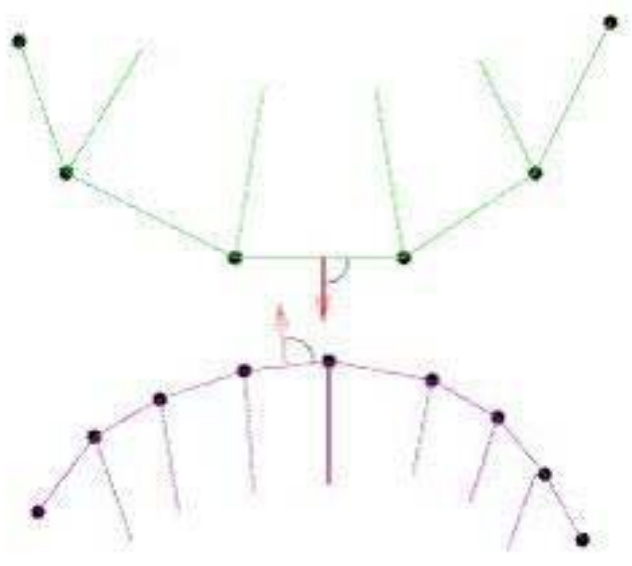

Figura 2.12 - Esquema do contato *CONTACT_SURFACE_TO_SURFACE (www.dynasupport.com) 
- Tipo i26: *CONTACT_AUTOMATIC_GENERAL_INTERIOR

Característica: contato geral dentro do domínio definido pelo contato. As superfícies de contato podem ser descontínuas. Permite "dobramento" (folding) da malha. Contato com alto custo computacional.

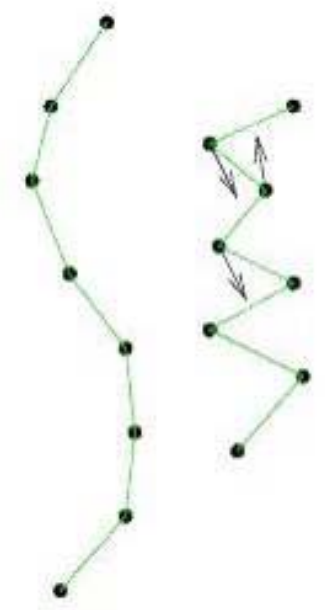

Figura 2.13 - Esquema do contato *CONTACT_AUTOMATIC_GENERAL_INTERIOR (www.dynasupport.com)

- Tipo 5: *CONTACT_NODES_TO_SURFACE

Característica: cada nó Slave é verificado para penetração através da superfície Master. A grande vantagem deste tipo de contato é que ele é facilmente definido.

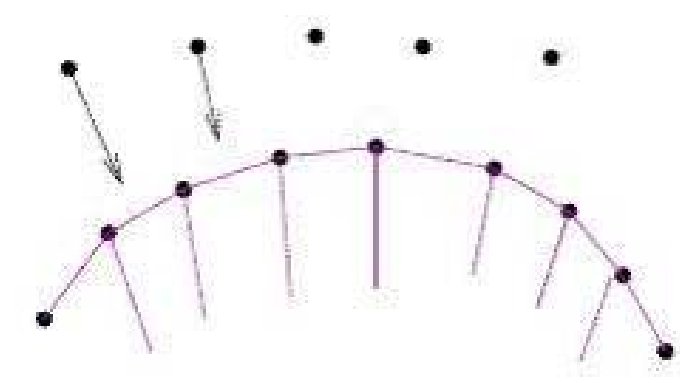

Figura 2.14 - Esquema do contato *CONTACT_NODES_TO_SURFACE (www.dynasupport.com) 
- Tipo 6: *CONTACT_TIED_NODES_TO_SURFACE

Característica: graus de liberdade de translação dos nós ligados à superfície. Distância entre o nó e o segmento é preservada com a opção Offset. Momentos não são transmitidos.
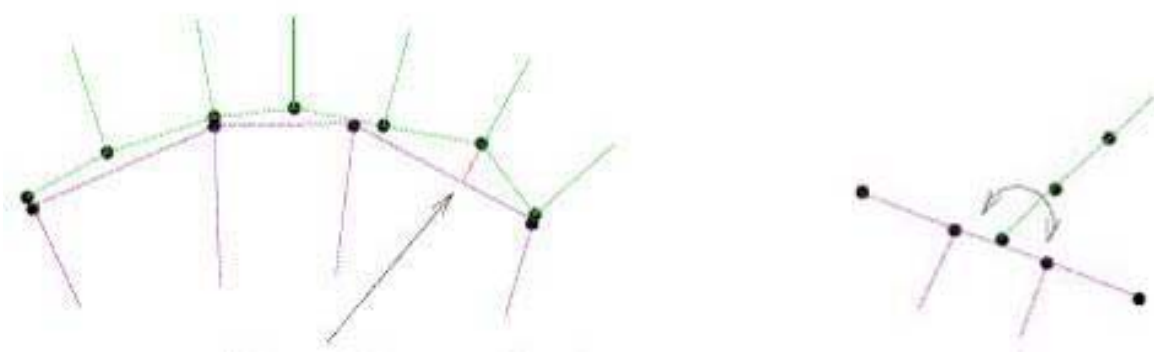

Figura 2.15 - Esquema do contato *CONTACT_TIED_NODES_TO_SURFACE

(www.dynasupport.com)

- Tipo 7: *CONTACT_TIED_SHELL_EDGE_TO_SURFACE

Característica: ambos os graus de liberdade de translação e rotação dos nós ligados à superfície. Distância entre o nó e o segmento é preservada com as opções: CONTRAINED_OFFSET e BEAM_OFFSET. Este é o contato utilizado nos modelos de elementos finitos deste estudo.

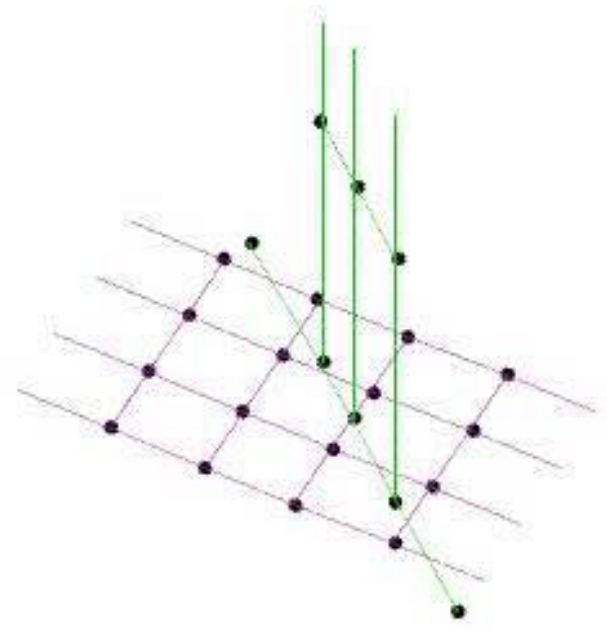

Figura 2.16 - Esquema do contato *CONTACT_TIED_SHELL_EDGE_TO_SURFACE (www.dynasupport.com) 
- Tipo i8: *CONTACT_TIEBREAK_NODES_ONLY

Característica: similar ao contato tipo 6 , mas apresenta critério de falha definido por:

$$
C F \rightarrow\left(\frac{f_{n}}{S_{n}}\right)^{n}+\left(\frac{f_{s}}{S_{s}}\right)^{m} \geq 1
$$

$f_{n}=$ força normal à interface

$f_{s}=$ força cortante à interface

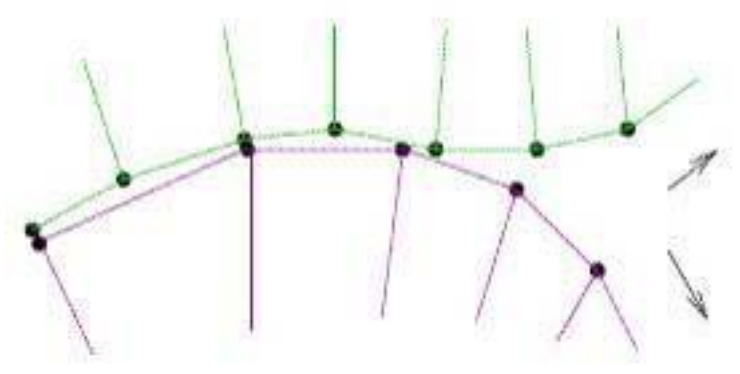

Figura 2.17 - Esquema do contato *CONTACT_TIEBREAK_NODES_ONLY (www.dynasupport.com)

- Tipo 9: *CONTACT_TIEBREAK_SURFACE_TO_SURFACE

Característica: similar ao contato tipo 8 , mas no critério de falha as forças são substituídas pelas tensões e $m=n=2$.

- Tipo 10: *CONTACT_ONE_WAY ${ }^{9}$ SURFACE_TO_SURFACE

Característica: somente os nós Slave são checados quanto à penetração através da superfície Master.

\footnotetext{
${ }^{9}$ Contato tipo One-Way: este tipo de contato permite cargas de compressão que são transferidas entre os nós Slave e as superfícies Master. Cargas tangenciais também são transmitidas se ocorrer um deslizamento relativo quando a opção de atrito está ativa nos controles do contato. Este tipo de contato pode ser apropriadamente utilizado quando a superfície Master é um corpo rígido, como por exemplo um punção ou ferramenta em uma simulação de estampagem. Outra aplicação que pode ser citada é quando o corpo deformável está representado por uma malha refinada (Slave) e encontra uma malha considerada "grosseira" (Master).
} 


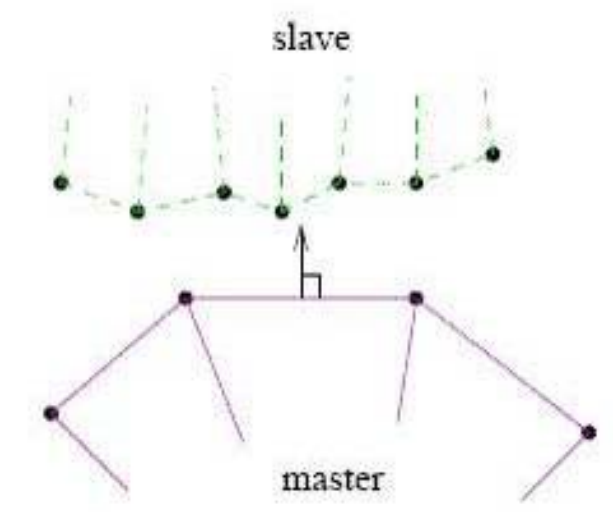

Figura 2.18 - Esquema do contato *CONTACT_ONE_WAY_SURFACE_TO_SURFACE (www.dynasupport.com)

\subsection{5 - Contatos de Superfície Simples (Single Surface)}

O contato do tipo superfície simples (single surface) deve ser tratado à parte por ser a opção de contato mais amplamente utilizada no LS-DYNA, especialmente para aplicações de Crashworthiness. Neste tipo de contato, a superfície Slave é tipicamente definida como uma lista de ID de partes do modelo. Nenhuma superfície Master é definida. O contato é considerado entre todas as partes do modelo que se encontram na lista Slave, incluindo o auto-contato de cada parte. Se o modelo é definido de maneira precisa, os contatos de superfície simples são bastante confiáveis e precisos. Entretanto, se existem demasiadas interpenetrações na configuração inicial do modelo, o balanço de energia pode mostrar crescimento ou decaimento da energia conforme os cálculos procedem.

Para uma análise de impacto, o contato recomendado é o tipo 13, denominado *CONTACT_AUTOMATIC_SINGLE_SURFACE. Outros contatos utilizados e que também podem ser enquadrados nesta categoria são 0 ${ }^{*}$ CONTACT_AUTOMATIC_GENERAL (tipo 26), de funcionamento similar ao tipo 13, mas com precisão inferior a este, além do contato ${ }^{*}$ CONTACT_AIRBAG_SINGLE_SURFACE (tipo a13) utilizado em modelos que incluem uma bolsa de ar (Airbag), e que pela sua dinâmica da abertura bastante complexa, apresenta contato entre os nós e múltiplos segmentos. 


\subsection{6 - Contatos Tied}

Este tipo de contato também merece destaque neste trabalho por ser 0 principal contato (tipo $7{ }^{*}$ CONTACT_SPOTWELD) utilizado neste estudo. A interface deste contato usa um método de restrição cinemática para amarrar os nós Slave aos segmentos Master e trata de ambos os graus de liberdade, translacionais e rotacionais. Além disso, este tipo de contato pode ser combinado com elementos sólidos e de barra do material tipo *MAT_SPOTWELD, associando-se um critério de falha no modelamento de pontos de solda. Outros exemplos desse tipo de contato são: $\quad{ }^{*}$ CONTACT_SPOTWELD_WITH_TORSION (tipo s7) e *CONTACT_TIED_SHELL_EDGE_TO_SURFACE.

Com os tipos de contato tipo Tied mencionados acima, os nós são projetados no plano normal do segmento Master. Esta característica é muito importante para o contato classificado acima como o mais importante deste estudo, o *CONTACT_SPOTWELD, uma vez que as barras ou sólidos que representam o ponto de solda precisam estar tão alongados quanto possível para minimizar o acréscimo de massa que é necessário para permitir o cálculo e assim ter um tamanho de time step razoável.

Com a opção TORSION, as forças de torção que são geradas no elemento que representa o ponto de solda são transmitidas como forças equivalentes ao redor dos nós da superfície Master. As restrições de rotação ao redor do eixo da barra são então reforçadas. Os elementos de casca não-lineares do LS-DYNA tem rigidez nula no grau de liberdade de rotação de cada nó, e assim é necessário levar as forças de torção através do comportamento de membrana da casca.

Uma análise de impacto envolvendo um veículo completo engloba interações de contato entre todas as superfícies livres. Isto é um tanto caro do ponto de vista computacional, uma vez que de 20 a $30 \%$ do total de tempo de ocupação dos processadores são usados para o tratamento do contato. Um dos aspectos desafiadores da modelagem de contato em uma análise de impacto é lidar com as interações entre peças metálicas e portanto estruturais, e componentes tipicamente feitos de espuma ou plástico, ou seja, não estruturais. Isto é especialmente importante quando modelos de ocupantes estão incluídos no modelo do veículo. 
Outro desafio é lidar com o contato nos cantos das bordas de partes de geometria complexa.

Assim, como a questão do contato é um tanto complexa por envolver inúmeros fatores, fica recomendada a realização de estudos comparando os diversos tipos de contato aplicáveis ao problema em questão, para que a simulação possa atingir certa estabilidade e o comportamento real dos contatos da estrutura possa ser bem representado. 


\section{CAPÍTULO 3 \\ DESCRIÇÃO DO PROCESSO DE SOLDAGEM POR RESISTÊNCIA ELÉTRICA}

\section{1 - INTRODUÇÃO}

De acordo com a Resistance Welders Manufacturers' Association (RWMA) apud Ruiz (2005, p.7), "solda consiste na junção de duas ou mais peças de metal através da aplicação de calor e às vezes de pressão, e solda por resistência indica o campo da solda onde o calor de solda nas peças a serem soldadas é gerado pela resistência oferecida por essas peças à passagem de uma corrente elétrica". Nos processos de soldagem por resistência sempre há a aplicação de uma pressão que garante a união das peças que são aquecidas por efeito Joule ${ }^{10}$ pela corrente elétrica que passa pelos eletrodos e as atravessa. Essa pressão deve ser aplicada às peças antes, durante e depois a passagem da corrente elétrica, o que permite uma boa área de contato entre as chapas, além de garantir o contato das mesmas durante o resfriamento.

Entre os processos mais comuns de soldagem por resistência, têm-se a solda a ponto, a solda por costura (que pode ser compreendida como uma solda a ponto contínua), e por fim a solda projeção, mostrados pela figura 3.1:

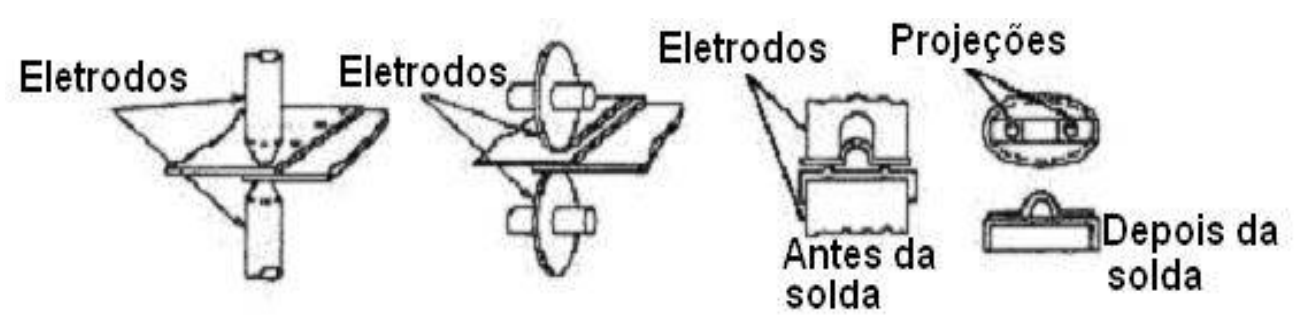

\section{Solda a Ponto Solda por Costura Solda por Projeção}

Figura 3.1 - Diagrama simplificado dos processos básicos de solda por resistência (AWS apud RUIZ, 2005)

\footnotetext{
${ }^{10}$ Efeito Joule - lei física que expressa a relação entre o calor gerado e a corrente elétrica que percorre um condutor em determinado tempo, expressa por $\boldsymbol{Q}=I^{2} \boldsymbol{R} \boldsymbol{t}$, onde $\boldsymbol{Q}$ é a quantidade de calor gerado, $\boldsymbol{I}$ é a corrente elétrica, $\boldsymbol{R}$ é a resistência e $\boldsymbol{t}$ é o tempo de duração da corrente. No entanto, para a obtenção do ponto de solda, deve ser levada em conta a eficiência do processo, uma vez que parte do calor (energia) $\boldsymbol{Q}$ é dissipada no ambiente.
} 
Os três processos mencionados acima possuem características semelhantes. O aquecimento devido à resistência é desenvolvido em três interfaces: entre eletrodo e chapa, entre chapa e chapa, e por fim entre chapa e eletrodo, como pode ser observado na figura 3.2, onde também é possível ver a distribuição de temperatura na solda a ponto.

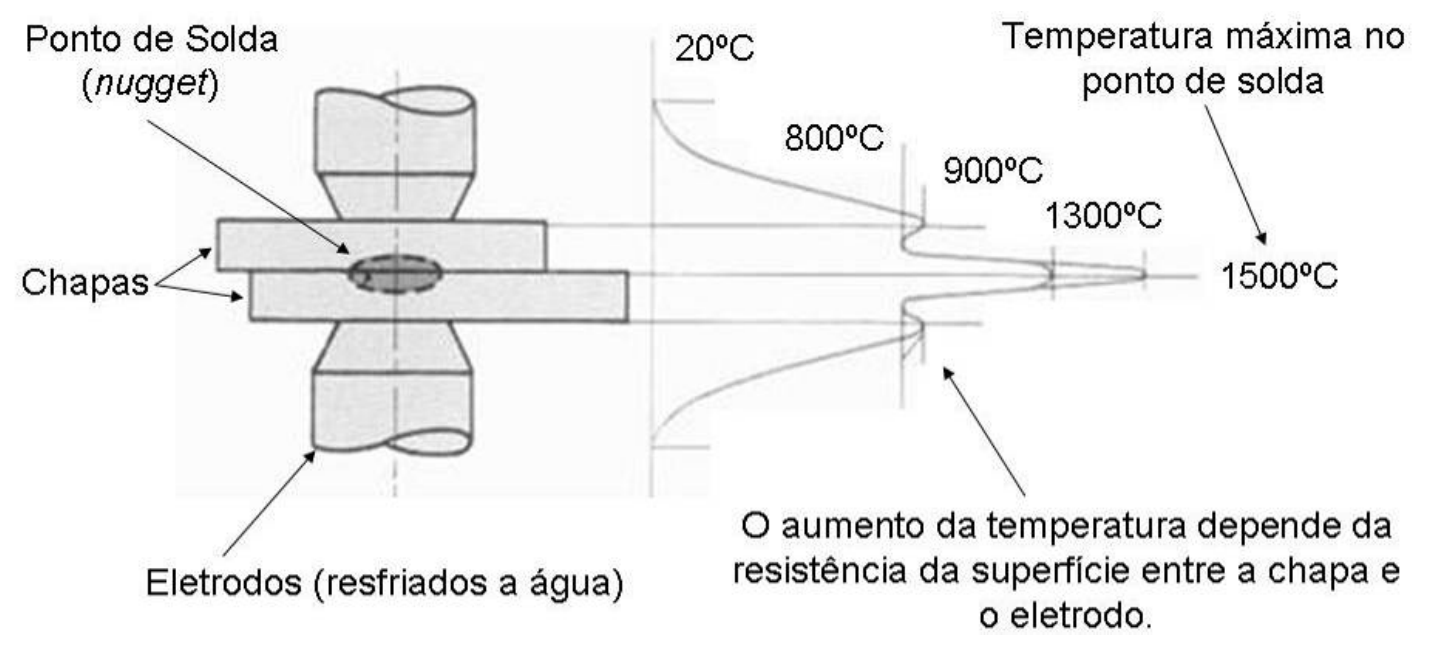

Figura 3.2 - Temperaturas no ponto de solda e demais regiões na máxima temperatura (SSAB TUNNPLÅT, 1996)

A solda a ponto tem entre todos os tipos de solda por resistência a maior aplicação na indústria automotiva devido à sua grande importância econômica, em virtude da simplicidade de operação e manutenção, por permitir controle relativamente fácil e soldagem de chapas muito finas, não depende da habilidade do soldador que deve apenas respeitar o posicionamento da solda, não são necessários materiais consumíveis e gases de proteção, além da elevada velocidade do processo. Existem também limitações do processo, e entre elas podem ser citados o custo elevado do equipamento, a demanda por energia elétrica durante a soldagem e o fato de o processo não ser adequado para unir peças de alto grau de complexidade geométrica.

O número de pontos de solda na carroceria de um automóvel pode chegar de 2000 a 5000 (CHAO, 2003) dependendo do tamanho do veículo e da possibilidade 
de empregar outros métodos de soldagem como MIG/MAG e Laser, que podem ser escolhidos para facilitar a montagem de certos componentes e melhorar a qualidade final do produto.

\section{2 - PROCESSO DE SOLDA A PONTO}

O processo de solda a ponto é principalmente utilizado para soldagem de chapas finas até aproximadamente $3,0 \mathrm{~mm}$ de espessura. $O$ método pode entretanto ser utilizado em espessuras consideravelmente maiores (SSAB TUNNPLAT, 1996).

Durante o ciclo da soldagem a ponto, mostrado na figura 3.3, a força do eletrodo se desenvolve durante o chamado tempo de compressão $T_{1}$, e a corrente de soldagem I é aplicada durante o tempo de soldagem T. As chapas que estão sendo soldadas são resfriadas durante o tempo de espera $T_{2}$, depois do qual a força do eletrodo cessa. O tempo de espera é ajustado no controlador de soldagem. $O$ ponto de solda é então resfriado pelos eletrodos durante o tempo de reação até o fim do tempo de espera, quando o eletrodo é retirado. O tempo de reação e o tempo de espera juntos, formam o tempo de resfriamento. Todos os tempos mencionados acima, juntamente com o Off Time ${ }^{11}$, formam o ciclo completo de soldagem.

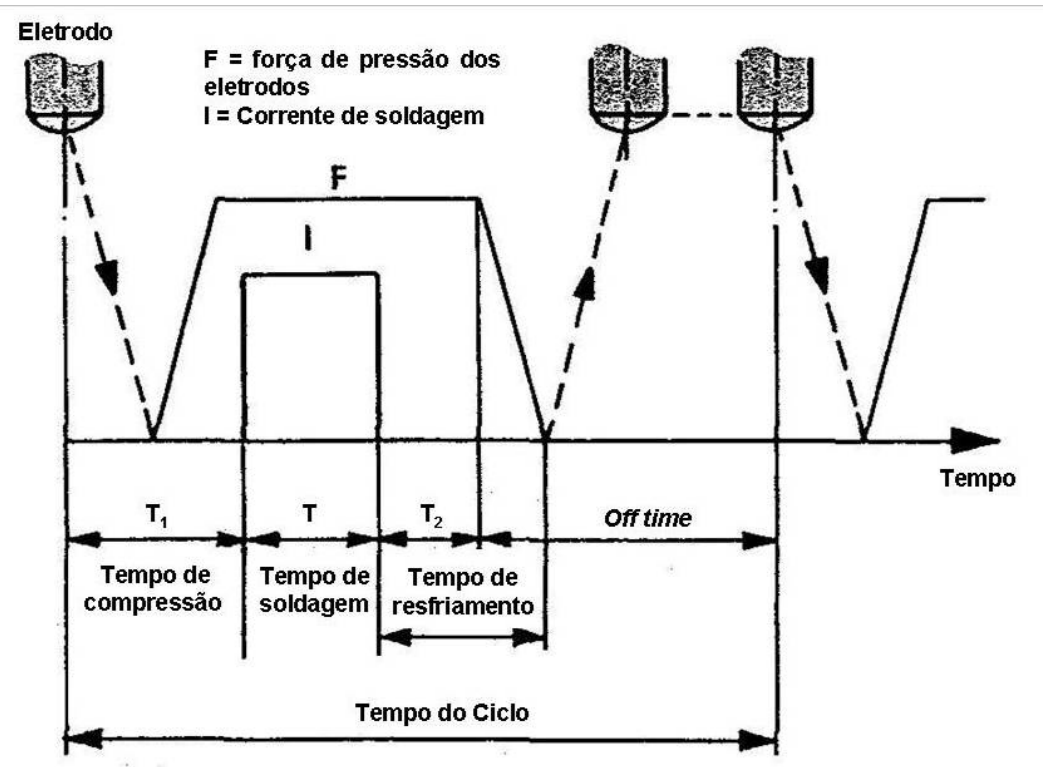

Figura 3.3 - Diagrama de Força e Tempo para Soldagem a Ponto (SSAB TUNNPLÅT, 1996)

\footnotetext{
${ }^{11}$ Off Time - considerado um tempo de pausa, durante o qual os eletrodos não estão em contato com as peças que estão sendo soldadas.
} 
O ponto de solda (nugget) é produzido na área de contato dos eletrodos com a chapa durante o tempo de soldagem, enquanto a corrente de soldagem passa de um eletrodo ao outro através das chapas, e em virtude da resistência apresentada, o calor necessário para a fusão dos materiais será gerado.

Para uma boa qualidade do ponto de solda, a aplicação correta e coordenada de corrente elétrica e pressão mecânica de intensidade e duração apropriadas deve ser controlada. O excesso em uma combinação de corrente e pressão pode causar problemas como a expulsão do material fundido. Pensando no equipamento de soldagem a ponto, a duração da corrente de solda deve ser suficientemente curta para prevenir excesso de calor nos eletrodos, o que reduziria significantemente sua vida útil.

Os fatores mecânicos que podem ser citados como os que estão sujeitos à modificações durante o processo de soldagem a ponto são: Tempo de compressão, Tempo de soldagem, Corrente de solda, Força do eletrodo, Tempo de resfriamento e o tipo do eletrodo utilizado, que pode variar de acordo com a chapa a ser soldada, pois esta pode apresentar ou não revestimento, além do tamanho do eletrodo, que determinará a área de contato entre eles e as chapas.

\subsection{1 - Ajuste dos Parâmetros do Processo de Soldagem a Ponto}

O ajuste da máquina de solda e a seleção dos parâmetros de soldagem são baseados nas espessuras, revestimentos e quantidade de chapas a serem soldadas. Assim, de acordo com SSAB TUNNPLÅT (1996), podem-se definir as seguintes condições:

- A força do eletrodo durante a porção final do tempo de compressão deve desenvolver uma intensidade suficiente para que um bom contato seja estabelecido entre as superfícies. Para aços de alta resistência, a força do eletrodo pode ser mais alta do que para aços de baixo carbono, não ultrapassando $50 \%$ dessa força;

- A superfície de contato do eletrodo deve ser ajustada. No caso de haver uma diminuição da área de contato dos eletrodos pelo fato de estes não estarem alinhados, ou por apontamento incorreto e deformações na face de contato do 
eletrodo, conforme ilustrado pela figura 3.4, haverá diminuição da resistência à passagem da corrente elétrica, e conseqüentemente um aumento da pressão de solda (considerando-se a força constante);

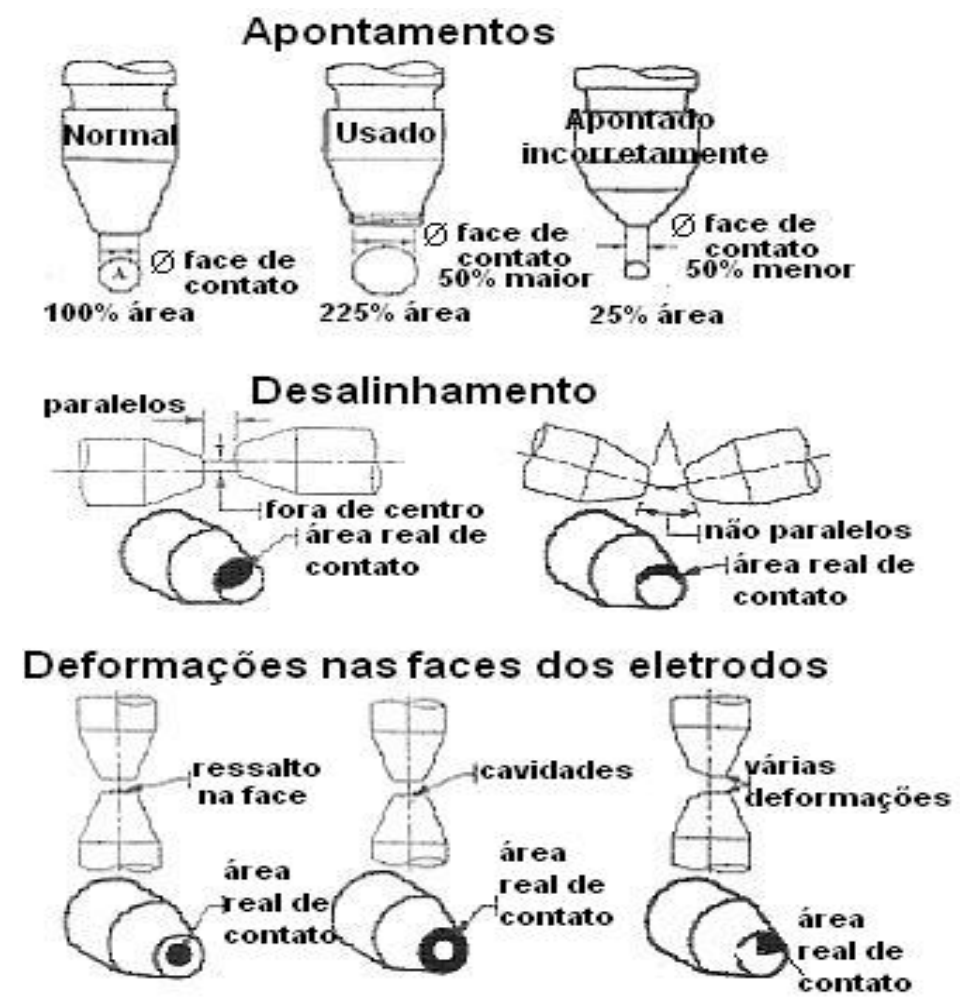

Figura 3.4 - Causas da Diminuição da Área de Contato dos Eletrodos (GMB apud RUIZ, 2005)

- O tempo de compressão, o tempo de soldagem e o tempo de espera devem ser selecionados e ajustados. Segundo SSAB TUNNPLÅT (1996), um valor típico para o tempo de soldagem é $10 x t$ (ciclos $/ 50 \mathrm{~Hz}$ ), onde té a espessura da chapa em mm. Nas uniões de chapas de diferentes espessuras, a menor espessura governa o tempo de soldagem;

- A corrente de soldagem deve ser determinada por ensaios de soldagem, soldando vários corpos de prova que representem a variedade de espessuras desejadas e tipos diferentes de materiais incluindo revestimentos, até que se possa ter um banco de dados que reúna os resultados dessas experiências. A relação entre o tempo e a corrente de soldagem pode ser descrita pelo Lóbulo de Soldabilidade, como mostrado na figura 3.5: 


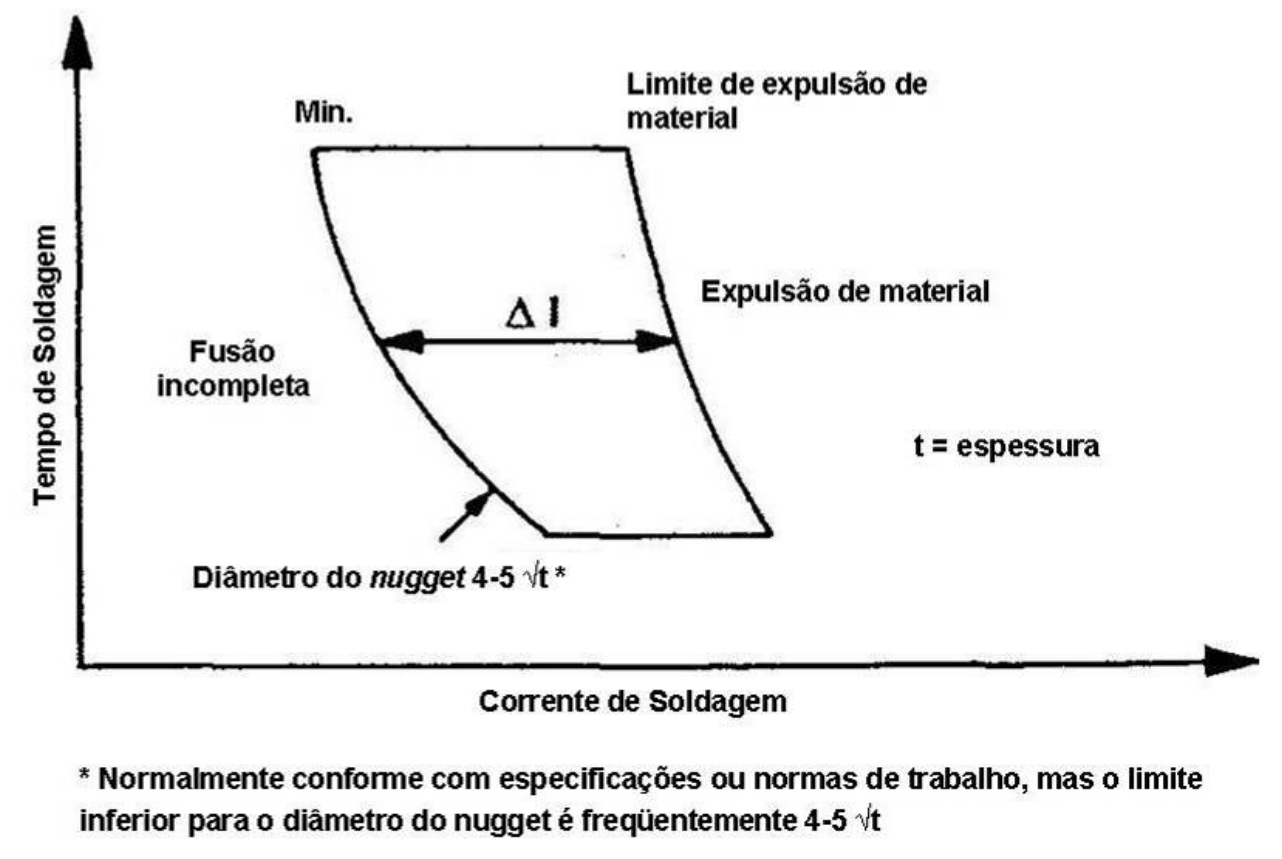

Figura 3.5 - Lóbulo de Soldabilidade, Diagrama Generalizado (SSAB TUNNPLÅT, 1996)

O Lóbulo de Soldabilidade mostra a região dentro do qual certa categoria de aço e espessura de chapa pode ser soldada com resultados satisfatórios. Um curto tempo de soldagem e uma alta corrente de soldagem são objetivados para uma fusão completa e a conseqüente boa qualidade do ponto de solda, desde que respeitado o limite de expulsão do material.

É importante ressaltar que os lóbulos não são geralmente válidos para certo aço e espessura de chapa, mas somente para a força e forma do eletrodo especificado e para a máquina que está sendo utilizada.

A fusão incompleta indica soldas pequenas. A região compreendida entre as linhas do lóbulo, identificada por DI, indica soldas aceitáveis. Muitos estudos foram feitos sobre as relações entre a corrente, o tempo de soldagem e a força dos eletrodos.

Ganowski \& Williams, Krause \& Simon e Dickenson apud Ruiz (2005), estabeleceram alguns fatores que são responsáveis pelo tamanho e posição do lóbulo de soldabilidade: com relação à força do eletrodo, o lóbulo é mais largo e se move para o sentido de maiores correntes de solda quanto maior a força. Quanto maior a espessura da chapa, maior a largura do lóbulo (exemplo: chapas de 0,4 0,6, 0,7 - 1,5, e acima de 1,5 mm têm uma largura de lóbulo de $1000, \sim 1500-$ 
2000, e acima de 2000 A, respectivamente). Quanto maior a resistividade do

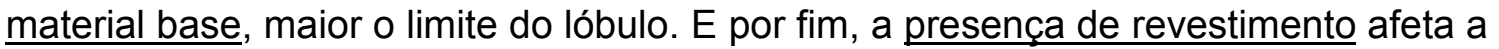
resistência de interface, e assim, a corrente necessária.

- O efetivo resfriamento do eletrodo é necessário para que um ponto de solda de qualidade aceitável em combinação com uma boa economia no processo de soldagem possa ser atingido. Entretanto, tubos de resfriamento dentro dos eletrodos não são geralmente encontrados ou até mesmo bem dimensionados, prejudicando assim a qualidade do processo.

\subsection{2 - Características do Ponto de Solda}

O ponto de solda é compreendido por duas regiões distintas: o ponto ou botão de solda (nugget) propriamente dito e a Zona Termicamente Afetada (ZTA), conforme ilustrado na figura 3.6:

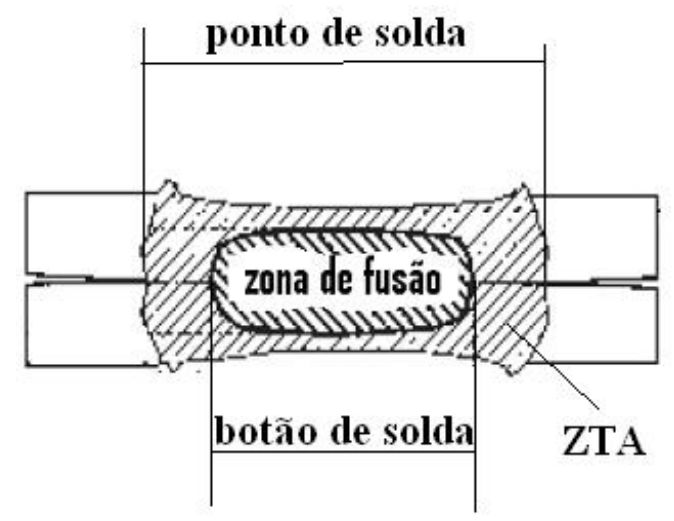

Figura 3.6 - Esquematização das Regiões do Ponto de Solda (RUIZ, 2005)

As regiões indicadas na figura acima são formadas durante o resfriamento do ponto de solda. O botão de solda corresponde à área fundida entre as chapas. A ZTA não compõe a região fundida e apresenta alterações nas propriedades do material base das chapas. Deste modo, para um ponto de solda de boa qualidade, esta é a região que deve apresentar a falha (ZHOU et al, 1999), o que será revisto com mais detalhes adiante. 
Outras características do ponto de solda, também podendo ser entendidas como atributos geométricos do ponto de solda (figura 3.7), são também importantes por estarem de acordo com a especificação ou critério de projeto. Em relação ao diâmetro ou largura da zona de fusão, na falta de um critério específico, em condições normais de produção, este deve ter de três a quatro vezes o valor da menor espessura das chapas que estão sendo soldadas.

Já em relação à profundidade de fusão, que é a espessura na qual o botão de solda penetra nas peças que estão em contato com os eletrodos, a profundidade mínima de fusão é aceita geralmente como sendo $20 \%$ da espessura da chapa mais fina. Esta profundidade de fusão gera por conseqüência uma redução na espessura das chapas soldadas na área do ponto de solda, fenômeno este que é chamado de Indentação.

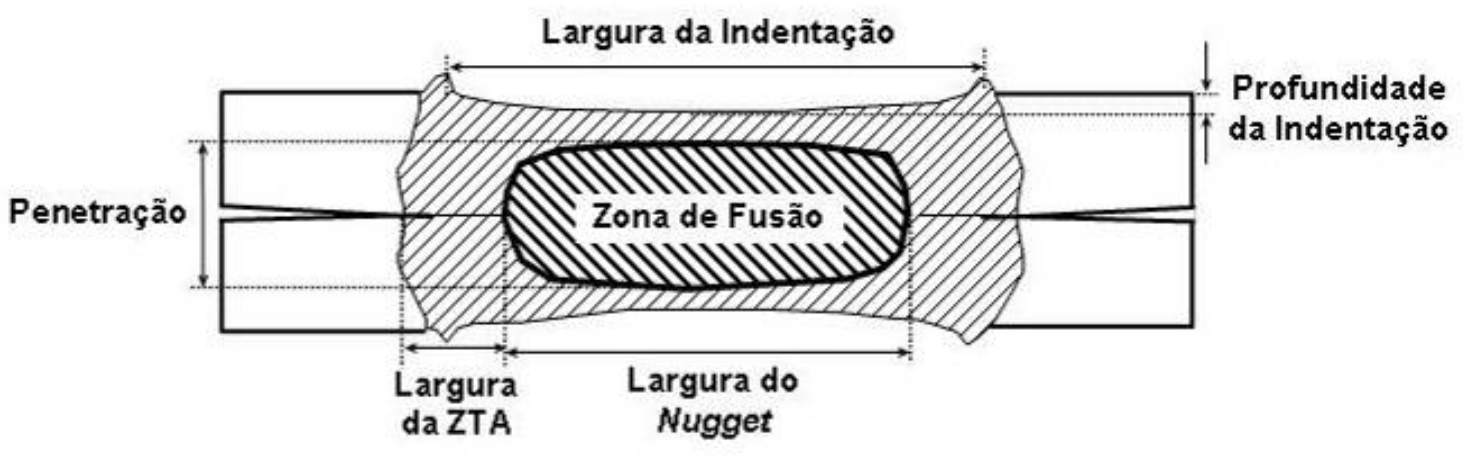

Figura 3.7 - Atributos Geométricos da solda mostrados esquematicamente em uma seção transversal de um Ponto de Solda (ZHOU et al., 2003)

Se menor que $20 \%$ a solda é chamada "solda fria", pois o calor gerado foi muito baixo. Variações normais na corrente, tempo e força dos eletrodos causam alterações indesejáveis na resistência da solda fria e em casos extremos não há a formação do botão de solda. Entretanto, a profundidade de fusão não deve exceder $80 \%$ da espessura da chapa mais fina, o que resultaria em indentação excessiva e expulsão do material. 
Com relação à qualidade do ponto de solda, além dos requisitos em torno dos atributos geométricos, como a definição de um diâmetro mínimo do ponto de solda ou a profundidade de penetração da solda, que vão variar para cada aplicação da solda, a consistência e a resistência da solda são critérios decisivos para a conclusão sobre a qualidade da solda, invariavelmente para qualquer aplicação.

$E$ as exigências em torno da consistência e da resistência do ponto de solda podem ser diferenciadas de acordo com classes de segurança, mostradas pela tabela 3.1 abaixo:

Tabela 3.1 - Atribuições das classes de segurança e dos critérios de qualidade incluindo definições complementares (DIN 8524 apud RUIZ, 2005)

\begin{tabular}{|c|c|c|c|c|c|c|}
\hline $\begin{array}{l}\text { Classes de } \\
\text { segurança }\end{array}$ & Efeito da Falha & $\begin{array}{l}\text { Diâmetro minimo } \\
\text { do ponto }\end{array}$ & $\begin{array}{c}\text { Diâmetro minimo } \\
\text { do botäo }\end{array}$ & $\begin{array}{l}\text { Profundidade de } \\
\text { indentaçäo no } \\
\text { botâo (") }\end{array}$ & $\begin{array}{l}\text { Minima força de } \\
\text { traçäo por } \\
\text { cisalhamento (*) }\end{array}$ & Exemplos de requisitos complementares \\
\hline A & $\begin{array}{l}\text { Risco da vida } \\
\text { humana }\end{array}$ & & & & & $\begin{array}{l}\text { Minima força de tração normal } \\
\text {-Tolerância para o ponto } 0 \\
\text {-Tipo de fratura }\end{array}$ \\
\hline B & $\begin{array}{l}\text { Inutilização do } \\
\text { produto }\end{array}$ & & \multicolumn{2}{|c|}{ ou } & & Penetração unilateral do eletrodo \\
\hline C & $\begin{array}{l}\text { Utilização } \\
\text { penalizada }\end{array}$ & & & & & $\begin{array}{l}\text { Máxima folga permitida entre as chapas } \\
\text { - Isençăo de poros e canais } \\
\text {-Năo formaçằo de liga na superficie da chapa }\end{array}$ \\
\hline
\end{tabular}

(") para combinaçōes de espessuras de chapas $1: 3$ a profundidade de indentação deve corresponder de 40 .... $60 \%$ das espessuras das respectivas chapas

(^) a minima força de tração por cisalhamento determinada pelo fabricante em função do diảmetro do ponto ou do botão e do valor minimo normalizado para o material (valor minimo do material conforme DIN 1623 parte 1)

Ainda para seja assegurada a qualidade do ponto de solda, é necessário o entendimento dos conceitos de falha e defeito. Falha diz respeito ao não atendimento de certo requisito ou característica exigida. Já os defeitos e suas respectivas causas são explicados com o auxílio da figura 3.8 na seqüência: 


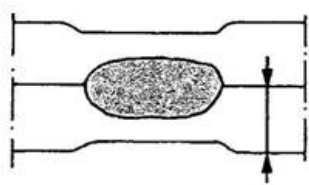

A - Solda Normal

1. Botâo de solda $50 \%$ em cada chapa

2. Indentaçẫo do eletrodo de $10 \%$ da espessura da

chapa (max. 20\%)

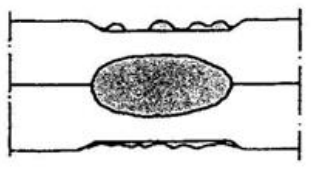

D - Superficies queimada

1. Corrente de soldagem

muito alta

2. Força do eletrodo muito pequena

3. Tempo de compressầo

muito curto

4. Diâmetro da ponta do

eletrodo muito pequeno

5. Forma do eletrodo

inadequada

6. Material do eletrodo

inadequado

7. Resfriamento das pontas

dos eletrodos insuficiente

8. Pontas dos eletrodos sujas

9. Chapas sujas

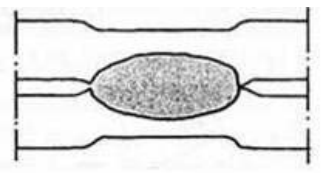

G - Espaçamento entre as chapas

1. Pobre ajuste das chapas

2. Força do eletrodo muito

3. Tempo de soldagem muito

longo

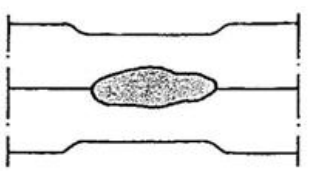

B - Botão de Solda muito pequeno

1. Corrente de soldagem

muito baixa

2. Tempo de soldagem

muito curto

3. Força do eletrodo muito alta

4. Ponta do eletrodo muito gasto

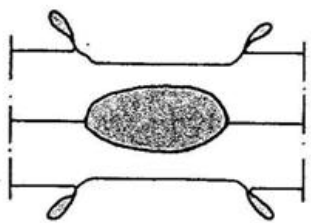

E-Respingo sobre as chapas

1. Tempo de compressẫo muito curto

2. Diâmetro da ponta do eletrodo muito pequeno

3. Corrente muito alta em relaçâo à pressâo

4. Material do eletrodo

inadequado (resistência

elétrica muito alta)

5. Superfícies contaminadas

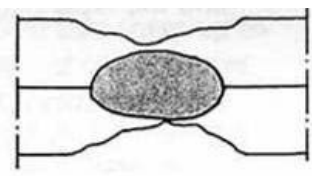

$\mathrm{H}$ - Afundamento da parte externa da solda

1. Tempo de espera muito

curto

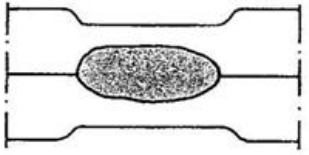

C - Indentação do eletrodo muito profunda

1. Força do eletrodo

inadequada

2. Corrente de soldagem

muito alta

3. Tempo de soldagem muito longo

4. Diâmetro da ponta do

eletrodo muito pequeno

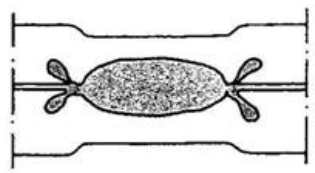

F-Respingo entre as chapas

1. Tempo de compressâo muito curto

2. Força do eletrodo muito pequena

3. Corrente de soldagem

muito alta

4. Tempo de soldagem muito

longo

5. Superfícies contaminadas

Figura 3.8 - Defeitos da Solda a Ponto e respectivas causas (SSAB TUNNPLÅT, 1996)

\section{3 - Solda a ponto em aços de baixo carbono}

Para pontos de solda presentes em chapas de aço de baixo carbono, a resistência ao cisalhamento depende de muitas variáveis, dentre os quais podemos citar a qualidade da solda, as propriedades do material base, o tamanho do ponto, a concentração de tensões, entre outras. Se o ponto de solda atinge um bom grau de qualidade e obedece aos requisitos pré-estabelecidos, a resistência que ele oferece deve ser igual à do material base e maior que uniões por rebites ou parafusos que 
possam estar presentes na mesma região. Um grande benefício que favorece o comportamento do ponto de solda, reduzindo problemas posteriores ao processo como trincas, é o resfriamento que ocorre ainda sob ação de compressão dos eletrodos.

A resistência dos pontos de solda depende também das propriedades mecânicas do material, que por sua vez dependente da composição, tratamento térmico e grau de trabalho a frio. Um bom ponto de solda é originado do equilíbrio entre o aumento da resistência e o controle da corrente, simultaneamente. Se a corrente utilizada para a soldagem não permite a produção de calor suficiente para as chapas atingirem a temperatura da fase plástica (incluindo-se as perdas de calor) não será possível alcançar pontos de solda com boa qualidade. Para o valor máximo da corrente de soldagem, o início da expulsão de metal pode ser usado como parâmetro de referência. Outro teste para a avaliação dos valores limites da corrente pode ser o ponto em que ocorre grande aumento na indentação.

\section{4 - Solda a ponto em aços de alta resistência}

Os aços de alta resistência são totalmente soldáveis. Quando aços dessa natureza são soldados, a corrente de soldagem é normalmente um pouco menor (aproximadamente 10\%) e a força do eletrodo maior (até aproximadamente $50 \%$ ) do que os valores utilizados para aços de baixo carbono.

A força de cisalhamento até a ruptura aumenta na proporção da tensão de ruptura do material base soldado, conforme mostrado na figura 3.9. E a capacidade de carga suportada por uma peça soldada de um aço de alta resistência pode ser a mesma que uma peça de maior espessura de aço de baixo carbono suporta.

A utilização de materiais de alta resistência tem se tornado mais comum na indústria automobilística principalmente porque esta classe de aços permite, além de um ganho substancial do desempenho dos veículos quando submetidos a carregamentos que geram grandes deformações plásticas (tais como impacto de carroceria, avaliações de ancoragem de bancos e cintos de segurança, entre outras), uma possível redução na massa da carroceria. Apesar dos aços de alta resistência serem mais caros do que os aços de baixo carbono, o aumento do preço 
da matéria prima é usualmente compensador em relação à redução de custo que pode ser obtida na redução da massa (figura 3.10), especialmente quando este cálculo é feito tomando-se como base um volume grande de produção.

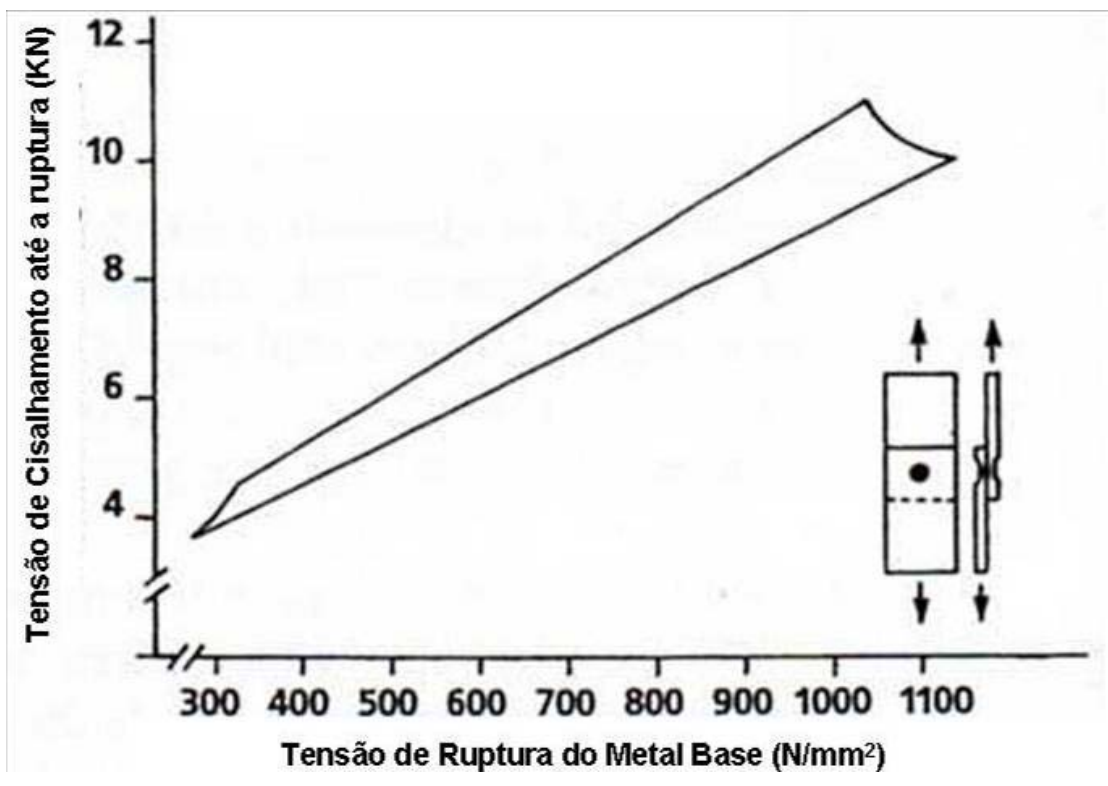

Figura 3.9 - Resistência ao Cisalhamento de Pontos de Solda em relação à Tensão de Ruptura do Material Base (SSAB TUNNPLÅT, 1996)

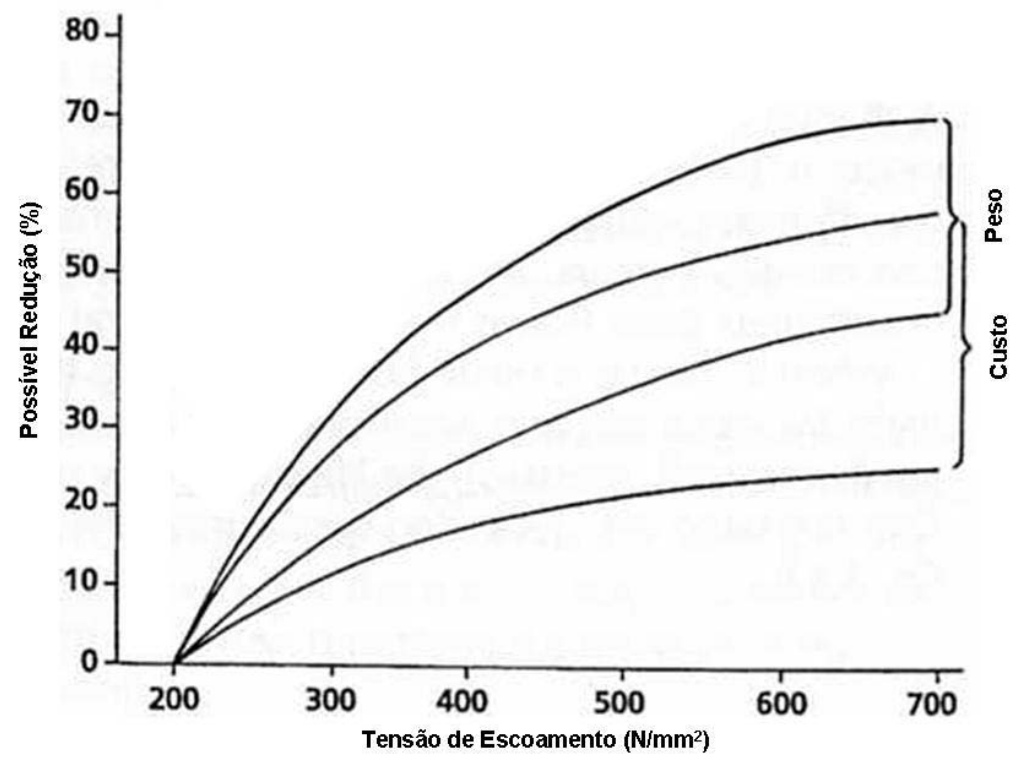

Figura 3.10 - Redução de Custo/Peso em relação à Tensão de Escoamento do material (SSAB TUNNPLÅT, 1996) 


\section{CAPÍTULO 4 \\ ESTUDO DO COMPORTAMENTO DE PONTOS DE SOLDA EM CORPOS DE PROVA}

\section{1 - INTRODUÇÃO}

Como já foi mencionado anteriormente, soldagem por resistência é o método mais comum de união de peças utilizado na indústria automobilística. Muitos são os métodos de representação de pontos de solda em modelos de elementos finitos de automóveis e como exemplo podem ser citados os elementos rígidos, elementos de viga, nós equivalenciados (ou coincidentes), etc. Mas independentemente da maneira que se queira representar os pontos de solda, os elementos devem estar associados a propriedades que possam representar o comportamento da junta soldada e assim permitir o menor erro possível na correlação dos resultados de teste de impacto de veículos automotores.

Assim como nas avaliações de adesivos estruturais, existem alguns testes que são comuns na determinação da resistência das juntas soldadas a ponto. Neste trabalho, ensaios de tração de força normal aplicada diretamente no ponto de solda, com o corpo de prova proposto por Lee et al (1998) e cisalhamento, denominado "Lap shear" foram os escolhidos para o estudo da correlação dos resultados de teste dos corpos de prova e das respectivas simulações.

Em uma avaliação de impacto veicular, pontos de solda podem ser rompidos, o que pode potencialmente afetar os sinais adquiridos no crash test. Por isso, a resistência dinâmica dos pontos de solda tem sido um dos pontos mais importantes no desenvolvimento estrutural de um veículo. E dessa forma, a modelagem da separação do ponto de solda deve ser uma das propriedades consideradas na análise.

\section{2 - PROCEDIMENTOS EXPERIMENTAIS}

Os ensaios de tração e cisalhamento em corpos de prova fabricados com aço de baixo carbono foram realizados no laboratório da área de Qualidade de Peças de Fornecedor da GMB. O equipamento de testes deste laboratório, Instron 4482, tem 
como principais características $100 \mathrm{KN}$ de capacidade, coluna dupla que proporciona um aumento de rigidez (figura 4.1) isolando o resultado do teste de possíveis erros provenientes de deformações do equipamento, faixa de velocidade de 0,001$500 \mathrm{~mm} / \mathrm{min}$, área de teste de $1309 \mathrm{~mm} \times 575 \mathrm{~mm}$, com aplicações em testes de adesivos, metais, cerâmicos, borrachas, papéis, madeira, asfalto, compósitos, realizando testes de tração, compressão e flexão.

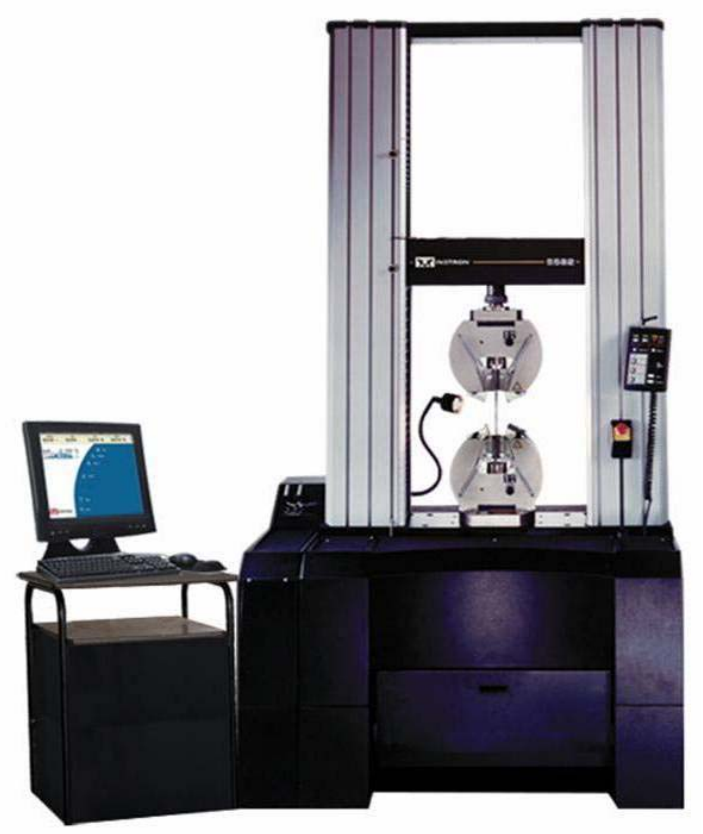

Figura 4.1: Equipamento de Testes Instron série 4480 (www.instron.us)

A velocidade do teste foi de $5 \mathrm{~mm} / \mathrm{min}$ para os testes de cisalhamento e de força normal aplicada diretamente no ponto de solda realizados no laboratório da GMB, para garantir a condição quasi-static do teste. A velocidade do teste foi devidamente reproduzida nas análises dos corpos de prova em elementos finitos.

Os deslocamentos foram medidos diretamente das garras da máquina onde 0 corpo de provas é preso ao invés de serem medidos de um extensômetro uma vez que a fratura do ponto de solda poderia danificá-lo. As curvas Força x Deslocamento foram gravadas durante cada teste, dos quais a força tensão-cisalhamento (TSF) para cada ensaio, que é a máxima força na curva Força x Deslocamento, foi extraída. 
Para relacionar os resultados dos testes de tração e cisalhamento à verdadeira deformação dos corpos de prova soldados, imagens digitais foram tiradas durante os testes. Em várias ocasiões, os testes foram interrompidos para a aquisição das imagens.

Os pontos de solda foram criados usando as combinações apropriadas de corrente, tempo e força de compressão entre os eletrodos de soldagem de acordo com a espessura e material das chapas utilizadas.

Os diâmetros dos pontos de solda foram medidos a partir de corpos de prova que tiveram a solda destacada. Através de duas medidas de diâmetro tomadas em duas direções, uma média foi tirada e adotada como o diâmetro do ponto de solda.

\subsection{1 - Parâmetros de Soldagem Utilizados}

Abaixo estão os parâmetros e algumas características da máquina de solda utilizada na confecção dos corpos de prova em aço de baixo carbono:

- Equipamento: Düring MSW-1000, Pinça tipo Trafogun - Média Freqüência; eletrodo de Cobre Cromo Zircônio com face ativa de $\varnothing 6 \mathrm{~mm}$; Modo de Correção da Corrente de Soldagem em Corrente Constante;

- Parâmetros de soldagem de acordo com a tabela 4.1 abaixo:

Tabela 4.1 - Parâmetros de soldagem utilizados na fabricação dos corpos de prova

\begin{tabular}{|c|c|c|c|c|c|c|c|c|c|}
\hline \multirow[b]{3}{*}{ Corpo de Prova } & \multicolumn{6}{|c|}{$2^{a}$ Solda } & \multirow[b]{3}{*}{ Retenção [ms] } & \multirow[b]{3}{*}{ Impulsos } & \multirow[b]{3}{*}{ Força dos eletrodos [kN] } \\
\hline & \multicolumn{2}{|c|}{ Sloope up } & \multicolumn{2}{|c|}{ Cte } & \multicolumn{2}{|c|}{ Sloope Down } & & & \\
\hline & Corrente $[\mathrm{kA}$ & Tempo [ms] & Corrente [kA] & Tempo [ms] & Corrente $[k A]$ & Tempo [ms] & & & \\
\hline $0.8 \times 0.8$ & 2.90 & 20 & 870 & 161 & 0.00 & 0 & 133 & 1 & 2.30 \\
\hline $12 m 1.2$ & 3.00 & 20 & 900 & 220 & 0.00 & 0 & 167 & 1 & 250 \\
\hline
\end{tabular}

\subsection{2 - Corpos de Prova}

As figuras 4.2 e 4.3 mostram de maneira esquemática os corpos de prova utilizados nos testes de cisalhamento Lap Shear com chapas de 0,8 e 1,2 mm. Estas dimensões a respeito do posicionamento do ponto de solda impedem as influências das bordas do corpo de prova, como por exemplo, a fuga de corrente, que não permitiria a existência de um ponto de solda de boa qualidade, e a falha do material 
base ao invés da falha ao redor do ponto de solda, que pode ser causada pela utilização de corpos de prova estreitos (ZHOU et al, 1999), detalhado na seção 6.2.

Os diâmetros dos pontos de solda medidos e considerados no modelo de elementos finitos são: 6,0 mm para os corpos de prova com espessura de 0,8 $\mathrm{mm} \mathrm{e}$ $6,5 \mathrm{~mm}$ para os corpos de prova com espessura de $1,2 \mathrm{~mm}$.

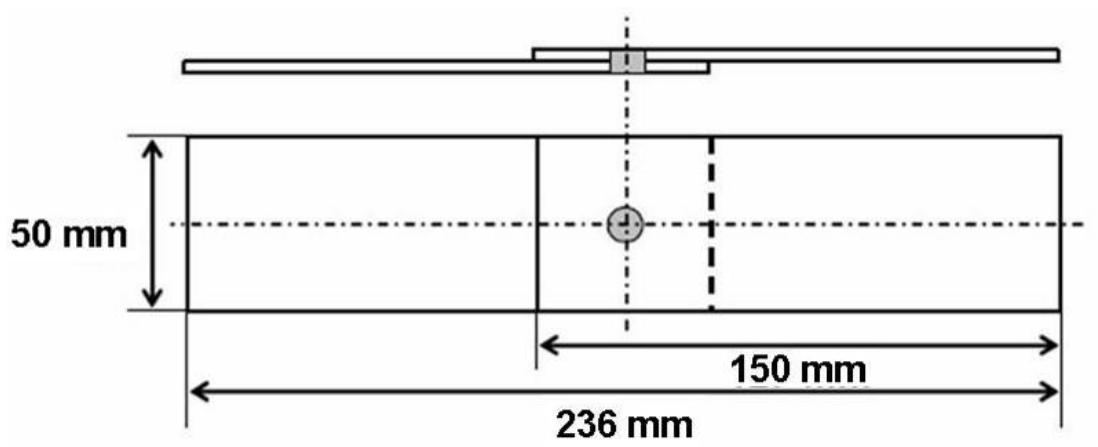

Figura 4.2: Dimensões do corpo de provas de espessura 0,8 mm utilizado no teste Lap Shear

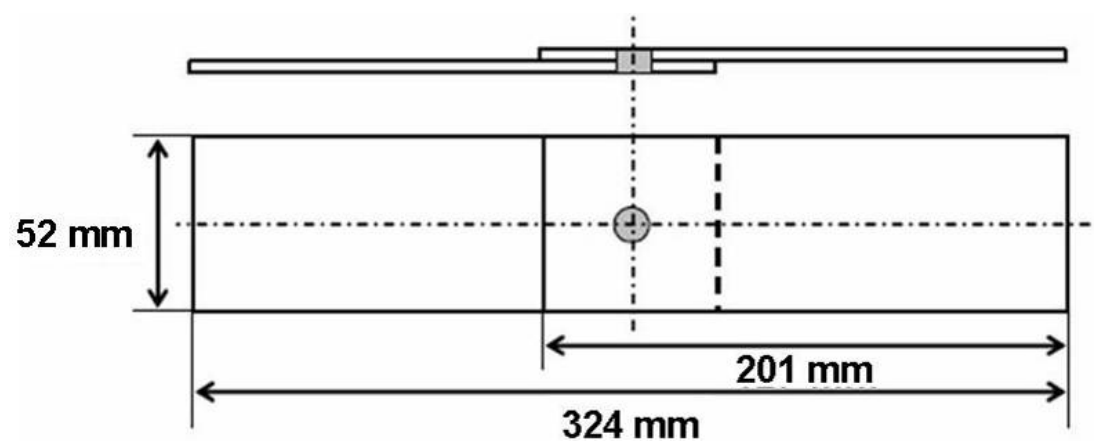

Figura 4.3: Dimensões do corpo de provas de espessura 1,2 $\mathrm{mm}$ utilizado no teste Lap Shear

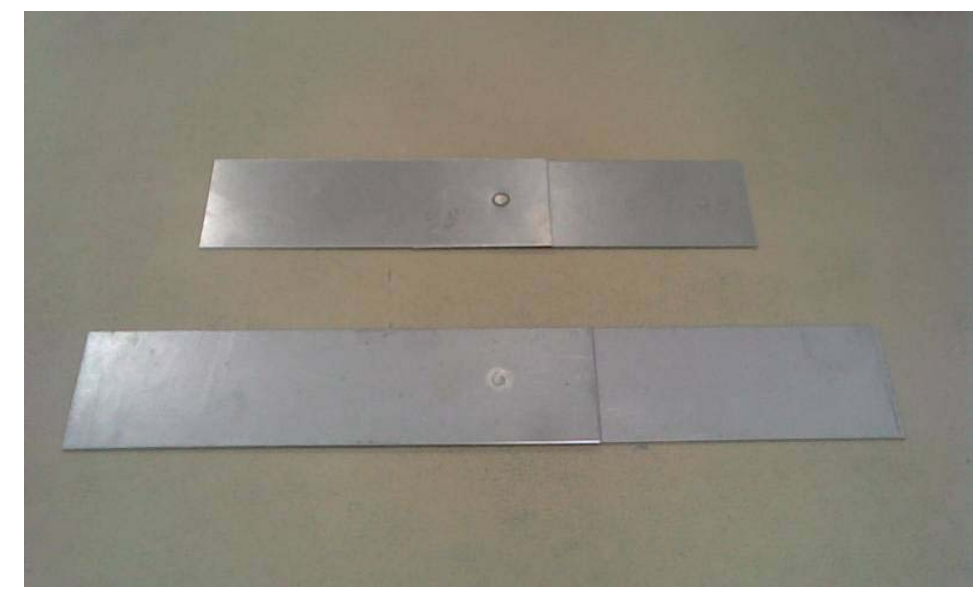

Figura 4.4: Imagem dos corpos de prova utilizado no teste Lap Shear (superior - 0,8 mm; inferior $1,2 \mathrm{~mm})$ 
No caso do teste que submete o corpo de prova a uma força normal aplicada diretamente no ponto de solda, o corpo de prova utilizado foi proposto por Lee et al (1998) e está esquematizado na figura 4.5. A largura do corpo de prova depende da espessura do mesmo, e assim como no corpo de prova do ensaio Lap Shear, o corpo de prova com espessura $0,8 \mathrm{~mm}$ apresenta largura de $50 \mathrm{~mm}$, enquanto que o corpo de prova com espessura 1,2 $\mathrm{mm}$ tem largura de $52 \mathrm{~mm}$.

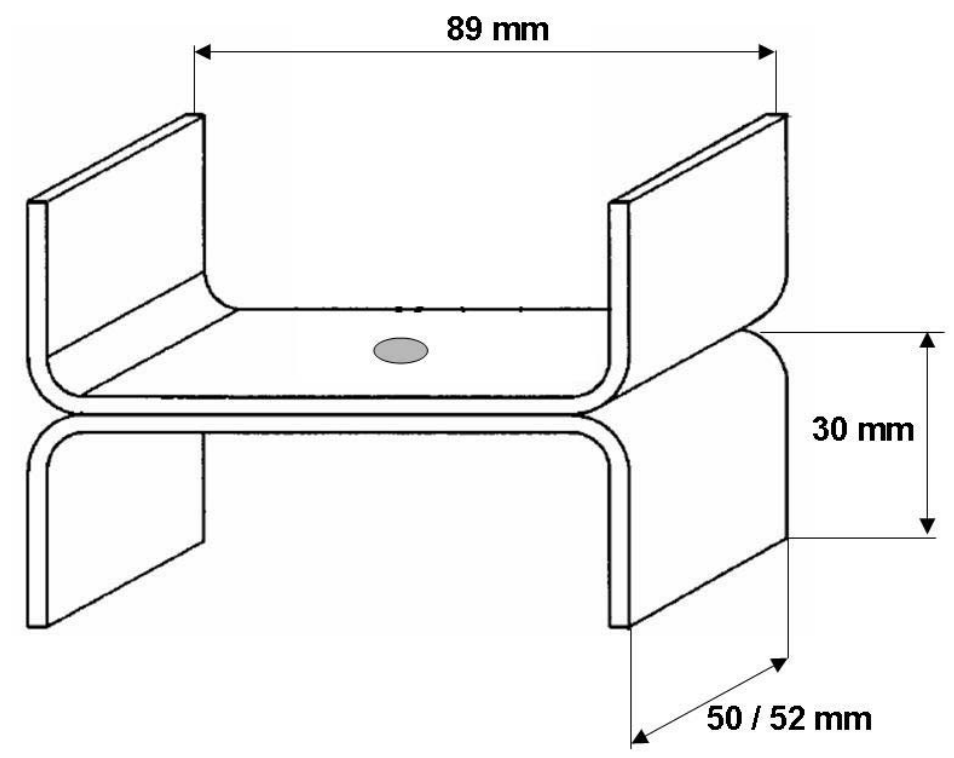

Figura 4.5: Dimensões dos corpos de prova utilizados no teste de força normal aplicada diretamente no ponto de solda
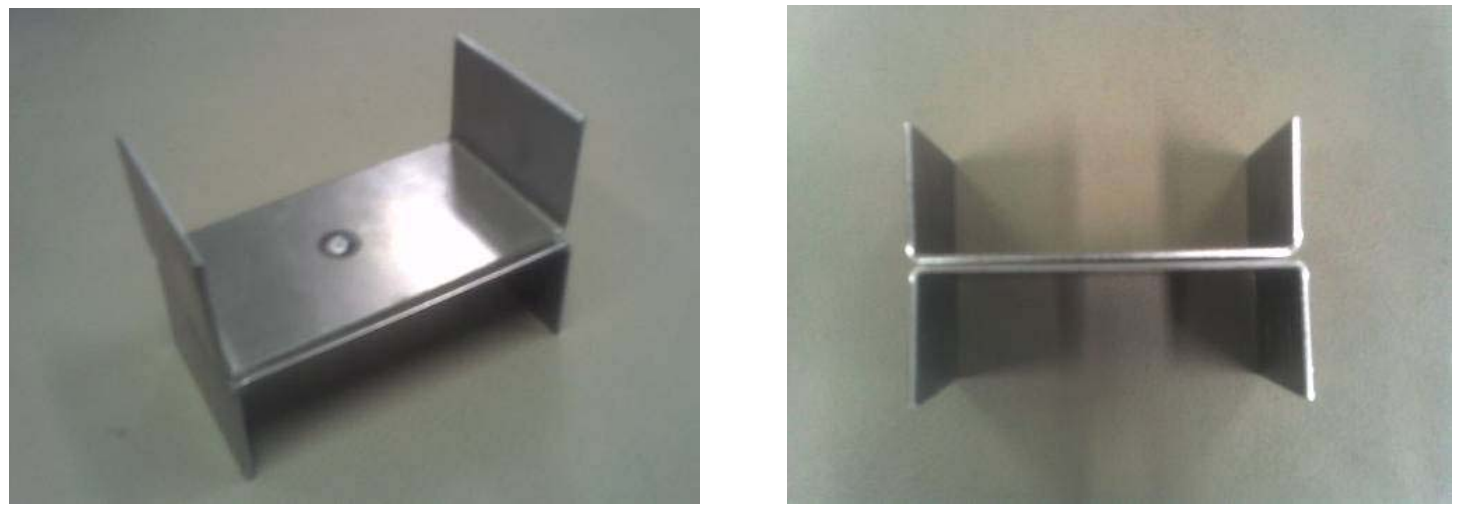

Figura 4.6: Imagem dos corpos de prova utilizados no teste de força normal aplicada diretamente no ponto de solda 
Os materiais das chapas dos corpos de prova de ambos os testes estão de acordo com a norma NBR 5906 (Chapas finas a quente de aço-carbono para estampagem, ABNT), equivalente às normas ASTM 751, ISO 10275 e DIN 50602 (GM, 2004). Como composição química, este tipo de aço apresenta no máximo 0,08\% de Carbono em termos de porcentagem em massa. Além de Carbono, ainda estão presentes na sua composição Magnésio (0,40\% em massa - máximo), Fósforo $(0,025 \%$ em massa - máximo), Enxofre (0,020\% em massa - máximo) e Alumínio (0,015\% em massa - máximo). E dentre as principais propriedades mecânicas, podem ser citados a faixa de tensão de escoamento do material utilizado, que pode variar entre 140 e $180 \mathrm{MPa}$, a tensão de ruptura, variando entre 270 e $330 \mathrm{MPa}$, e alongamento total em $50 \mathrm{~mm}$ com valor mínimo e $40 \%$.

\subsection{3 - Fixação dos Corpos de Prova}

Os corpos de prova foram fixados a dispositivos que eliminam a existência de escorregamento, e assim, o deslocamento medido nas garras da máquina de tração não implica em leituras errôneas.

Para cada tipo de teste, um dispositivo adequado foi utilizado. Ambos estavam disponíveis no laboratório e permitiram a escolha das geometrias dos corpos de prova de acordo com suas dimensões, após a definição teórica das respectivas dimensões dos corpos de prova pelo critério proposto por Zhou et al (1999). 


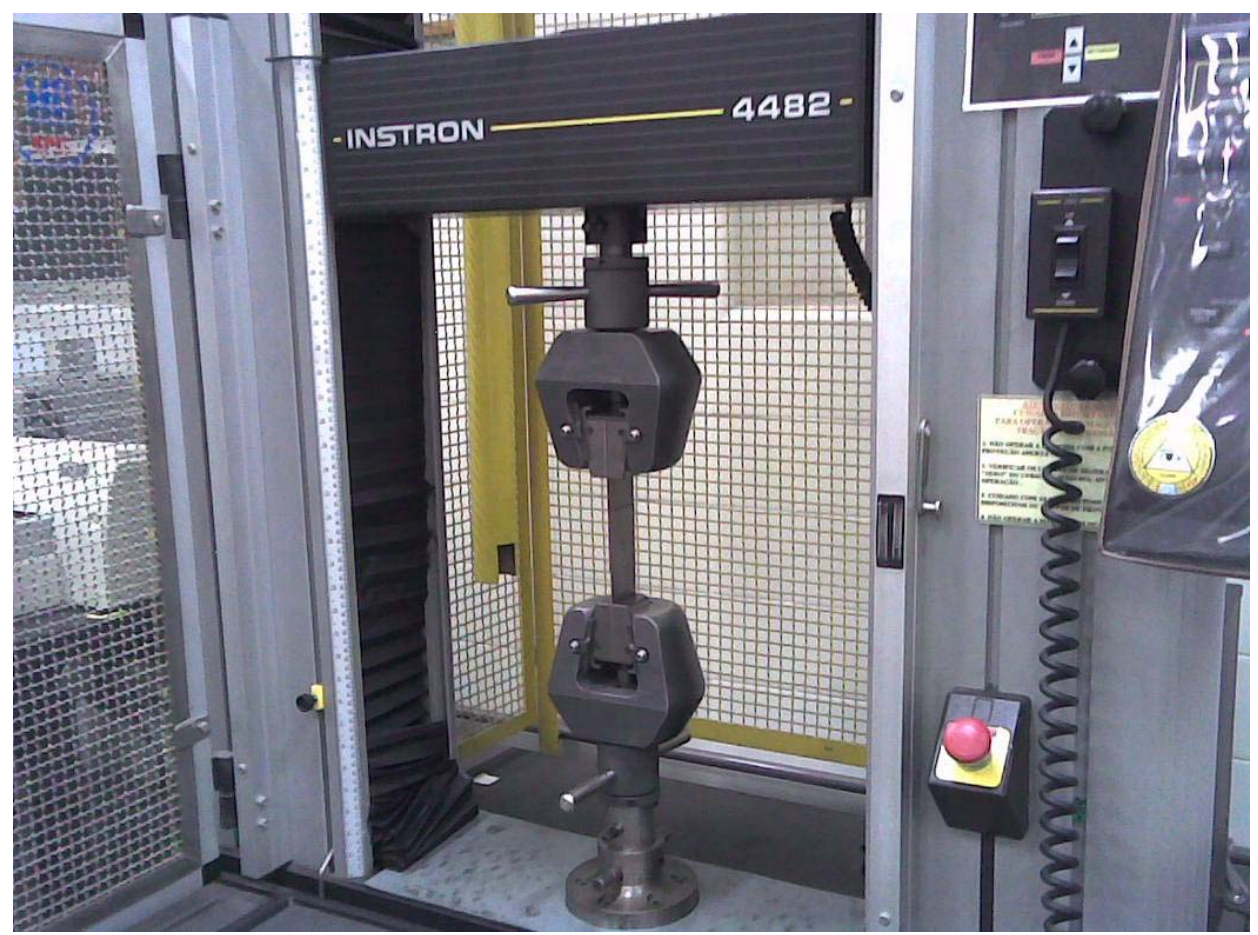

Figura 4.7: Detalhe da fixação do corpo de prova Lap Shear

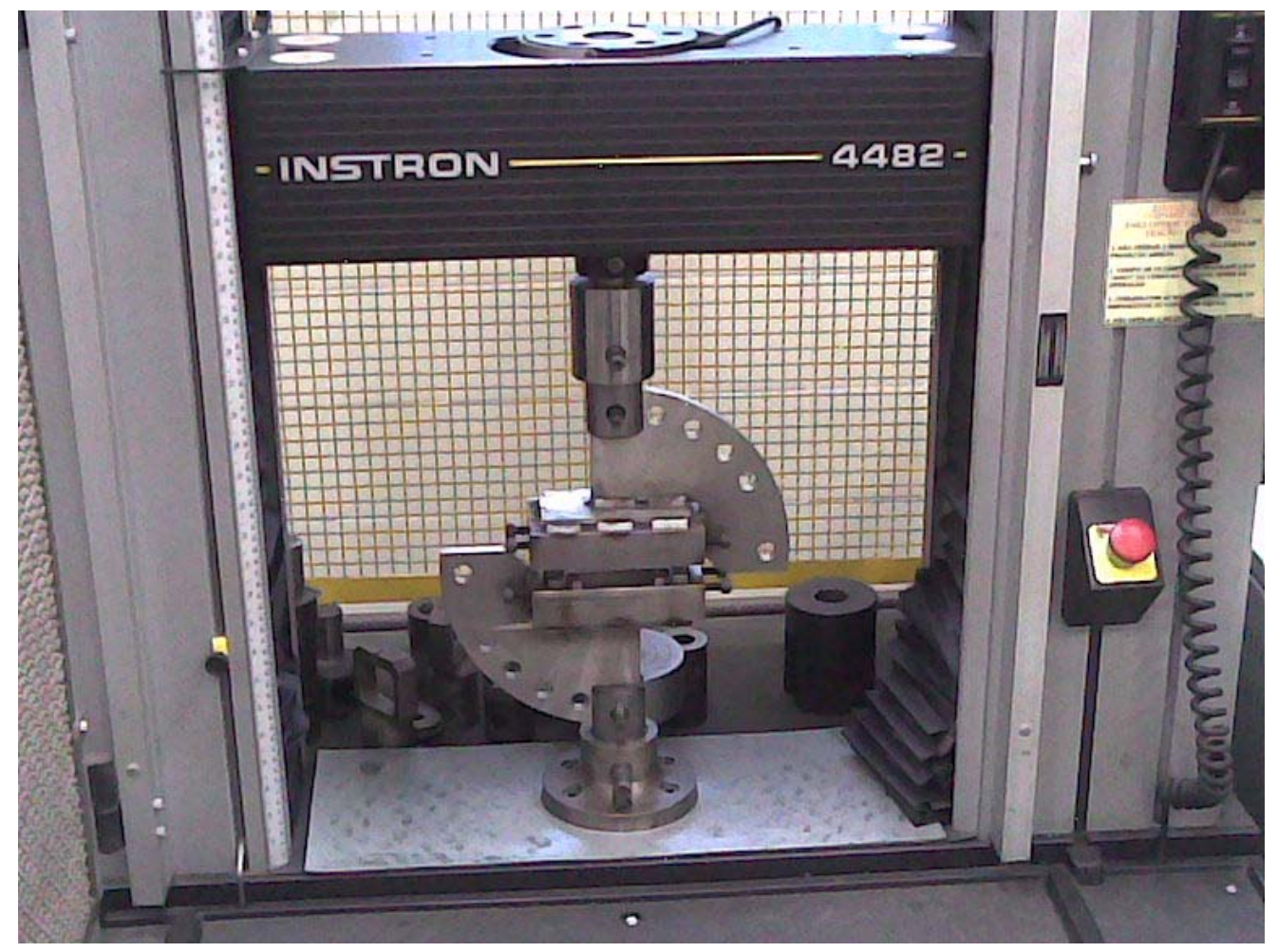

Figura 4.8: Detalhe da fixação do corpo de prova de tração (normal) aplicada diretamente no ponto de solda 


\section{CAPÍTULO 5 \\ CORRELAÇÃO DOS RESULTADOS DE TESTE E SIMULAÇÃO DO COMPORTAMENTO DE PONTOS DE SOLDA EM CORPOS DE PROVA}

\section{1 - INTRODUÇÃO}

Este capítulo apresenta detalhadamente os modelos de elementos finitos utilizados no estudo de correlação, bem como a apresentação dos resultados obtidos nos testes em laboratório e na simulação. O objetivo da comparação dos resultados das avaliações física e virtual é que a partir dos valores de força máxima na ruptura do ponto de solda, poder criar um modelo de elementos finitos que represente o comportamento do ponto de solda de maneira que os dados obtidos desse estudo possam ser implementados no modelo de impacto do veículo completo.

As previsões de falha ainda precisam atingir um maior grau de confiança, especialmente quando estão envolvidos aços de alta resistência. As aproximações feitas para o tratamento da falha ainda não estão amplamente aceitas e por isso muitos estudos experimentais, como os citados no capítulo 6, têm sido feitos para complementar o entendimento da falha do ponto de solda.

\section{2 - REVISÃO BIBLIOGRÁFICA DOS ESTUDOS DE CORRELAÇÃO TESTE vs. SIMULAÇÃO}

A grande possibilidade de redução nos custos de projeto com uma maior utilização do método de elementos finitos, que como já dito na introdução deste trabalho é uma ferramenta que permite redução no tempo e custo do projeto por meio da redução de protótipos, o interesse em representar melhor o comportamento do ponto de solda virtualmente tem sido objeto de estudo em várias universidades, como a Universidade da Carolina do Sul (EUA) e a Universidade Técnica de Graz (Áustria), e também dentro da indústria automobilística. 
Combescure et al (2003), ligados à empresas como a Renault e a PSA Peugeot, apresentam a formulação, identificação e aplicação em um problema complexo que é o comportamento da junta soldada sob atuação de cargas de impacto. Com o comportamento elasto-plástico do material, critério de falha baseado na mecânica do dano e com a proposta de que a falha ocorre de maneira dúctil ao redor da solda pelo rasgamento (tearing) do material, eles executaram a simulação e os testes (cisalhamento, normal e descascamento) dos corpos de prova para com o intuito da correlação dos resultados. O software utilizado nas análises de elementos finitos é o RADIOSS (Altair Engineering), código para simulação de impacto de veículos automotivos, que utiliza integração explícita do tempo.

O estudo conduzido por Heubrandtner et al (2005) da Universidade Técnica de Graz (Áustria), lida com um modelo avançado para pontos de solda em carrocerias sob cargas de impacto. $O$ tratamento é também elasto-plástico, e o elemento que representa a solda é baseado na formulação híbrida de Trefftz através de um cilindro rígido representando um ponto de solda também rígido, o qual é ligado à chapa ao redor do ponto através de um polígono arbitrário, com a vantagem segundo os autores de representar um comportamento cinético mais realista do ponto de solda dentro da estrutura completa durante um carregamento de impacto, devido ao modelo levar em conta o formato circular do ponto e seu devido tamanho. A modelagem da região soldada é feita através de um modelo análogo de barras elasto-plásticas que substitui os elementos de casca, e estas barras são ligadas por outro elemento de barra que inclui critérios de falha.

Cheng (2004) investigou uma modelagem combinada dos dois principais modos de falha do ponto de solda: a falha na interface do ponto de solda e a falha por destacamento do ponto, com o rasgamento do material base na ZTA. A modelagem combinada leva em conta o critério de falha por deformação no caso da falha por destacamento do ponto e o critério de falha baseada na força no caso da falha na interface do ponto, e para ambas as falhas, o elemento que atinge o limite estabelecido para o critério de falha, seja por força ou por deformação, é apagado do modelo de elementos finitos. A proposta para a representação do ponto de solda estudada por Cheng (2004) é que o ponto seja representado por múltiplos elementos rígidos ou de barra. Ainda é recomendado neste estudo que sejam utilizados para a representação do ponto de solda no mínimo seis elementos, o que representaria 
melhor a deformação local sob diferentes condições de carregamento. Uma quantidade mínima de elementos representando o ponto de solda e o diâmetro do ponto influenciam o tamanho da malha na região.

Um estudo detalhado do comportamento mecânico tridimensional de juntas soldadas a ponto foi conduzido por Deng et al (2000) da Universidade da Carolina do Sul (EUA). A determinação da distribuição de tensões no material base e na região do ponto de solda em corpos de prova sob cargas de cisalhamento e força normal aplicada diretamente no ponto de solda foi feita em análises de elementos finitos. $O$ efeito do diâmetro do ponto na distribuição de tensões e no modo de falha também foi investigado. Como principais conclusões do estudo de Deng et al (2000), têm-se que a transferência de carga no ponto de solda é acontece principalmente pelo material próximo à periferia do ponto enquanto que a região central do ponto é apresentada com baixos níveis de tensão; com o aumento da espessura de uma das duas chapas soldadas e sem nenhuma outra modificação na configuração da solda, a chapa mais fina apresenta maiores níveis de tensão o que afeta de maneira geral a resistência da solda; o modo de falha da junta soldada depende fortemente da relação entre o diâmetro da solda e a espessura das chapas (pontos de solda com diâmetro pequeno tendem a apresentar falha na interface, enquanto que pontos de solda com diâmetros maiores apresentam a falha por destacamento do ponto, com rasgamento do material base).

Os efeitos do processo de soldagem e a conseqüente influência dos mesmos nas características das propriedades da solda, incluindo a tensão residual na área soldada, foram investigados por Dong (1999). A dureza na ZTA pode apresentar valor até duas vezes maior do que a dureza do metal base no caso de aços de alta resistência, e assim as propriedades mecânicas da solda, da ZTA e do material base são diferentes e deveriam ser levados em consideração na modelagem em elementos finitos. Algumas iterações foram feitas variando as propriedades dos materiais envolvidos até que o modelo de elementos finitos estivesse calibrado com os resultados obtidos nos testes em laboratório.

Utilizando elementos bidimensionais para representar o ponto de solda, Hamze e Duval (1999) estudaram a correlação em testes de juntas soldadas sob carga de impacto. A melhor correlação foi obtida utilizando uma malha mais refinada, com comprimento de elemento em torno de 1,5 mm (os testes iniciais consideraram 
elemento com $10 \mathrm{~mm}$ ), rigidez do ponto de solda representada por elemento rígido e material isotrópico de comportamento elasto-plástico.

Buscando uma representação de ponto de solda simples e que seja capaz de reproduzir o carregamento relevante, a distribuição de tensões e a deformação ao redor do ponto de solda quando comparados a modelos mais complexos, Xu e Deng (2004) estudaram em corpos de prova fabricados em Alumínio (Al 2024-T4) algumas combinações de diferentes tipos de modelagem para representar a solda e refinamento da malha sob cinco diferentes carregamentos, entre eles a torção no plano e fora dele e cisalhamento (Lap Shear). A avaliação dos diferentes modelos é baseada na consideração da rigidez estrutural representada por cada uma das configurações estudadas, que incluem: elemento de barra para representar a solda e casca, ambos com propriedades elásticas, solda como elemento rígido e casca elástica, solda e casca como rígidos, modelos com múltiplas barras para representar um único ponto de solda e ainda o ponto representado por elementos sólidos. As conclusões dos estudos de Xu e Deng (2004) mostram que a correlação dos resultados não foi boa apenas nos casos de torção e cisalhamento no plano até mesmo com uma malha bastante refinada (os estudos foram realizados em modelos que variaram de 35.000 a 390.000 elementos), e uma investigação adicional é recomendada para identificar o equilíbrio entre precisão e eficiência em modelos utilizados em analises estruturais de "larga escala".

\section{3 - MODELO DE ELEMENTOS FINITOS}

Para as estruturas automotivas que possuem uma grande quantidade de pontos de solda, não é conveniente representar um único ponto de solda através de vários elementos, até mesmo por questões computacionais. Uma representação simples, de preferência com um único elemento que conecte dois componentes de elementos de casca sem a necessidade de um refinamento da malha na área de ligação onde está representado o ponto de solda, é a maneira mais compensadora de criar e manter atualizado com certa facilidade o modelo de elementos finitos (ZHANG, 2001).

Assim, o objetivo desta investigação é definir um modelo adequado para representar o ponto de solda que inclua o comportamento de falha e que 
posteriormente possa ser aplicado em um modelo completo para análise de impacto veicular. Mas se apenas um elemento se propõe a representar o comportamento do material e o comportamento na falha, testes devem ser providenciados a fim de permitir uma base para investigação, verificação, calibração e validação dos modelos de elementos finitos que representam o ponto de solda.

A modelagem de pontos de solda no LS-DYNA possui uma particularidade e ao mesmo tempo uma facilidade, que é permitir uma conexão arbitrária, ou seja, em qualquer lugar das superfícies da casca. Isso significa que através do contato, o elemento que representa o ponto de solda pode ser posicionado na exata localização definida em conjunto pelas engenharias responsáveis pelo projeto do produto e pela manufatura, uma vez que as extremidades do elemento estão "presas matematicamente" às superfícies por meio de equações de restrição, quando projetadas nas mesmas (LS-DYNA, 2006). Esta característica permite também uma modelagem da solda independente da malha de elementos finitos, pois o elemento não fará a ligação entre as chapas através dos nós da malha.

Os elementos que representam o ponto de solda são deformáveis e podem incluir parâmetros que permitirão a falha desse elemento, que resultará na separação dos componentes que estavam ligados, importante característica nos estudos de correlação de impacto veicular.

Existem diversas opções para modelar pontos de solda no LS-DYNA, incluindo nós coincidentes, elementos sólidos, molas, vigas rígidas sem-massa, elementos rígidos nodais e vigas.

Após uma investigação preliminar, eliminando a representação por elementos rígidos que seriam adequados para representar os pontos de solda apenas quando nenhuma falha ocorra, dois modelos foram selecionados para ser objeto deste estudo de correlação: elemento sólido (LS-DYNA formulação tipo 1 - Constant Stress Solid Element) e elemento de viga (LS-DYNA formulação tipo 9 - Spot Weld Beam). Obviamente, o uso de um elemento de viga indica o menor esforço de discretização do modelo do ponto de solda com elementos finitos. Uma característica inconveniente na utilização de elementos de viga é o posicionamento dos nós destes em relação à superfície da casca. 
Wang (2000) investigou as diferenças nos resultados posicionando o elemento de viga que representa o ponto de solda em doze diferentes localizações e utilizando um corpo de provas com espessura das duas chapas igual a 1,0 $\mathrm{mm}$ para o teste Lap Shear (figura 5.1), quatro diferentes localizações e corpo de prova com espessura de 2,1 $\mathrm{mm}$ para o teste Cross Tension (figura 5.2), e aço de alta resistência em ambos os casos.

Localizando o elemento no centro dos elementos de casca, obteve-se resposta com maior rigidez (menor deslocamento), e o contrário acontece com o elemento posicionado nos cantos do elemento de casca, entretanto a força permanece no mesmo nível para qualquer posicionamento do elemento no caso dos resultados do teste Cross Tension e difere bastante nos resultados do teste Lap Shear.

E tomando como base este último teste, a correlação dos resultados em relação à força de falha mostra que o posicionamento mais indicado para o elemento que representa o ponto de solda é o centro da casca a qual os nós da viga estão projetados (WANG, 2000).

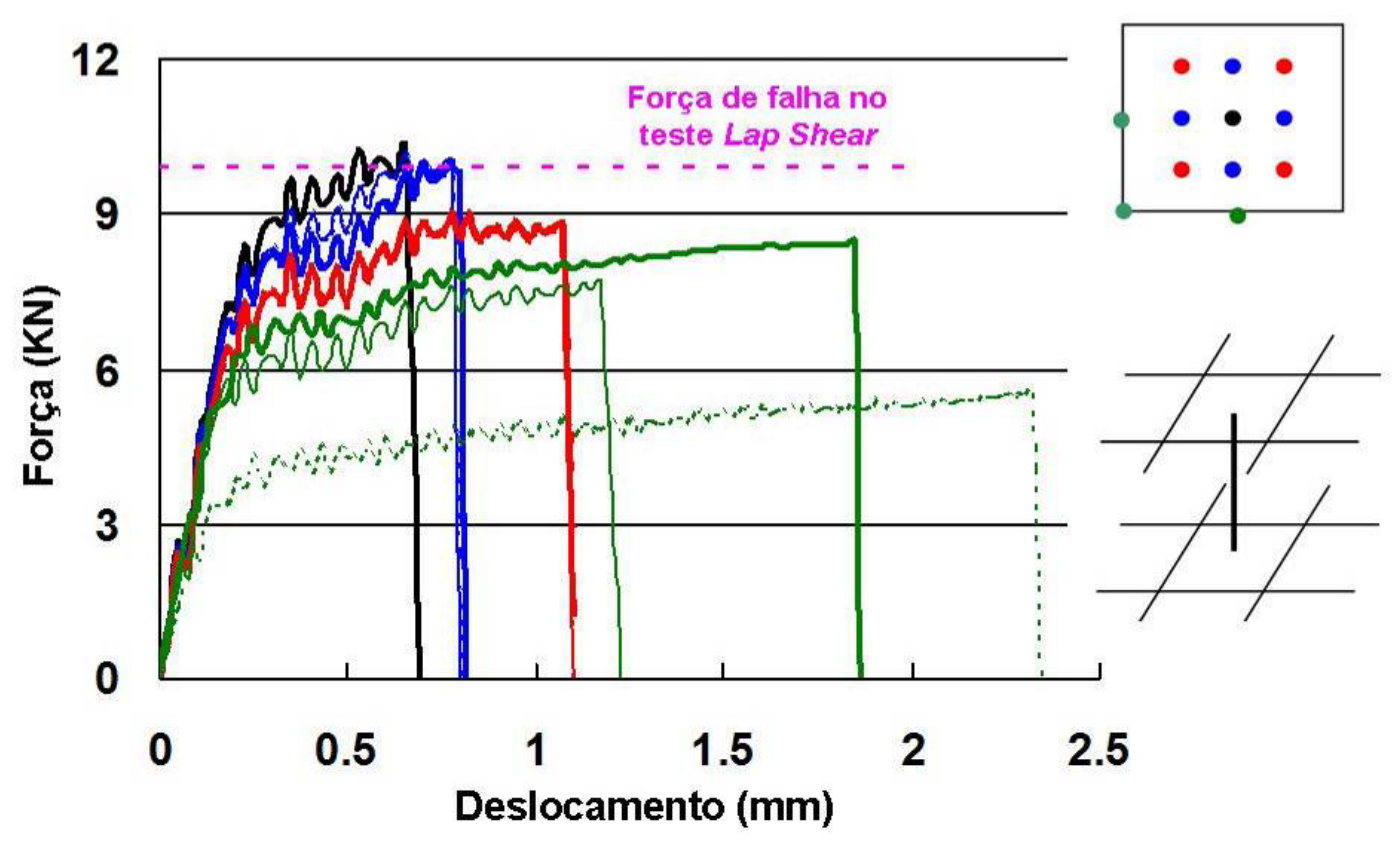

Figura 5.1: Efeito da Localização do Elemento de Viga no teste Lap Shear (Wang, 2000) 


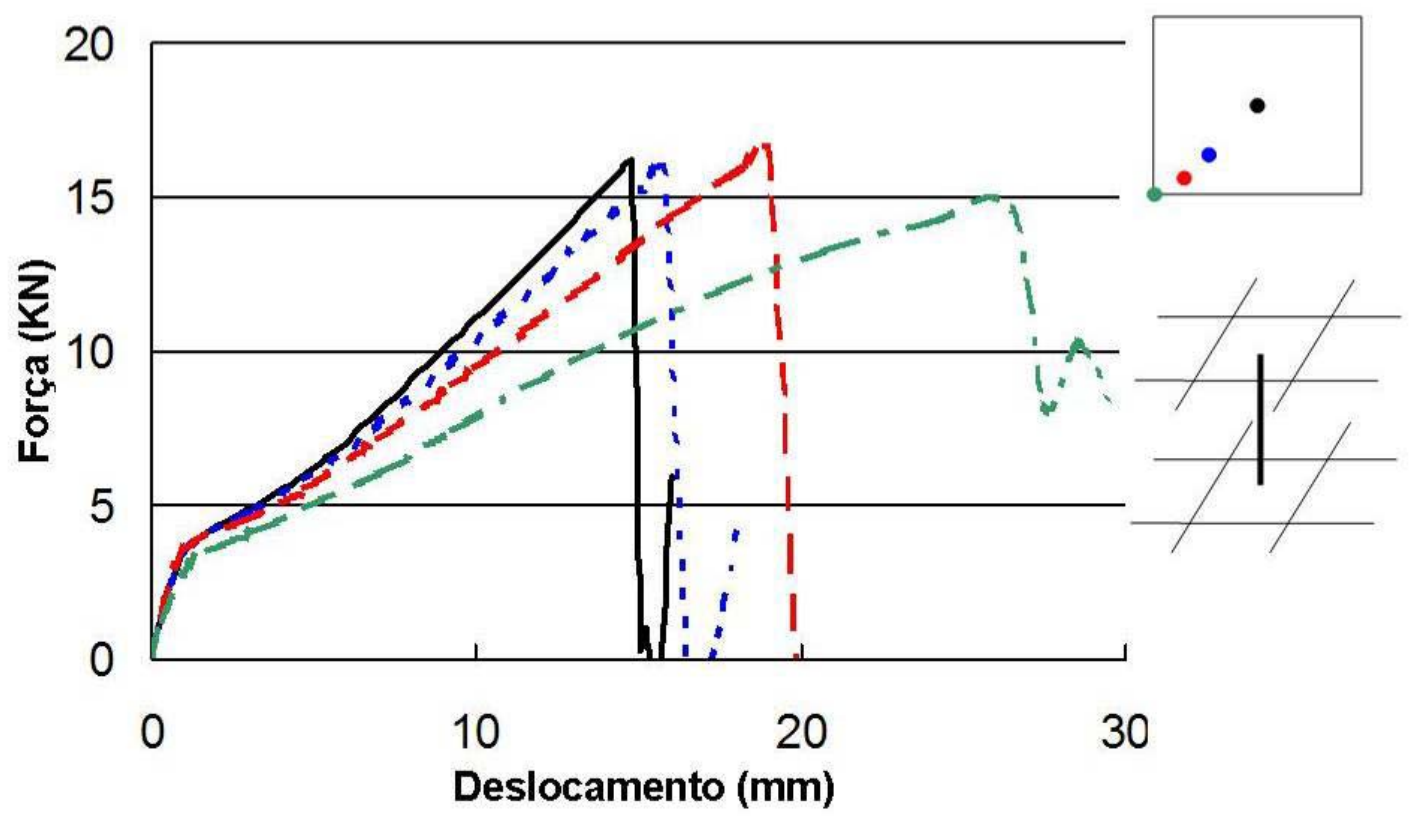

Figura 5.2: Efeito da Localização do Elemento de Viga no teste Cross Tension (Wang, 2000)

Este inconveniente detectado na modelagem com elementos de viga pode ser minimizado com a criação de um algoritmo de modelagem que posicione o elemento que representa a solda na melhor localização, ou seja, o centro da casca.

Para a modelagem do material da solda, foi utilizado um material de comportamento elasto-plástico conforme identificado na literatura estudada. Como dados de entrada, o Módulo de Elasticidade $(E)$ e o Coeficiente de Poisson $(P R)$ são necessários para a determinação do comportamento elástico, e a Tensão de Escoamento (SIGY) juntamente com o Módulo de Endurecimento $\left(E_{t}\right)$ são necessários para definição do comportamento plástico.

O material disponível no LS-DYNA para representar a solda conforme o comportamento elasto-plástico é o *MAT_SPOTWELD (LS-DYNA formulação tipo 100), e que permite o acoplamento de dois diferentes mecanismos de falha: o primeiro especifica o valor da deformação para falha e calcula a deformação em cada ponto de integração do ponto de solda independentemente. O segundo mecanismo de falha permite ao elemento que representa a solda "romper-se" (ou separar-se) do modelo se as forças resultantes estiverem para fora da superfície definida por: 


$$
\left(\frac{N_{r r}}{N_{r r F}}\right)^{2}+\left(\frac{N_{r s}}{N_{r s F}}\right)^{2}+\left(\frac{N_{r t}}{N_{r t F}}\right)^{2}+\left(\frac{M_{r r}}{M_{r r F}}\right)^{2}+\left(\frac{M_{s s}}{M_{s s F}}\right)^{2}+\left(\frac{T_{t t}}{T_{t t F}}\right)^{2}-1=0
$$

onde $N_{\text {ri }}(i=r, s, t)$ são as forças no componente e $N_{\text {riF }}(i=r, s, t)$ são as forças de falha no componente, $M_{j j}(j=r, s)$ e $T_{t t}$ são os momentos no componente e $M_{j j F}(j=r, s)$ são os momentos de falha no componente, $r$, s e $t$ são os três eixos locais do elemento que representa a solda, ilustrados pelo elemento de viga da figura 5.3.

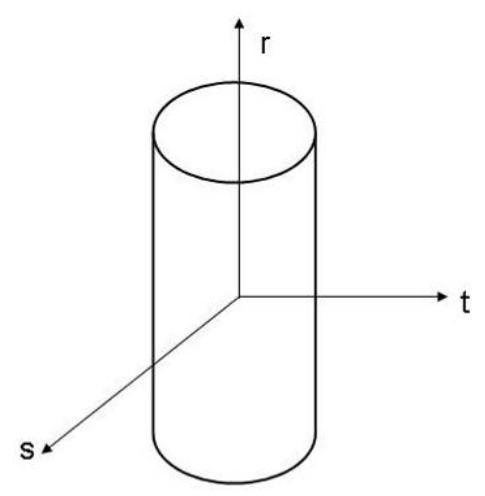

Figura 5.3: Sistema de Coordenadas Locais do Elemento de Viga (Wang, 2000)

As dimensões dos corpos de prova, do elemento sólido e do elemento de viga que são representadas de acordo com o diâmetro medido do ponto de solda, estão descritos na seção 4.2.2, no capítulo 4.

O pico de força do teste Lap Shear foi usado como dado de entrada para os valores de força de falha em cisalhamento $\mathrm{N}_{\mathrm{rsF}}$ e $\mathrm{N}_{\mathrm{rtF}}$, e o pico de força do teste de força normal aplicada diretamente no ponto de solda foi usado como dado de entrada para a força de falha normal $\mathrm{N}_{\text {rrF. }}$. Neste estudo, como os carregamentos que foram impostos aos corpos de prova são de cisalhamento e força normal aplicada diretamente no ponto de soldas, os momentos $M_{\text {rrF, }} M_{\text {ssF }}$ e $T_{\text {ttF }}$ não foram considerados.

Uma grande vantagem dos modelos sólidos e de viga associados com o material *MAT_SPOTWELD é possibilitar o monitoramento das forças de tração e cisalhamento ao longo do tempo do carregamento aplicado através do parâmetro *DATABASE_SWFORC. E baseado nos resultados deste monitoramento, o estudo de correlação pode ser viabilizado. 
O contato utilizado nos modelos de elementos finitos do LS-DYNA foi o contato *CONTACT_TIED_SHELL_EDGE_TO_SURFACE (LS-DYNA formulação tipo 7), que tem como característica eliminar a necessidade de ligar os elementos que representam o ponto de solda em nós adjacentes da malha.

As extremidades dos corpos de prova (elementos casca) foram representadas com o material considerado rígido (LS-DYNA formulação tipo 20 - *MAT_RIGID) por duas conveniências: a primeira se refere à forma simples de restringir ou não o movimento dos componentes associados a esse material em cada um dos seis graus de liberdade. $\mathrm{O}$ controle dos graus de liberdade é feito diretamente no cartão do material, separadamente para translações e rotações. A segunda conveniência é o fato de poder aplicar a curva Deslocamento vs. Tempo também diretamente aos componentes associados a esse material, apenas determinando em qual direção e sentido essa curva deve ser aplicada. O comando que aplica essa curva aos componentes no LS-DYNA é o *BOUNDARY_PRESCRIBED_MOTION_RIGID.

Os demais componentes de elementos de casca, incluindo aos que estão ligados pelo contato ao elemento que representa a solda, seja o elemento sólido ou o elemento de viga, estão representados com o material de comportamento elastoplástico *MAT_PIECEWISE_LINEAR_PLASTICITY (LS-DYNA formulação tipo 24) que tem como parâmetros o Módulo de Elasticidade, o Coeficiente de Poisson, a Tensão de Escoamento e a referência à curva Tensão vs. Deformação do material.

As unidades consistentes utilizadas nos modelos de elementos finitos deste estudo, bem como alguns valores de referência para as propriedades mecânicas do aço, estão descritos no Anexo I, coluna (c) da tabela retirada do manual do LSDYNA.

As figuras 5.4 e 5.5 mostram respectivamente os modelos de elementos finitos dos corpos de prova dos ensaios Lap Shear e de força normal aplicada diretamente no ponto de solda, indicando quais os materiais utilizados para cada componente, além da direção e sentido de aplicação da curva Deslocamento vs. Tempo. O tamanho médio da malha considerado é de 5,0 $\mathrm{mm}$. 


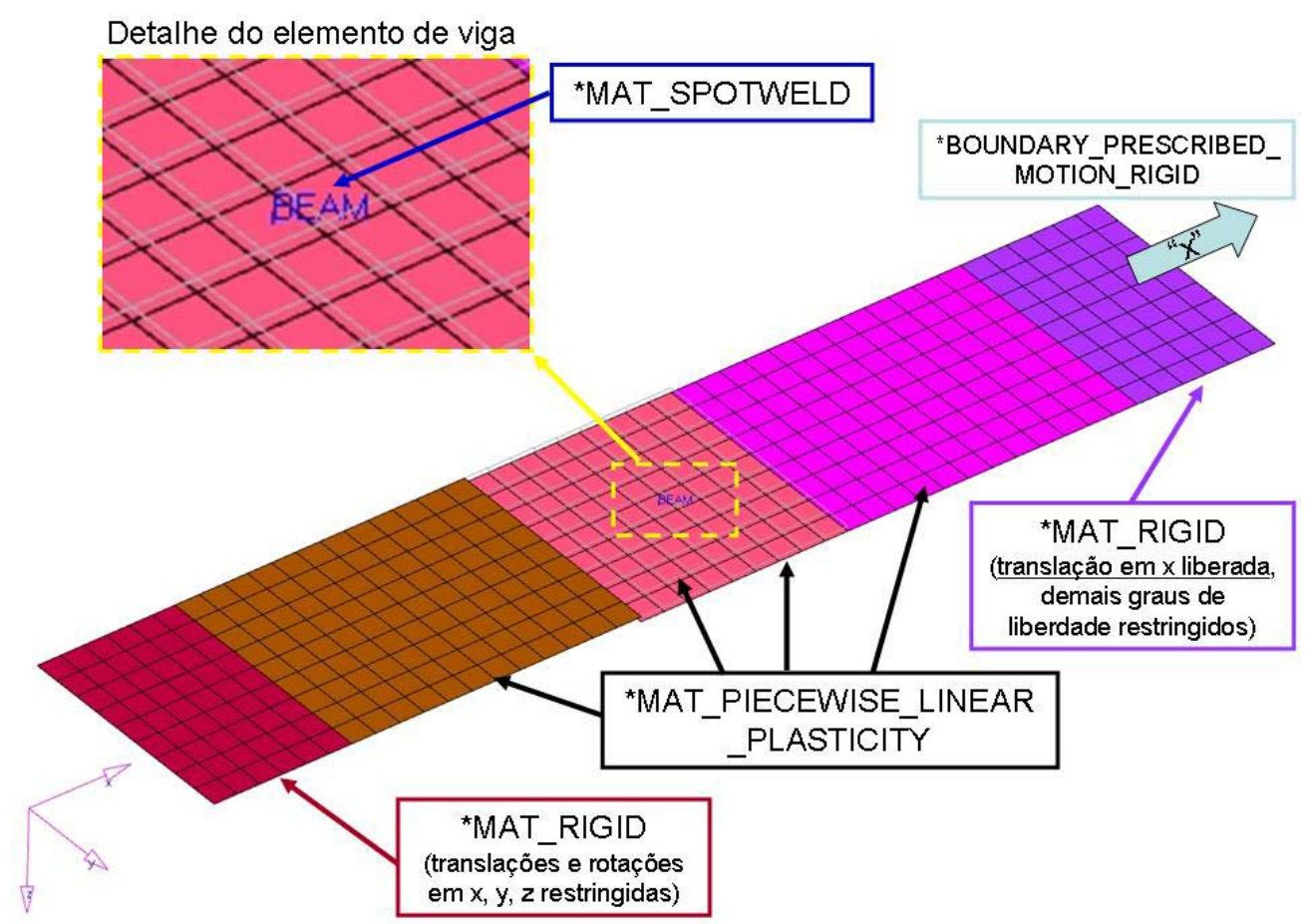

Figura 5.4: Modelo de elementos finitos do corpo de prova do ensaio Lap Shear, com representação da solda por elemento de viga

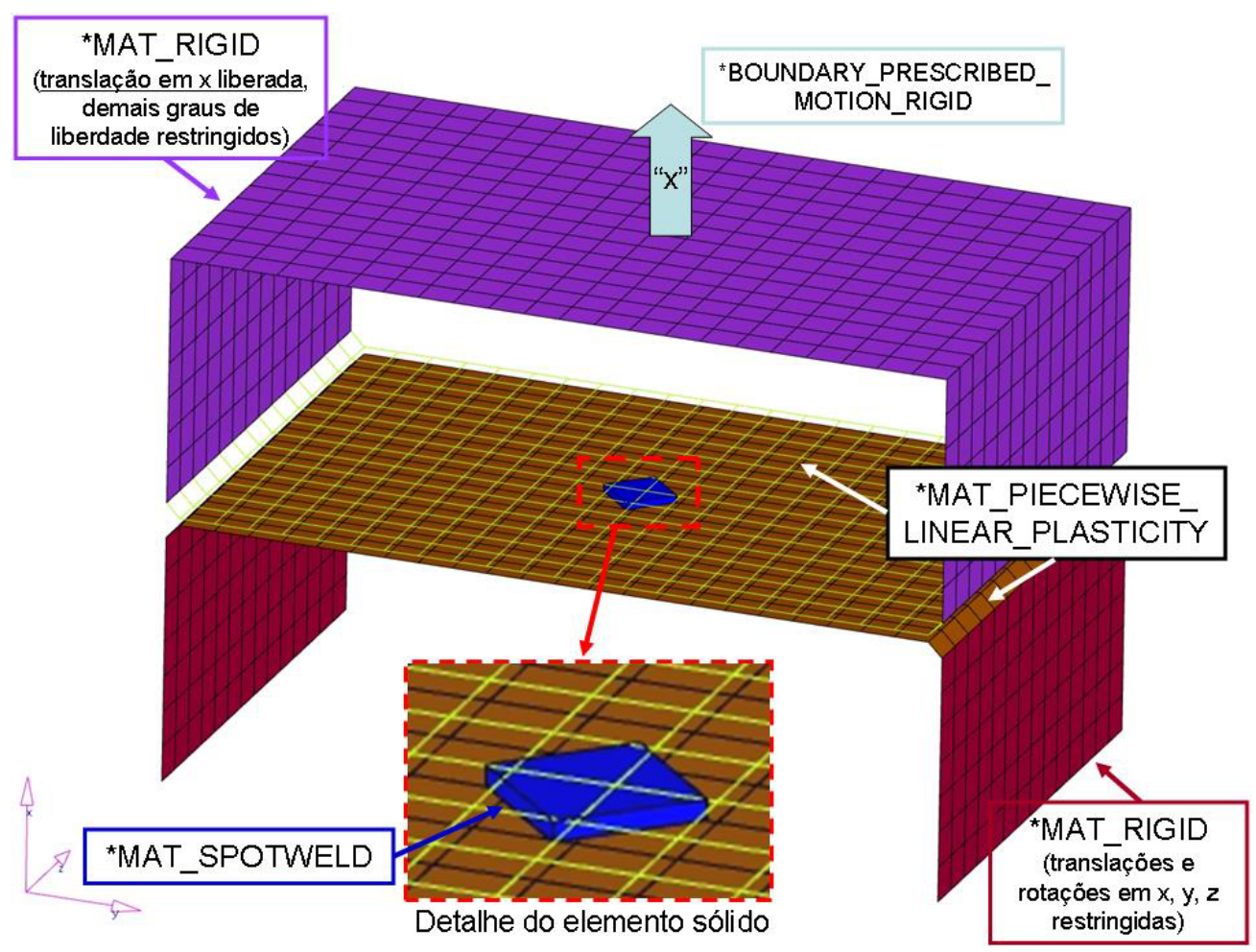

Figura 5.5: Modelo de elementos finitos do corpo de prova do ensaio de força normal aplicada diretamente no ponto de solda, com representação da solda por elemento sólido 
Nas seções a seguir, os resultados dos testes e simulações efetuados neste estudo de correlação estão apresentados em forma de curvas de força suportada pela junta soldada vs. deslocamento, com a identificação dos valores de força máxima no rompimento (separação) do elemento representativo do ponto de solda.

\section{4 - RESULTADOS DO TESTE LAP SHEAR}

- Teste 1: espessura das chapas de $0,8 \mathrm{~mm}$, velocidade de ensaio $5 \mathrm{~mm} / \mathrm{min}$

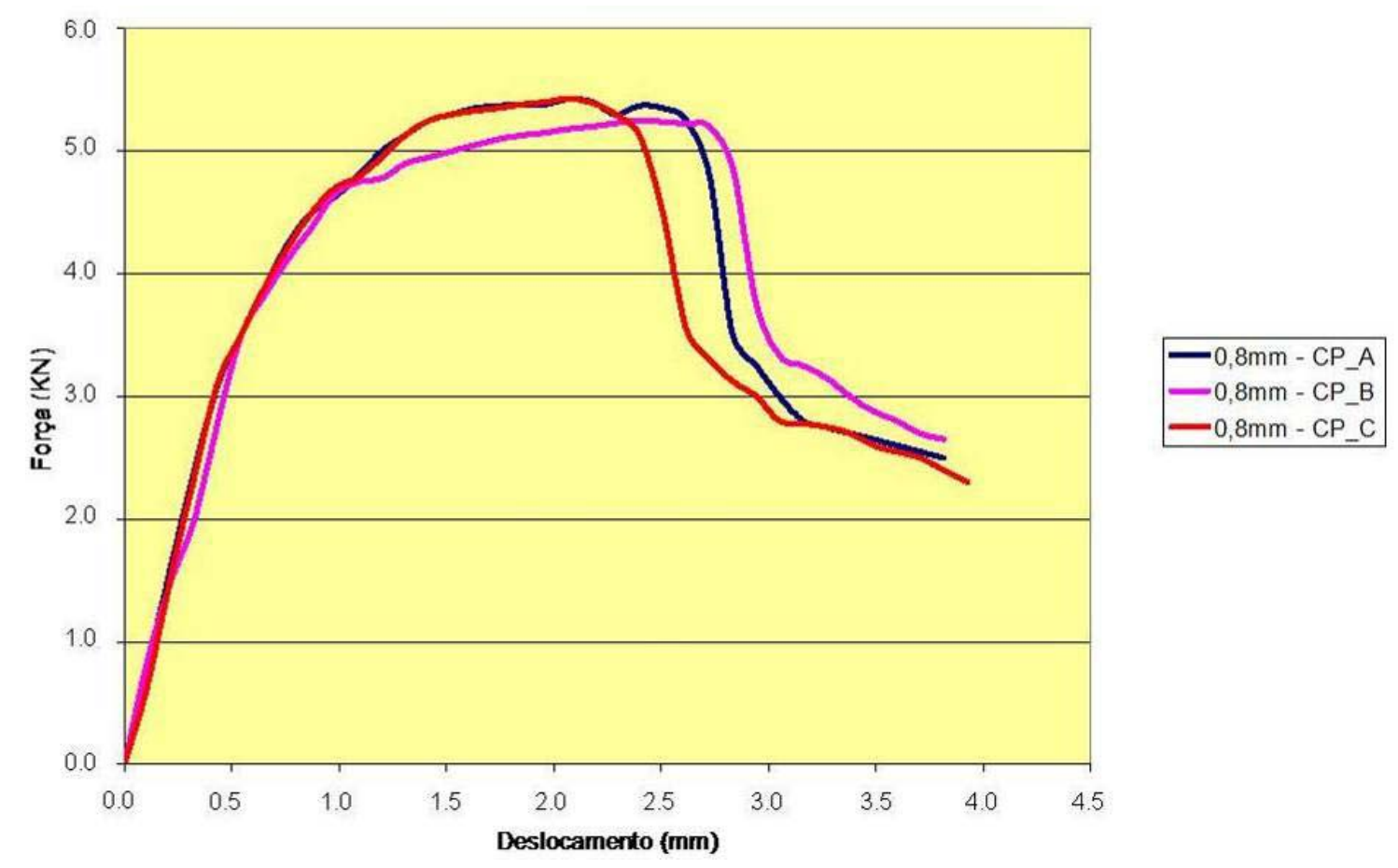

Figura 5.6: Resultados dos Testes Lap Shear (3 amostras) com espessura 0,8 mm

Força máxima detectada:

Corpo de Prova "A": 5,452 KN

Corpo de Prova "B": 5,251 KN

Corpo de Prova "C": 5,428 KN

Média do teste 1: $\mathbf{5 , 3 7 7} \mathrm{KN}$ 
- Teste 2: espessura das chapas de $1,2 \mathrm{~mm}$, velocidade de ensaio $5 \mathrm{~mm} / \mathrm{min}$

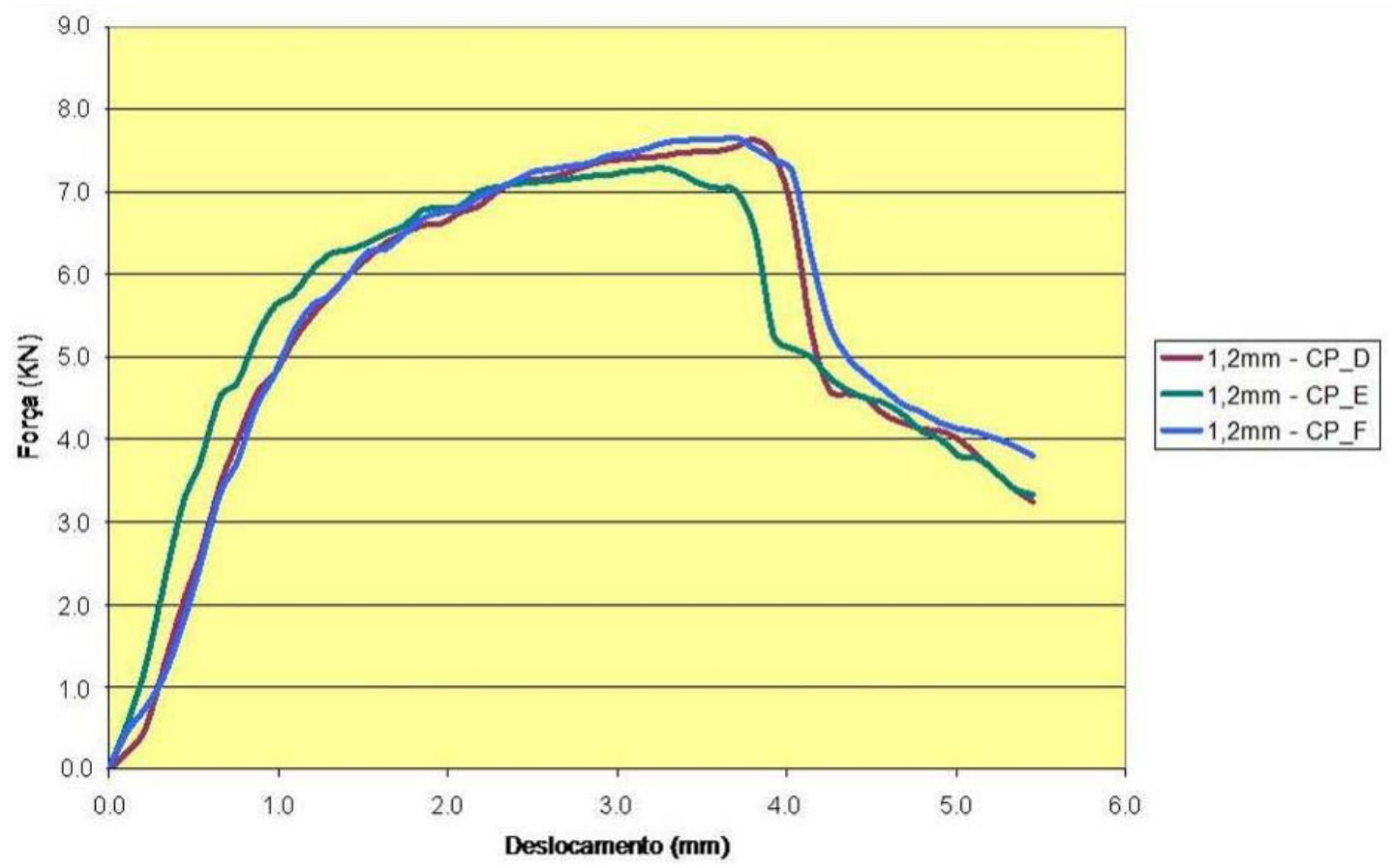

Figura 5.7: Resultados dos Testes Lap Shear (3 amostras) com espessura 1,2 mm

Força máxima detectada:

Corpo de Prova "D": 7,630 KN

Corpo de Prova "E": 7,291 KN

Corpo de Prova "F": 7,659 KN

Média do teste 2: $7,527 \mathrm{KN}$
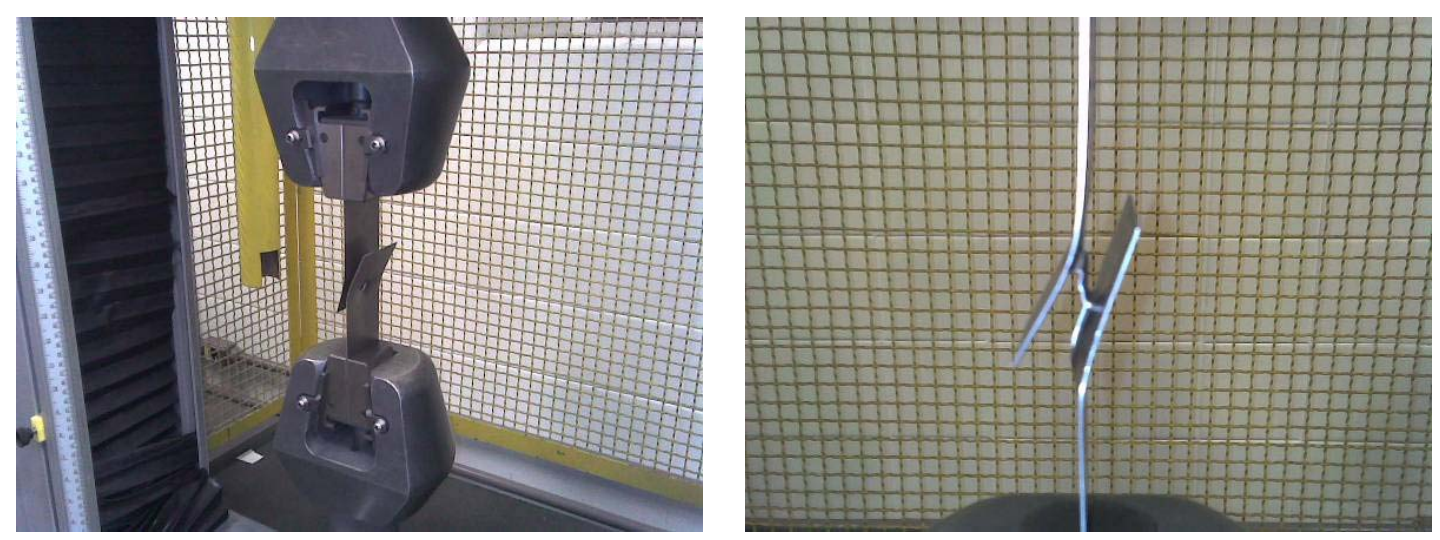

Figura 5.8: Imagens do Teste Lap Shear - Corpo de prova com espessura de 1,2 mm 
- Simulações com chapas de 0,8 mm e 1,2 mm, elemento de viga e elemento sólido representando o ponto de solda

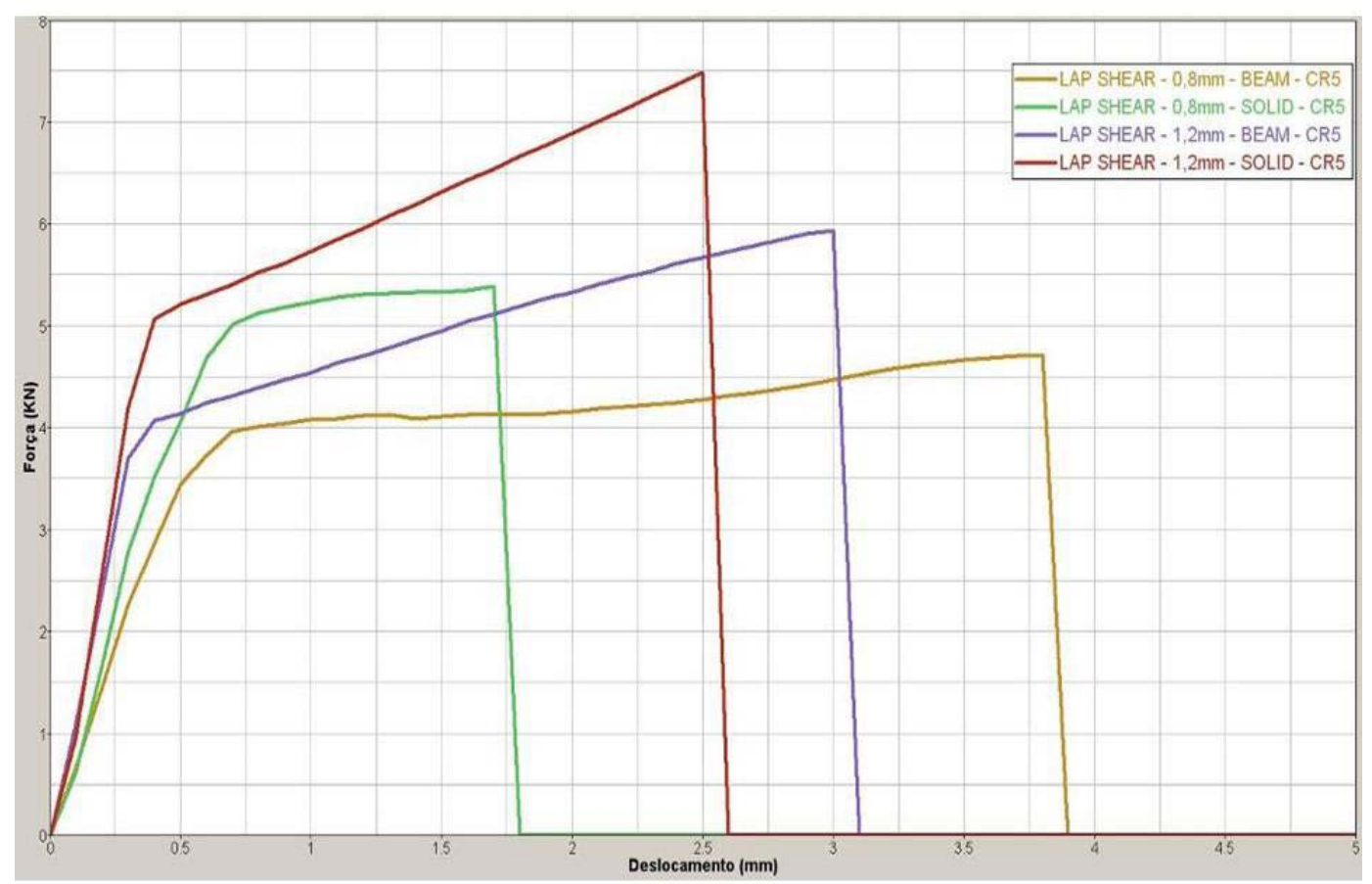

Figura 5.9: Resultados de Simulação do Teste Lap Shear usando elementos de barra e sólido na representação do ponto de solda - espessuras de 0,8 e 1,2 mm

Força máxima detectada para simulação do corpo de prova com $0,8 \mathrm{~mm}$ :

Representação com elemento de viga: 4,679 KN

Representação com elemento sólido: $5,411 \mathrm{KN}$

Força máxima detectada para simulação do corpo de prova com 1,2 mm:

Representação com elemento de viga: 5,893 KN

Representação com elemento sólido: 7,487 KN
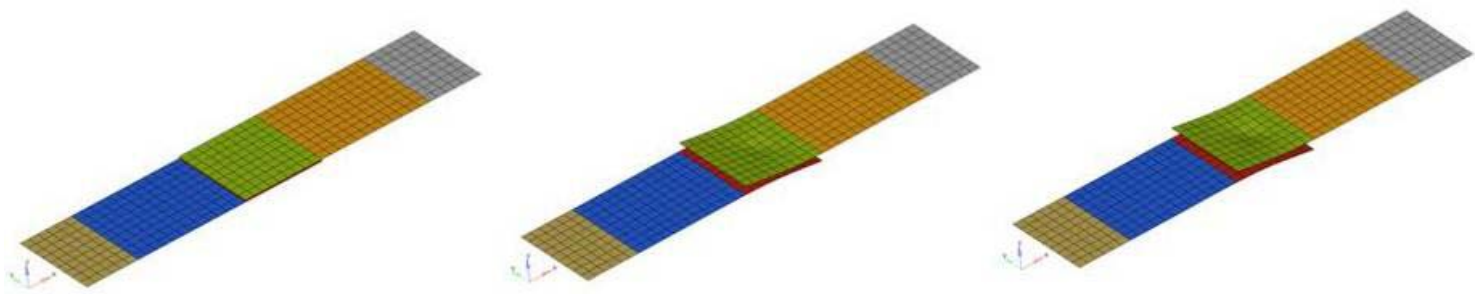

Figura 5.10: Evolução da deformação do corpo de prova com espessura de 1,2 mm - elemento de viga 
Um estudo considerando o refinamento da malha também foi efetuado para que se tenha idéia da dependência dos resultados de força máxima suportada pelo elemento que representa o ponto de solda em relação ao tamanho médio do elemento. Essa avaliação foi feita para o teste Lap Shear, apenas com a espessura de 1,2 $\mathrm{mm}$, comparando o comportamento do ponto modelado com o elemento de viga e sólido, e considerando o tamanho médio da malha de 5,0 e 2,5 mm.

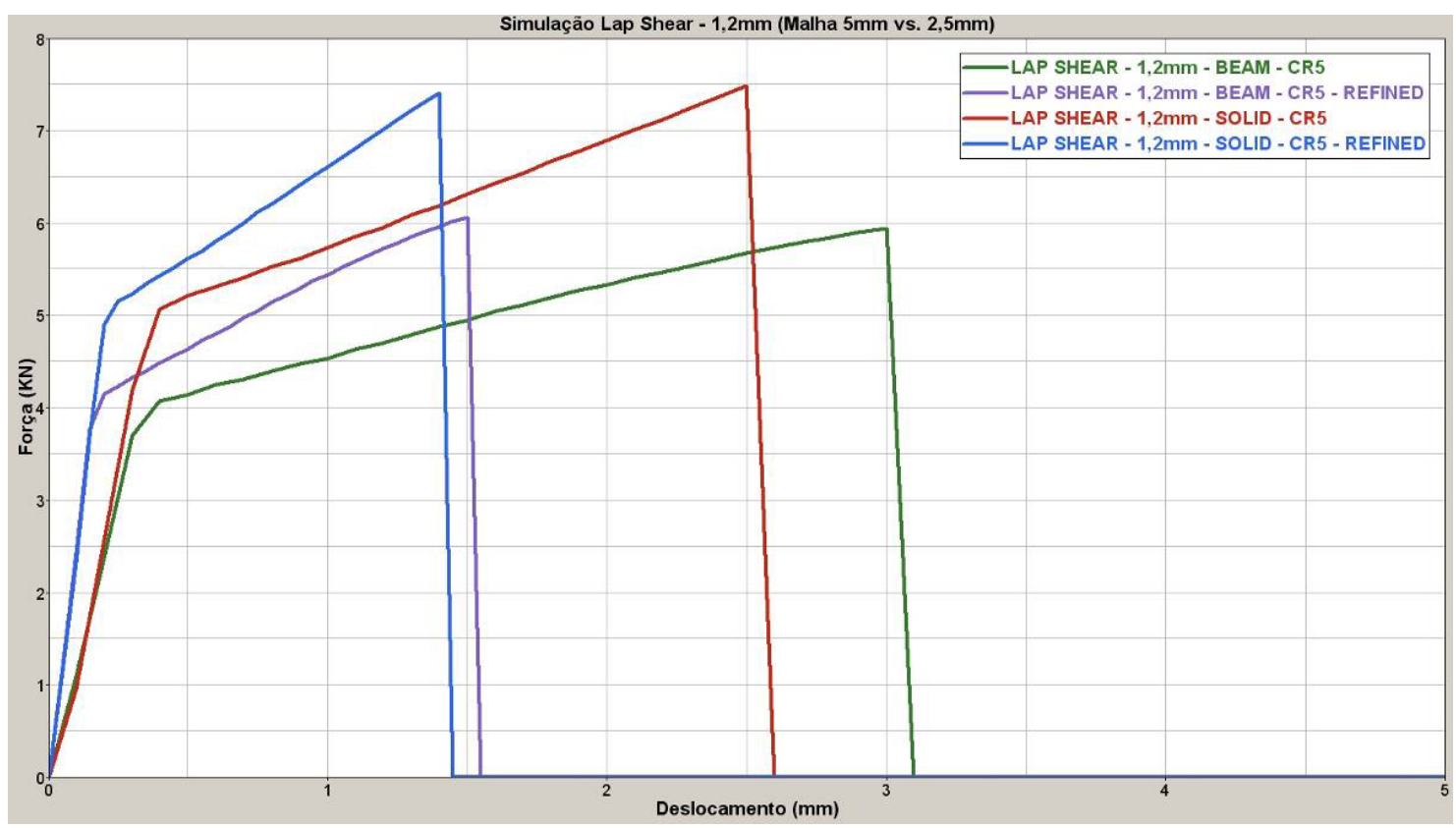

Figura 5.11: Resultados de Simulação do Teste Lap Shear usando elementos de barra e sólido na representação do ponto de solda com diferentes tamanhos de malha- espessura de 1,2 mm

Força máxima detectada:

Representação com elemento de viga - malha de 5,0 mm: 5,893 KN Representação com elemento sólido - malha de 5,0 mm: 7,487 KN

Representação com elemento de viga - malha de 2,5 mm: 6,068 KN Representação com elemento sólido - malha de 2,5 mm: 7,388 KN 


\section{5 - RESULTADOS DO TESTE DE FORÇA NORMAL APLICADA DIRETAMENTE NO PONTO DE SOLDA}

- Teste 3: espessura das chapas de $0,8 \mathrm{~mm}$, velocidade de ensaio $5 \mathrm{~mm} / \mathrm{min}$

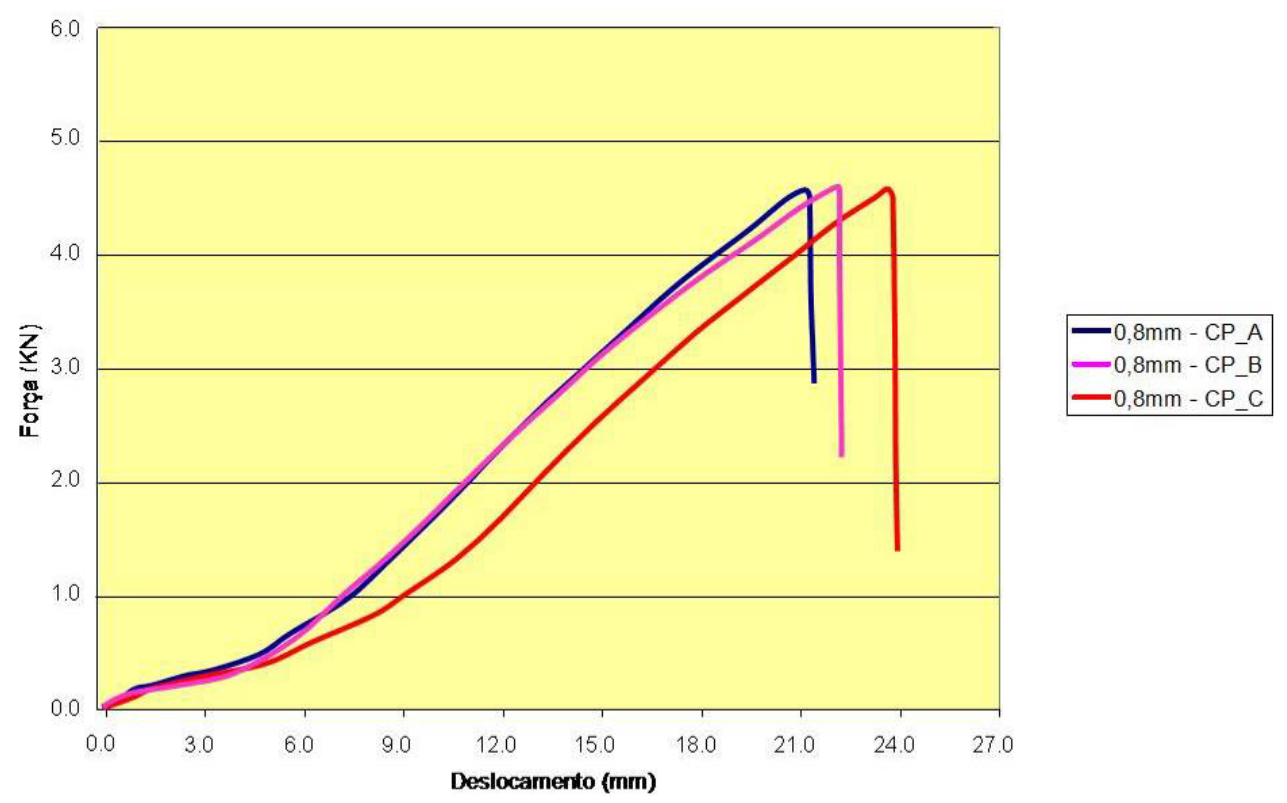

Figura 5.12: Resultados dos Testes de Força Normal Aplicada diretamente no ponto de solda (3 amostras) com espessura $0,8 \mathrm{~mm}$

Força máxima detectada:

Corpo de Prova "A": 4,423 KN

Corpo de Prova "B": 4,507 KN

Corpo de Prova "C": 4,490 KN

Média do teste 3: $\mathbf{4 , 4 7 3 ~ K N}$
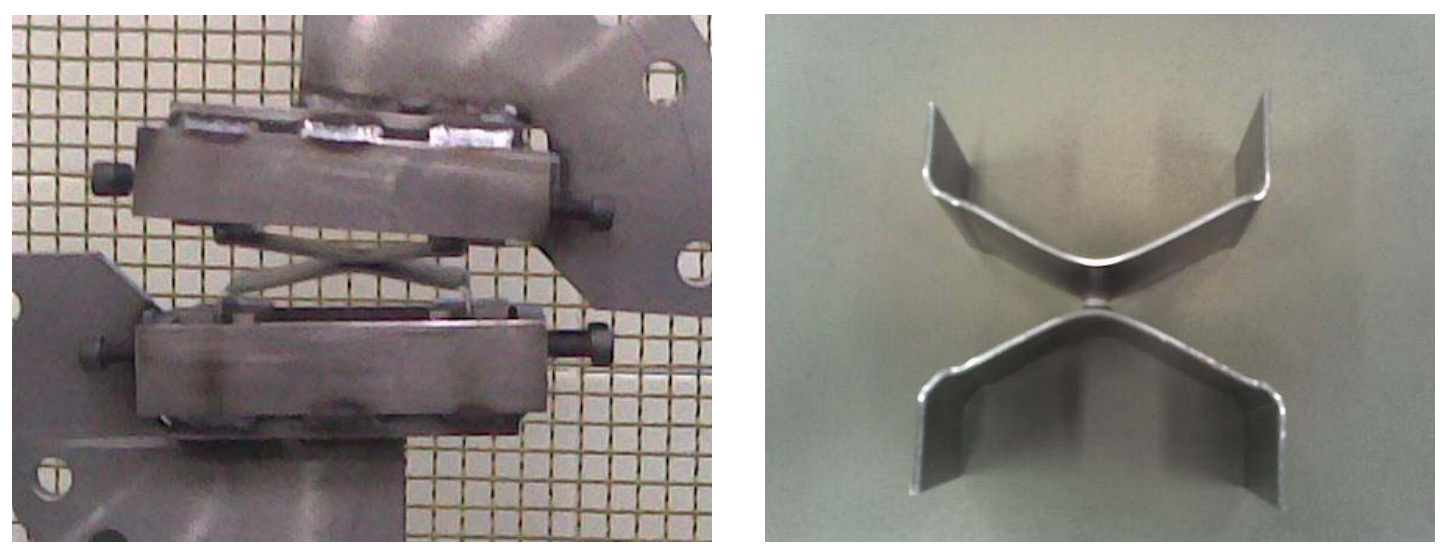

Figura 5.13: Imagens do Teste de Força Normal Aplicada diretamente no ponto de solda - Corpo de prova com espessura de $0,8 \mathrm{~mm}$ 
- Teste 4: espessura das chapas de 1,2 mm, velocidade de ensaio $5 \mathrm{~mm} / \mathrm{min}$

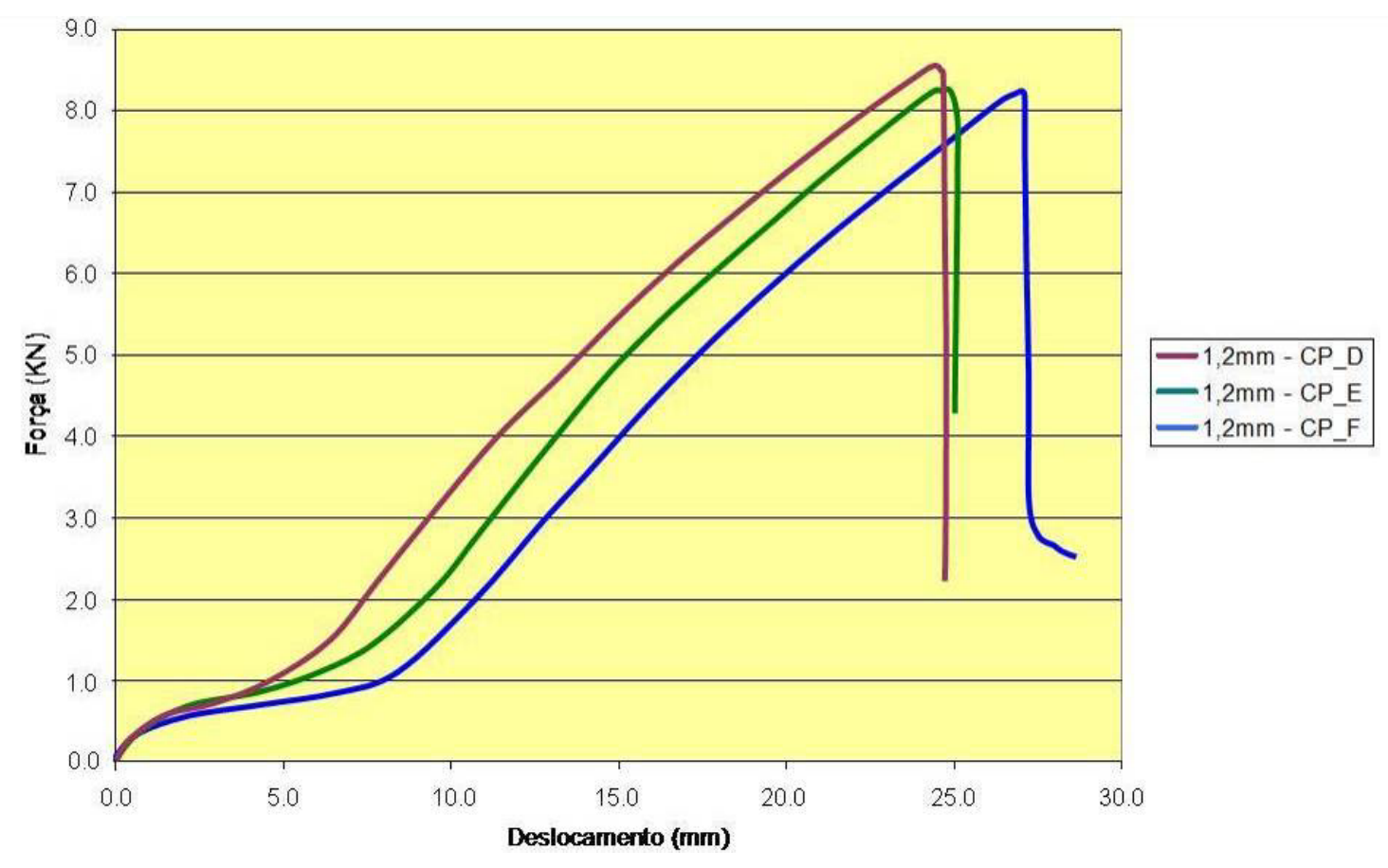

Figura 5.14: Resultados dos Testes de Força Normal Aplicada diretamente no ponto de solda (3 amostras) com espessura 1,2 mm

Força máxima detectada:

Corpo de Prova "D": 8,722 KN

Corpo de Prova "E": 8,335 KN

Corpo de Prova "F": 8,396 KN

Média do teste 4: $\mathbf{8 , 4 8 4} \mathrm{KN}$ 
- Simulação com chapas de $0,8 \mathrm{~mm}$, solda por elemento de viga e sólido

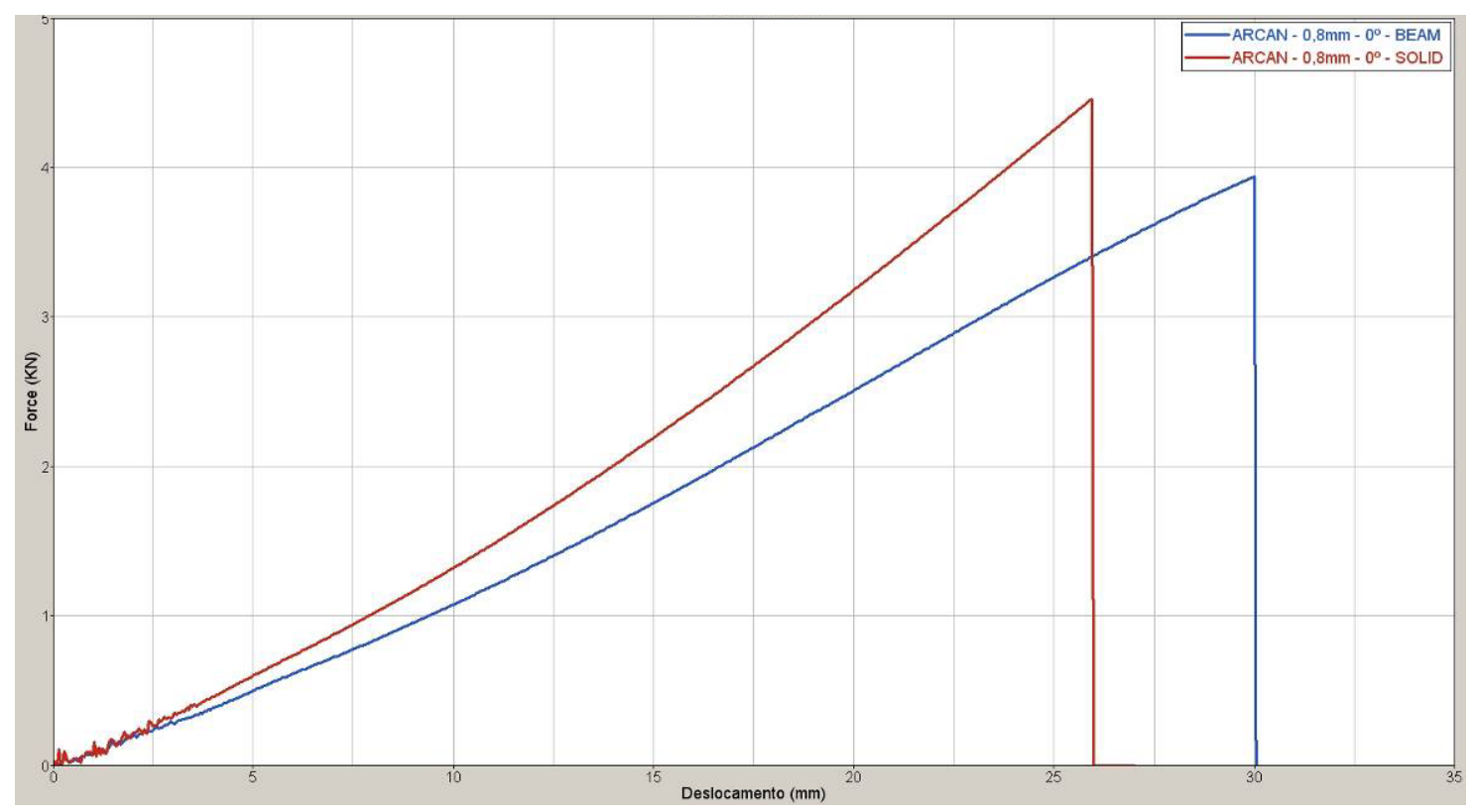

Figura 5.15: Resultados de Simulação dos Testes de Força Normal Aplicada diretamente no ponto de solda com espessura $0,8 \mathrm{~mm}$

Força máxima detectada para simulação do corpo de prova com $0,8 \mathrm{~mm}$ :

Representação com elemento de viga: 3,932 KN

Representação com elemento sólido: $4,465 \mathrm{KN}$
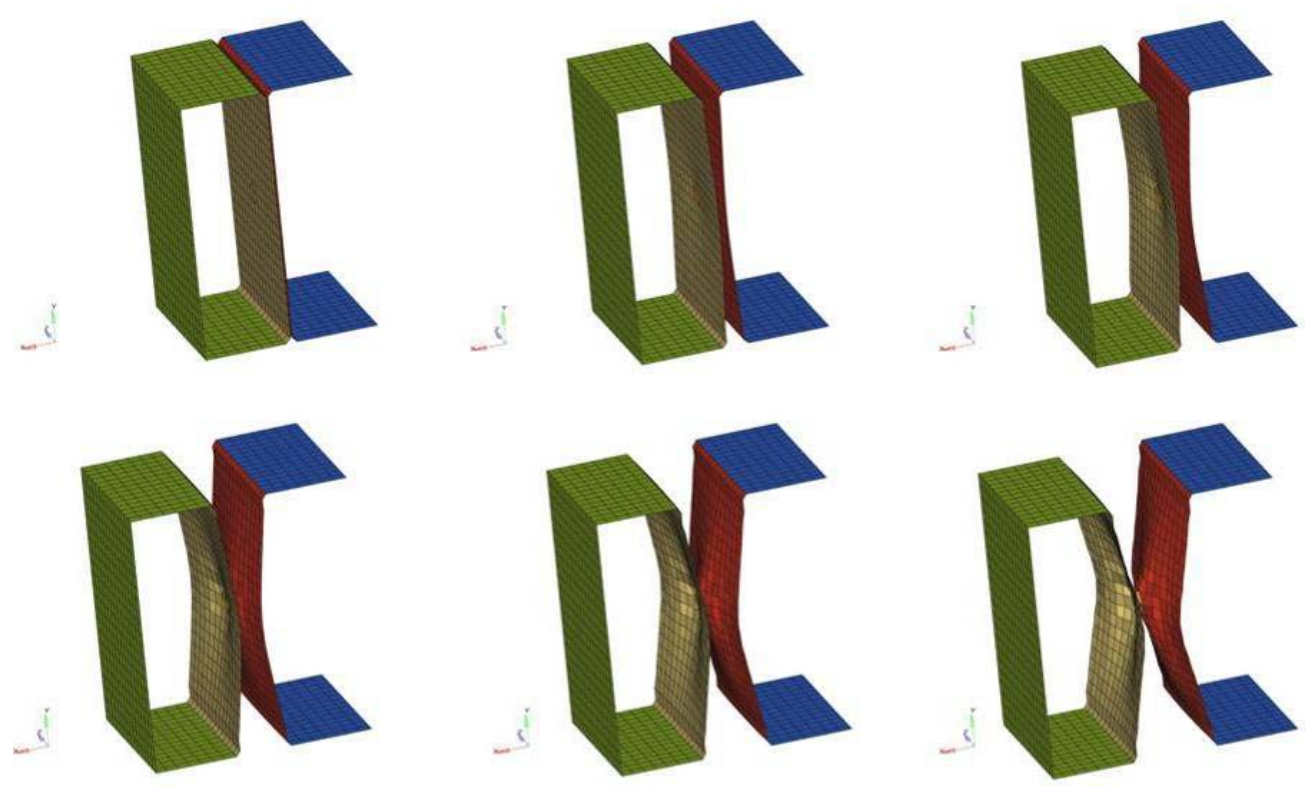

Figura 5.16: Evolução da deformação do corpo de prova com espessura de 0,8mm - elemento sólido 
- Simulação com chapas de 1,2 mm, solda por elemento de viga e sólido

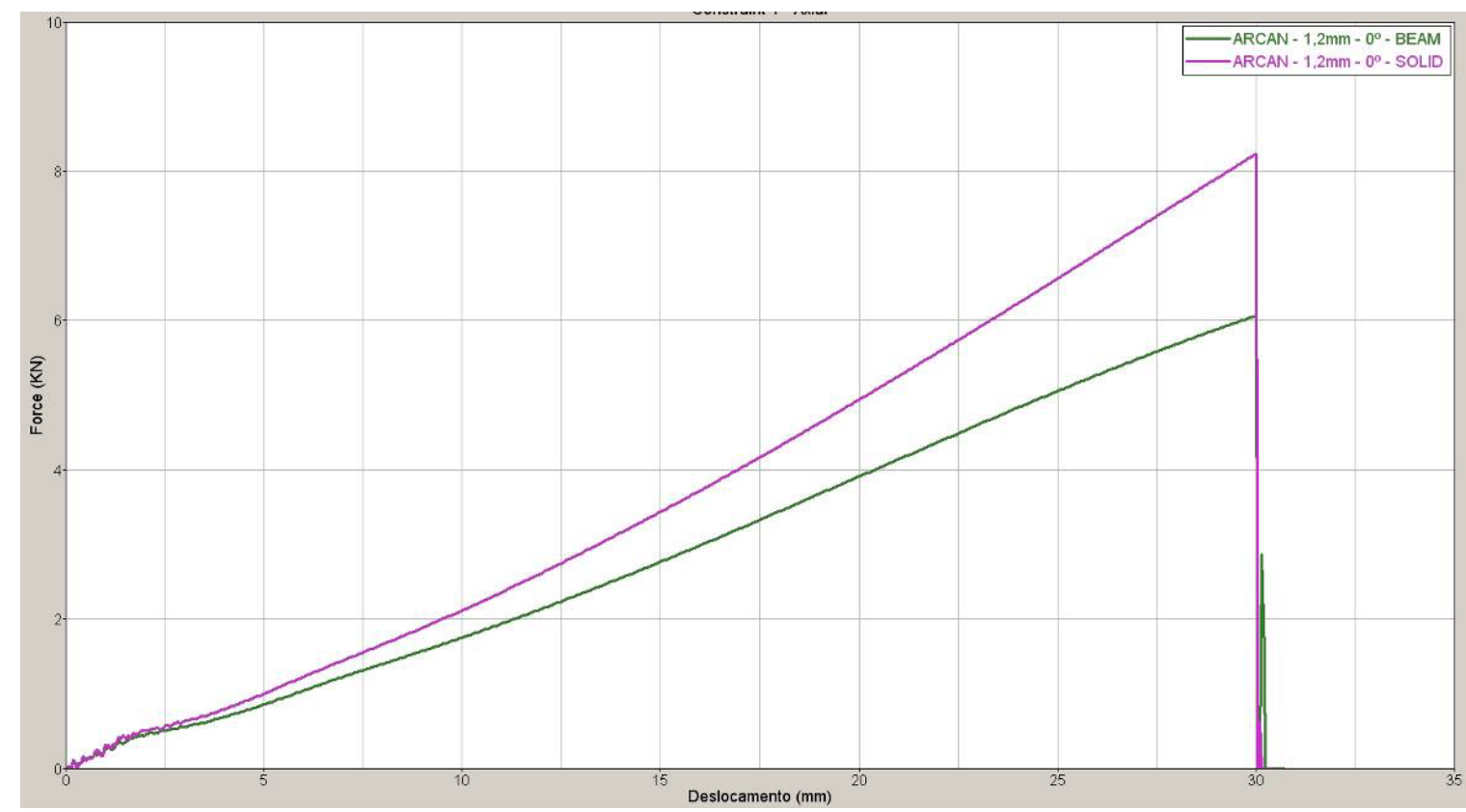

Figura 5.17: Resultados de Simulação dos Testes de Tração (Normal) Aplicada diretamente no ponto de solda com espessura $1,2 \mathrm{~mm}$

Força máxima detectada para simulação do corpo de prova com 1,2 mm:

Representação com elemento de viga: $6,009 \mathrm{KN}$ Representação com elemento sólido: $\mathbf{8 , 1 3 2 ~ K N}$ 


\section{CAPÍTULO 6 \\ AVALIAÇÃO DA FALHA DE PONTOS DE SOLDA}

\section{1 - INTRODUÇÃO}

Mesmo sendo o objetivo principal deste trabalho o estudo da correlação do comportamento do ponto de solda e a sua melhor representação na modelagem em elementos finitos, o entendimento do mecanismo de falha de uma junta soldada a ponto e os fatores que são relevantes para que a falha ocorra são meios importantes que permitirão a representação do fenômeno real.

Muitos estudos foram e continuam sendo feitos para determinar as propriedades mecânicas dos pontos de solda quando submetidos a carregamentos quasi-static, de impacto e fadiga, e são bastante importantes para o projeto e a manufatura de um veículo, como mostrados em Zhang (1998), Wung (2001) e Chao (2003).

A resistência do ponto de solda tipicamente diz respeito à máxima força que um ponto de solda pode resistir sem apresentar fratura (LIN et al, 2002). Em um componente soldado a ponto, onde as cargas a que este componente está sujeito não estão distribuídas igualmente entre cada ponto de solda, as propriedades que caracterizam o desempenho do componente durante a deformação e a posterior fratura são consideravelmente mais difíceis de capturar, especialmente na falta de um critério de falha para cada ponto de solda.

A fratura da solda é amplamente dependente da relação entre a geometria da solda, a geometria do teste e o estado de tensões de cada solda, condições exploradas por VandenBossche (1977), o qual concluiu que existe uma dependência do modo de falha do ponto de solda com a espessura das chapas soldadas, a tensão de escoamento do material base, o diâmetro do ponto e a resistência do material da solda. E de acordo com a combinação destes fatores, surgem diferentes modos de falha dos pontos de solda, como estudados por Chao (2003), Birch e Alves (2000), e Marya; Wang; Hector e Gayden (2006).

O efeito das diferentes propriedades do material na ZTA em relação ao restante do material não afetado pelo calor proveniente do processo de soldagem é investigado por Zuniga e Sheppard (1995). Esse efeito não foi considerado em 
estudos como os conduzidos por VandenBossche (1977) e Lin et al (2002), o que provavelmente não levará a resultados absolutamente precisos.

Mas mesmo chegando a um resultado aproximado, não se pode considerá-lo um resultado errôneo, sobretudo quando os resultados obtidos forem utilizados em aplicações industriais, onde o processo de soldagem é bem conhecido e controlado, e uma modelagem robusta baseada nos dados experimentais será suficiente para alcançar a correlação dos modelos, principal objetivo da área de cálculo estrutural.

\section{2 - TIPOS DE FRATURA DE JUNTAS SOLDADAS A PONTO}

Para o entendimento dos tipos de fratura de juntas soldadas, estas devem ser submetidas a diversas cargas em ensaios que possam reproduzir pelo menos uma parte da condição real de trabalho e também permitam o levantamento de informações que ajudem na compreensão do comportamento do ponto de solda.

Um dos primeiros modelos propostos para o entendimento do comportamento do ponto de solda foi desenvolvido por VandenBossche (1977), que estudou a relação entre o diâmetro do ponto e a falha por cisalhamento na ZTA ao redor desse ponto. Neste estudo, a carga que provoca o cisalhamento do ponto inclui a maioria das características de uma junta soldada a ponto, e permanece suficientemente simples para validar a análise de tensões ao redor do ponto, mas com a suposição de que nenhum momento fletor fosse transmitido. O modelo pode ser aplicado para aços de baixo carbono e de alta resistência.

Sendo a carga que provoca cisalhamento no ponto de solda um importante

meio do entendimento do comportamento da junta, Zhou; Hu e Zhang (1999) estudaram as influências das dimensões do corpo de prova como largura, comprimento, diâmetro do ponto, espessura e sobreposição (overlapping) das chapas soldadas. O estudo conclui que a largura é o parâmetro mais influente na medição da força resistiva do ponto de solda, e influencia também na deformação e no modo de falha obtido após o teste. E baseado nos estudos experimentais e numéricos conduzidos neste trabalho, os tamanhos críticos dos corpos de prova podem ser determinados de acordo com a condição a ser estudada. 
As figuras a seguir ilustram os cinco modos de falha identificados por Zhou; Hu e Zhang (1999):
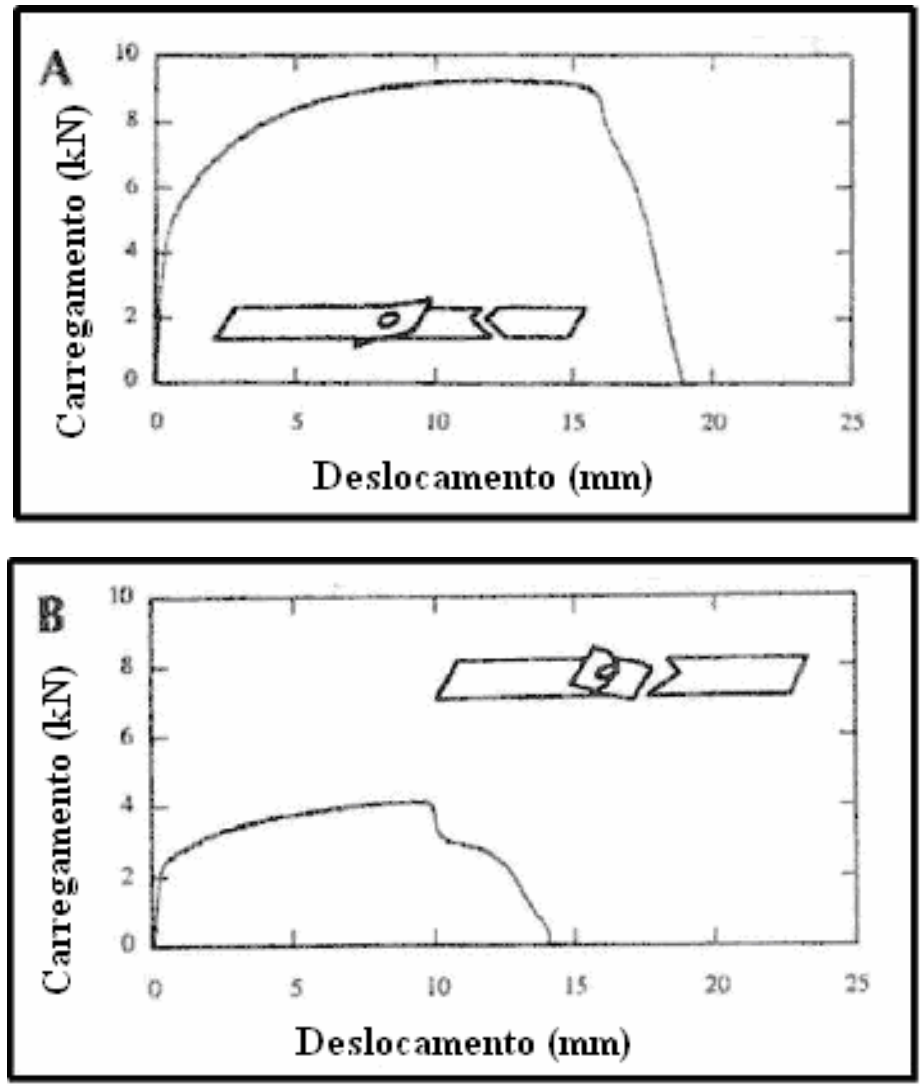

Figura 6.1: Curva Força x Deslocamento - Modos de falha A e B (Zhou; Hu; Zhang, 1999)

Nos dois modos de falha ilustrados na figura 6.1, ocorre a falha do metal base, portanto o ponto de solda permanece intacto. Nos ensaios dos corpos de prova, esse tipo de falha ocorre usualmente quando a largura do corpo de prova é inadequada, estreita. E com esse tipo de falha, não há possibilidade de avaliação da resistência do ponto de solda.

$\mathrm{Na}$ figura 6.2, estão representadas falhas dos pontos de solda, mas com características diferentes. No modo de falha $C$ está representado o destacamento do ponto de solda ao redor da ZTA. No modo de falha D ocorreu o rasgamento da chapa na ZTA ao redor do ponto de solda. E por fim, o modo de falha $E$ indica o colapso do ponto na interface da solda. Nestes três tipos de falha é possível a 
avaliação das características do ponto, o que vai permitir a aplicação do estudo no projeto da carroceria do veículo.
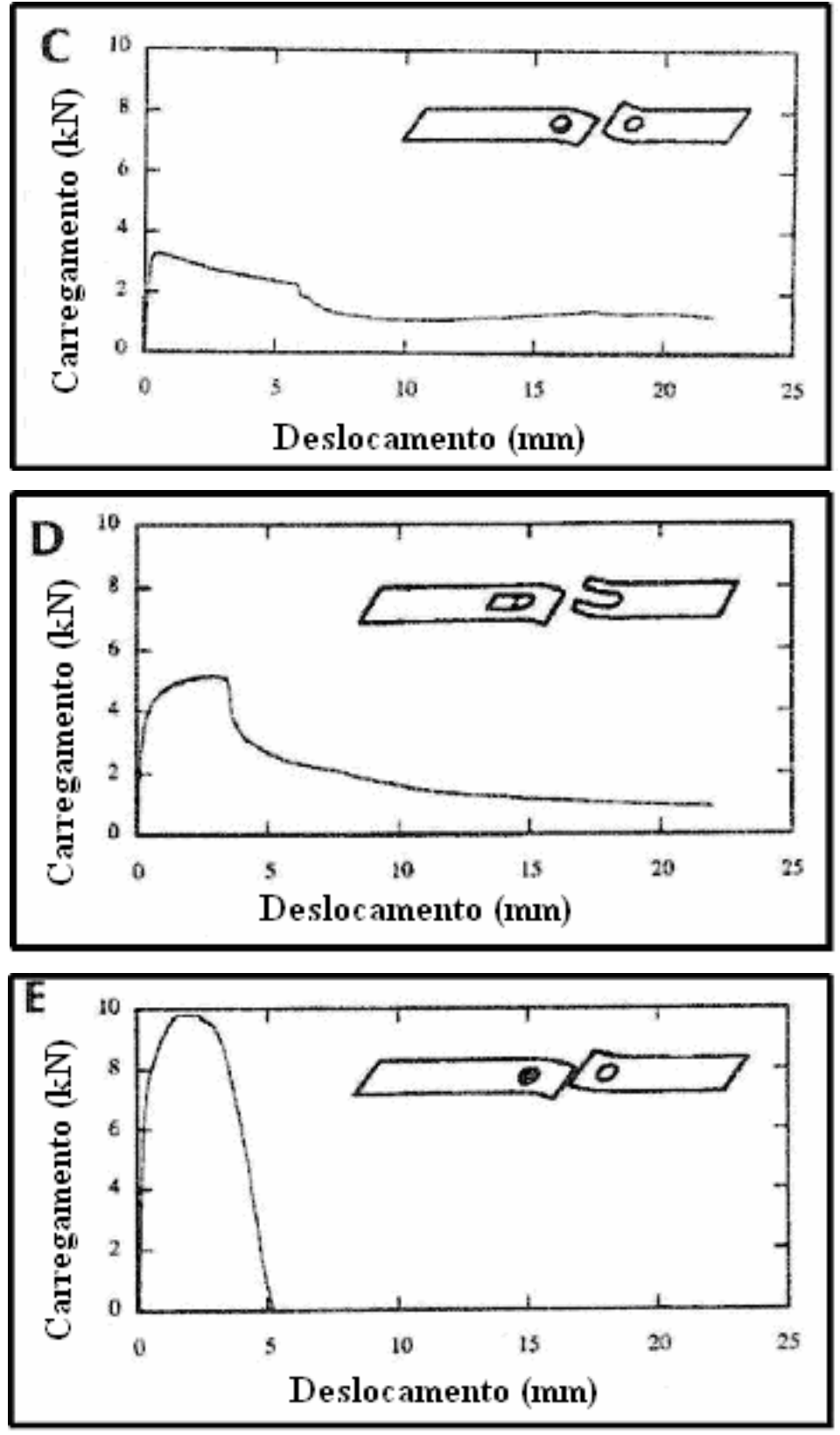

Figura 6.2: Curva Força x Deslocamento - Modos de falha C, D e E (Zhou; Hu; Zhang, 1999)

Assim como em SSAB TUNNPLÅT AB (1996), Koenigsberger (1948) apud Zhou; Hu e Zhang (1999) propõe uma relação entre o diâmetro do ponto e a espessura da chapa, que pode ser expressa por:

$$
d=a \sqrt{t}
$$


em que $\boldsymbol{d}$ é o diâmetro do ponto de solda, $\boldsymbol{t}$ é a espessura da chapa mais fina e a é uma constante empírica que varia entre 3 e 6 . Valores práticos para diferentes tipos de aço podem ser adotados. No caso de um aço de baixo carbono, a constante a pode variar entre 4 e 5 , mas no caso de solda em aços de alta resistência, a vale pelo menos 6 (SSAB TUNNPLÅT AB, 1996).

Lin et al (2002) utilizaram o corpo de prova tipo "Square-cup" (figura 6.3) para obter falhas em pontos de solda mediante um carregamento combinando cisalhamento e tração. Baseado em análises metalográficas dos corpos de prova falhados, concluiu-se que quando estes são submetidos à tração, ocorre a falha por arrancamento do ponto de solda. Sob o efeito de cargas combinadas, os corpos de prova apresentam estricção ao redor da ZTA com a rotação do ponto de solda e o posterior destacamento da junta soldada. Além dos dados experimentais presentes neste estudo, um modelo matemático foi proposto como critério de falha da junta soldada, determinando a máxima capacidade de carga suportada pelo ponto de solda, adotando um comportamento perfeitamente plástico do material base e o ponto de solda representado por um cilindro.

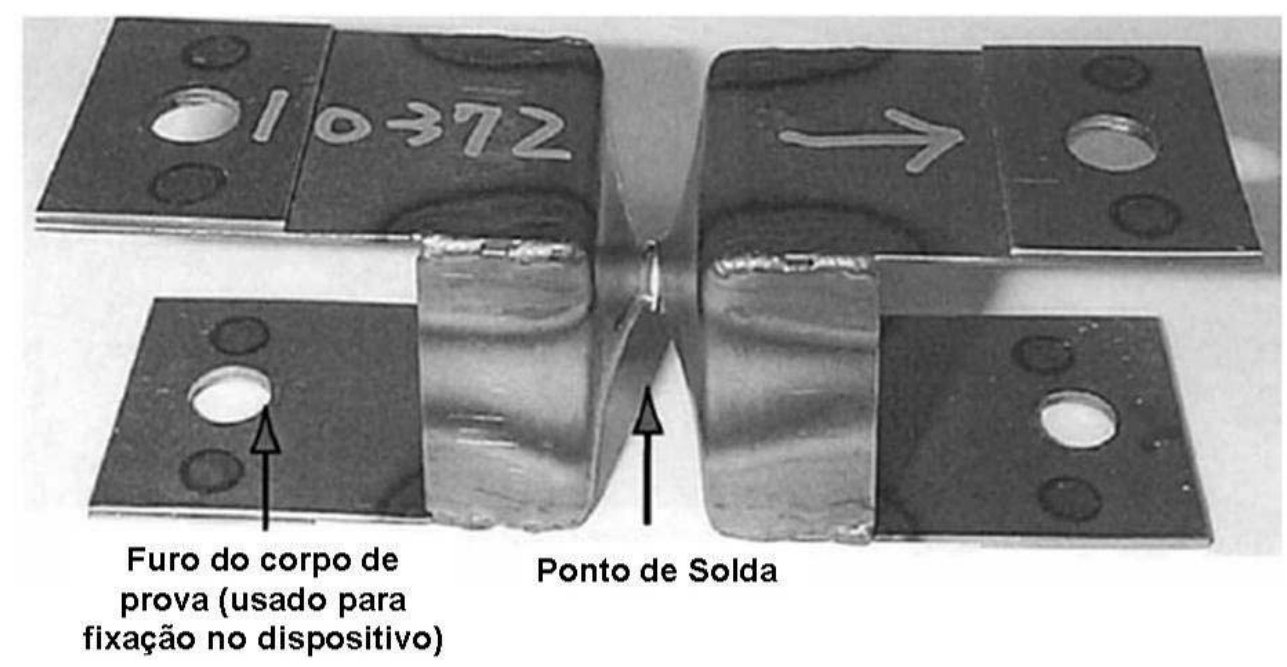

Figura 6.3: Corpo de Prova tipo "Square-cup" (Lin et al. 2002) 
Em uma investigação usando aços bifásicos (Dual Phase Steels ${ }^{12}$ ), Marya; Wang; Hector e Gayden (2006) utilizaram testes de tração e cisalhamento separadamente para desenvolver um critério de fratura de pontos de solda sob baixas taxas de deformação. Três relações foram propostas para descrever o comportamento do ponto de solda nos testes de tração e cisalhamento: a primeira relaciona a força necessária para a fratura da junta soldada com o diâmetro do ponto. A segunda e a terceira equações relacionam respectivamente o diâmetro crítico do ponto de solda e a força crítica de tração e cisalhamento para fratura na interface do ponto com a espessura das chapas e a dureza na ZTA. Uma diferença deste trabalho para com os demais que estudam a fratura de juntas soldadas corresponde à realização de testes com corpos de prova apresentando múltiplos pontos de solda.

Assim como verificado por Zhou; Hu e Zhang (1999) e Chao (2003), Marya; Wang; Hector e Gayden (2006) também identificam os tipos de falha em juntas soldadas, que são as falhas na interface do ponto (figura 6.4), resultado da fratura através da solda, e as falhas que apresentam o destacamento do ponto (figura $6.5 \mathrm{a}$ e 6.5b). Este último é considerado o tipo de falha preferido, uma vez que a energia absorvida pelo ponto de solda é maior que no caso da falha na interface do ponto.
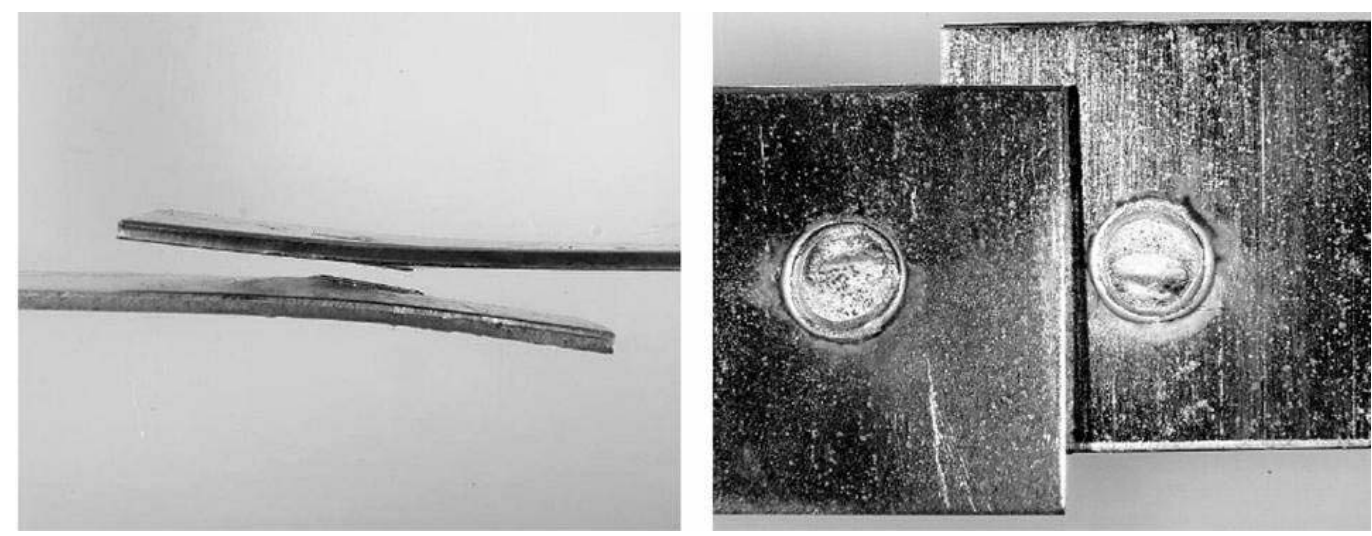

Figura 6.4: Fratura na interface do ponto de solda - vista lateral e superior (Marya; Wang; Hector e Gayden, 2006)

${ }^{12}$ Aços bifásicos (Dual Phase) - Tipo de aço caracterizado pela alta resistência e ao mesmo tempo alta deformabilidade. Em sua microestrutura esses aços apresentam "duas fases" $\underline{\alpha-f e r r i t a, ~}$ relativamente "mole" cúbica de corpo centrado, e martensita, relativamente "dura" tetragonal de corpo centrado, e são provenientes de um tratamento térmico especial. 

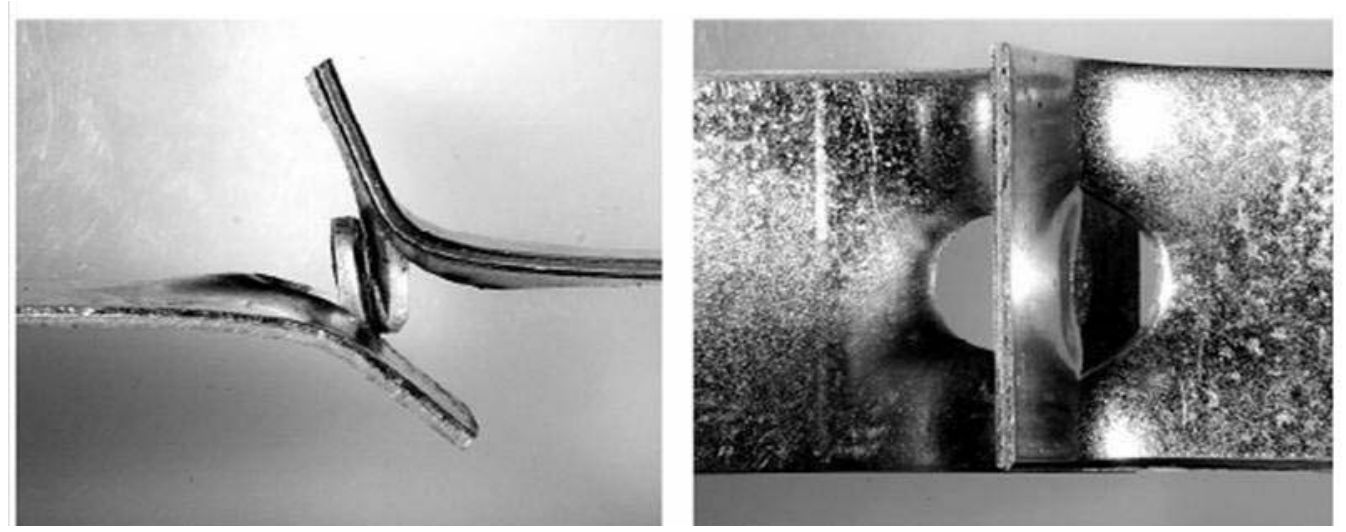

Figura 6.5a: Fratura por destacamento do ponto de solda - vista lateral e superior (Marya; Wang; Hector e Gayden, 2006)
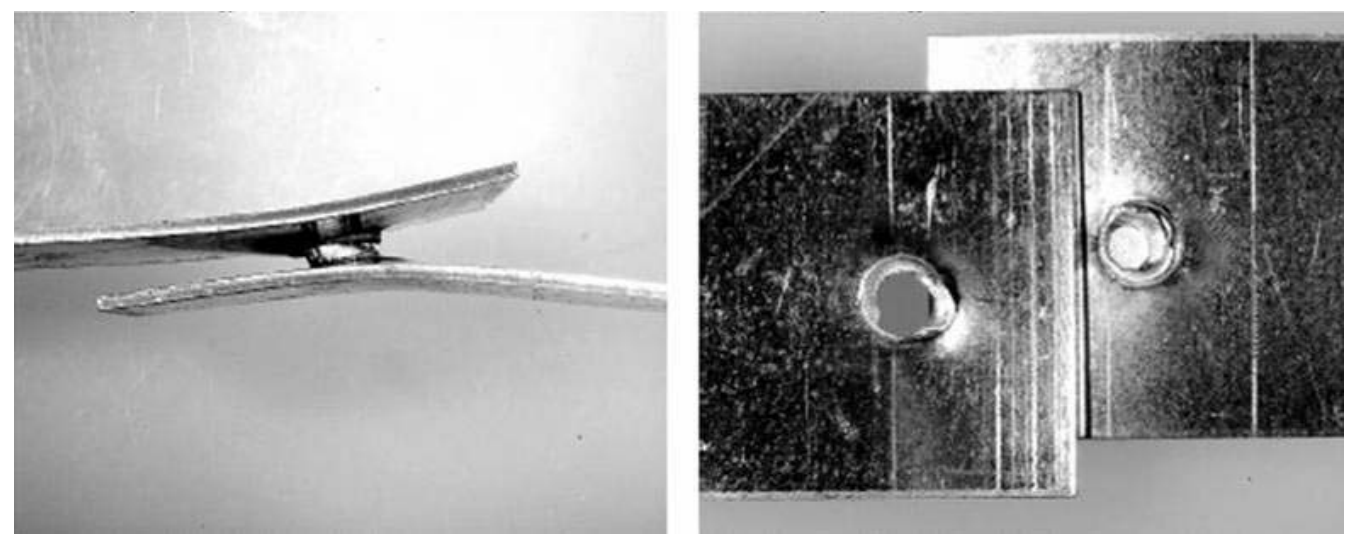

Figura 6.5b: Fratura por destacamento do ponto de solda - vista lateral e superior (Marya; Wang; Hector e Gayden, 2006)

Embora ambas as figuras $6.5 \mathrm{a}$ e $6.5 \mathrm{~b}$ ilustrem a fratura por destacamento do ponto de solda, ainda é possível identificar uma diferença entre elas: na figura 6.5a, a fratura pelo destacamento do ponto de solda envolve também a fratura do metal base em vez da fratura através do ponto de solda. Já na figura $6.5 \mathrm{~b}$, pode-se observar que a fratura ocorre ao redor do ponto de solda, dentro da ZTA, onde um furo é deixado em uma das chapas.

Birch e Alves (2000) também estudaram o comportamento dos pontos de solda, mas investigando os modos de fratura da junta sob efeito de cargas dinâmicas de impacto. E a investigação conduzida por eles concluiu que o efeito da taxa de deformação do material base tem fundamental importância na determinação das 
cargas atuantes e na determinação da energia absorvida relacionada ao modo de falha, além de terem encontrado os mesmo modos de falha descritos anteriormente (apenas a nomenclatura utilizada é diferente).

Outra conclusão deste trabalho é que a resistência do ponto submetido ao impacto aumenta quanto maior for o diâmetro do ponto, e com a influência da taxa de deformação proveniente deste carregamento, o limite de resistência à falha da junta soldada é aumentado quando comparado com a deformação originada do carregamento quasi-static.

Com os estudos concentrados no comportamento do ponto de solda sob um carregamento excessivo e de característica quasi-static, e assim como Lin et al (2002), Chao (2003) utilizou as cargas de tração e cisalhamento separadas e combinadas para descrever o comportamento da junta soldada. Para combinar as cargas, Lee et al (1998) apud Chao (2003) projetou um corpo de prova de tal forma que permite que a carga seja aplicada sob cisalhamento, força normal aplicada diretamente no ponto de solda e o cisalhamento com a força normal combinadas, trocando o ângulo do carregamento no dispositivo ao qual o corpo de prova está fixado.

E conforme descrito nos capítulos 4 e 5, este modelo de corpo de prova (figura 6.6) foi escolhido para realizar as avaliações em que o carregamento é o de força normal por duas razões: a primeira é a simplicidade de construção do corpo de prova (o que pode ser verificado quando comparado ao corpo de prova ilustrado na figura 6.3), formado por duas chapas dobradas e unidas por um ponto de solda no centro da superfície que não fica em contato com o dispositivo de fixação; e a segunda razão é o próprio dispositivo, que já estava disponível no laboratório da área de Qualidade de Peças de Fornecedor da GMB, facilitando o uso do corpo de prova escolhido.

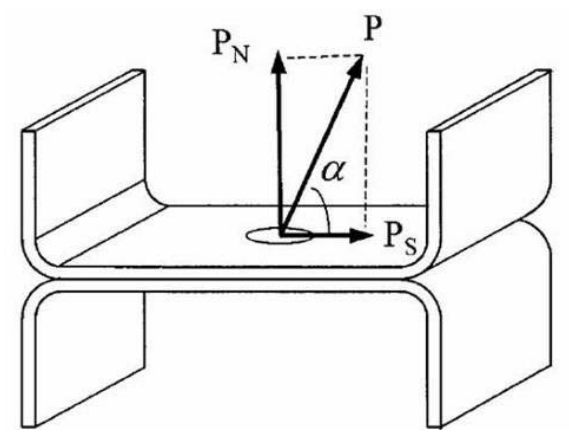

Figura 6.6: Corpo de Prova para ensaio misto de carga normal $\left(P_{N}\right)$ e cisalhamento $\left(P_{S}\right)($ Chao, 2003) 
Chao (2003) ainda descreve esquematicamente os mecanismos de falha nos corpos de prova testados sob as cargas de cisalhamento (figura 6.7 e 6.8) e normal (figura 6.9), além de identificar curvas-padrão do comportamento de juntas soldadas a ponto nos dois ensaios mencionados acima (figura 6.10).

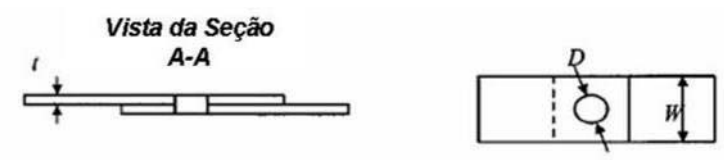

(a)

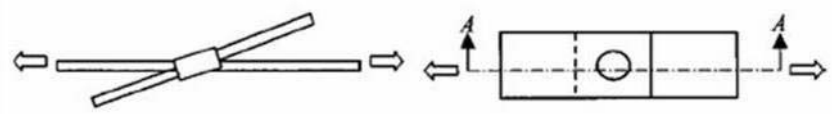

(b)

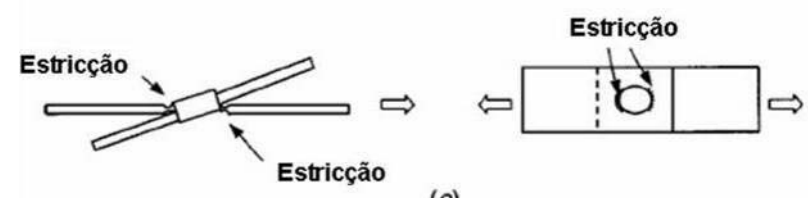

(c)
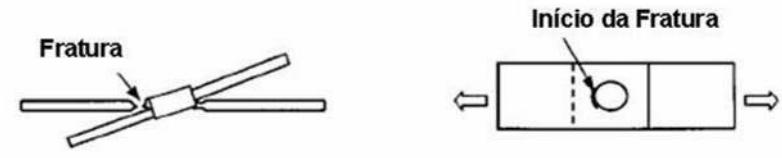

$(d)$

Figura 6.7: Modo geral de deformação de uma junta soldada a ponto submetida ao ensaio Lap Shear - (a) configuração inicial, (b) rotação do ponto, alinhando-o com a linha de carga, (c) estiramento, afinamento e estricção, e (d) fratura devido a estricção (Chao, 2003)

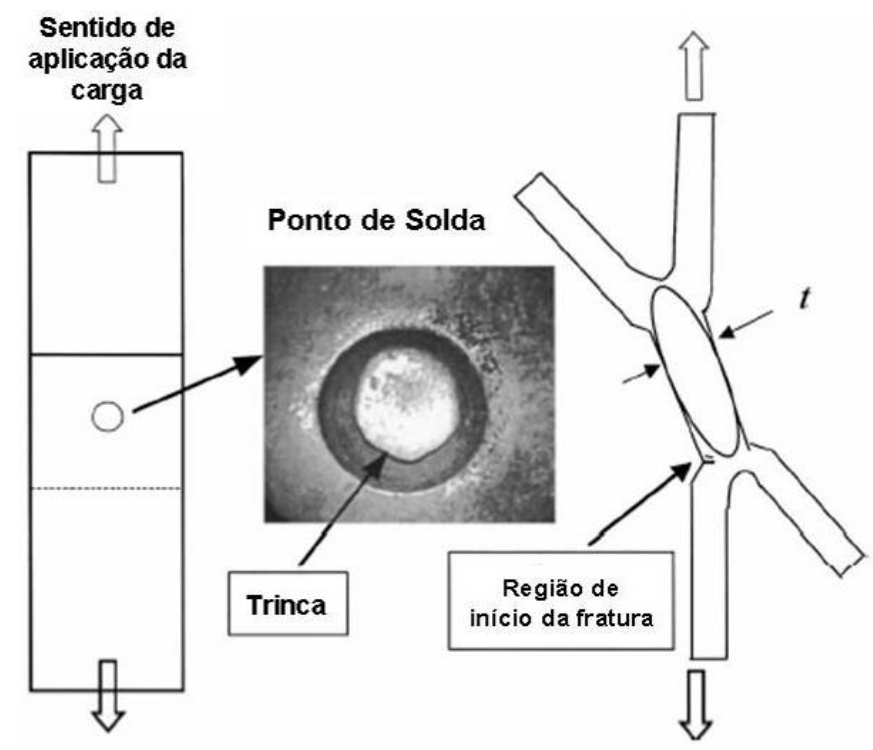

Figura 6.8: Início da fratura no corpo de prova no ensaio Lap Shear (Chao, 2003) 
(a)
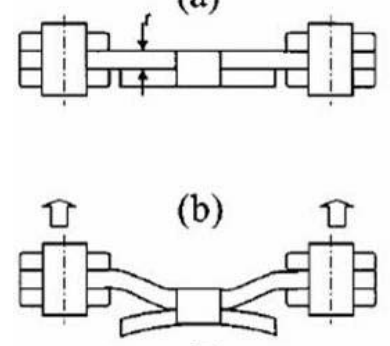

[3

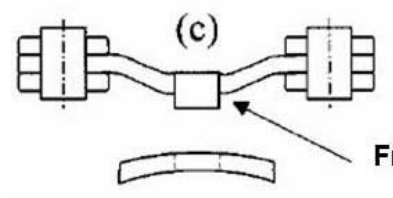

Fratura por cisalhamento ao redor do ponto de solda

Vista superior do corpo de prova Cross Tension (Força Normal Pura)

Figura 6.9: Modo geral de deformação de uma junta soldada a ponto submetida ao ensaio Cross Tension - (a) configuração inicial, (b) deformação do corpo de prova, (c) fratura por destacamento do ponto (Chao, 2003)

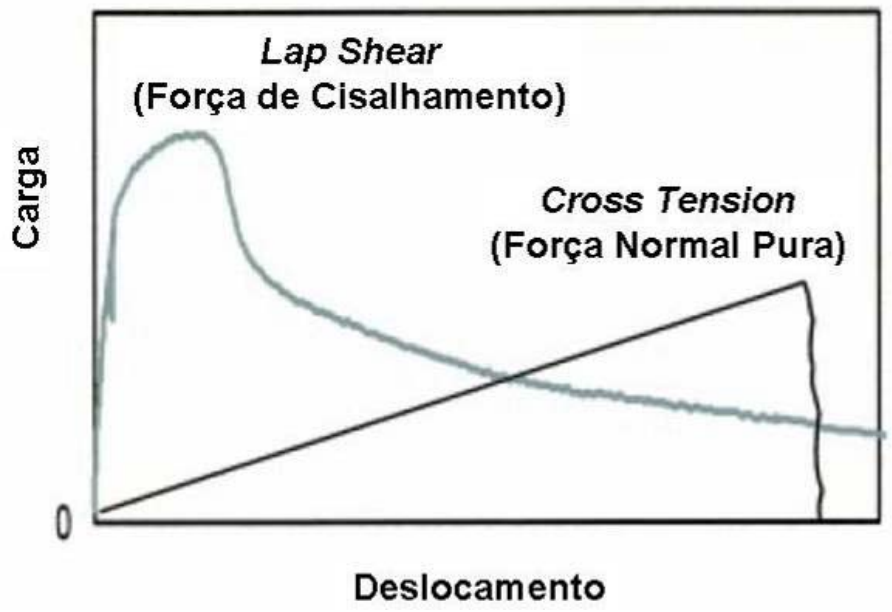

Figura 6.10: Esquema geral das curvas Carga vs. Deslocamento para os ensaios Lap Shear e Cross Tension (Chao, 2003)

\section{3 - CRITÉRIOS DE FALHA DE UMA JUNTA SOLDADA}

As falhas em pontos de solda, sejam pela fadiga, pelo efeito de cargas estáticas ou por impacto, são consideradas sob dois aspectos: a força que leva à falha e a resistência à falha. A força que leva à falha é determinada principalmente pelas forças externas e pela geometria estrutural enquanto que a resistência à falha é determinada principalmente pela composição interna e a microestrutura do 
material (ZHANG, 2001). E para determinar um critério de falha, soluções baseadas em tensões locais próximas à região soldada e baseadas nas forças e momentos na interface da solda (solução esta que também permite a determinação das tensões locais na área da solda), foram desenvolvidas para permitir a criação de modelos analíticos que representem o comportamento do ponto de solda.

Em um estudo onde são apresentadas fórmulas derivadas que apresentam fatores de intensificação de tensões, tensões em entalhe e integrais-J para pontos de solda sob cargas de cisalhamento e normal em testes Lap Shear, Cross Tension e Coach Peel (figura 6.11), Zhang (1998) caracteriza estas fórmulas através das tendências de concentração das tensões com os parâmetros de projeto, tais como o diâmetro do ponto de solda, as espessuras das chapas e o espaçamento das cargas aplicadas. Segundo ele, com esses meios teóricos de previsão das tensões na área da solda, em alguns casos seria dispensável o estudo do problema pelo método dos elementos finitos. A grande limitação deste trabalho reside no fato de que estas fórmulas propostas servem apenas para pontos de solda entre chapas de mesma espessura e mesmo material. Apesar disso, fatores que refletiriam a desigualdade das espessuras das chapas e a heterogeneidade dos materiais poderiam corrigir as fórmulas uma vez que as tendências dos parâmetros do projeto da junta soldada poderiam ser determinadas.

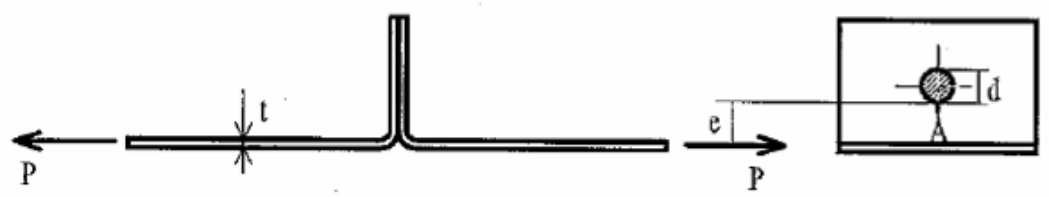

Figura 6.11: Corpo de Prova para ensaio do tipo Coach Peel (Zhang, 1998)

Combinando quatro diferentes modos de falha (cisalhamento, rotação, normal e descascamento - peeling), Wung (2001) propõe uma fórmula simples e empírica, baseada nas forças e momentos na interface da solda provenientes dos modos de falha combinados, determinados separadamente através dos testes correspondentes em vários corpos de prova (figura 6.12). O critério de falha proposto neste trabalho objetiva permitir um direcionamento no projeto de carrocerias visando melhoria em durabilidade. 


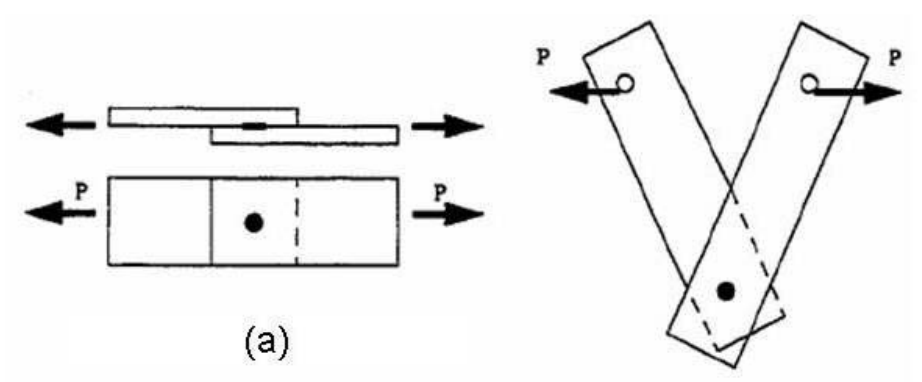

(b)

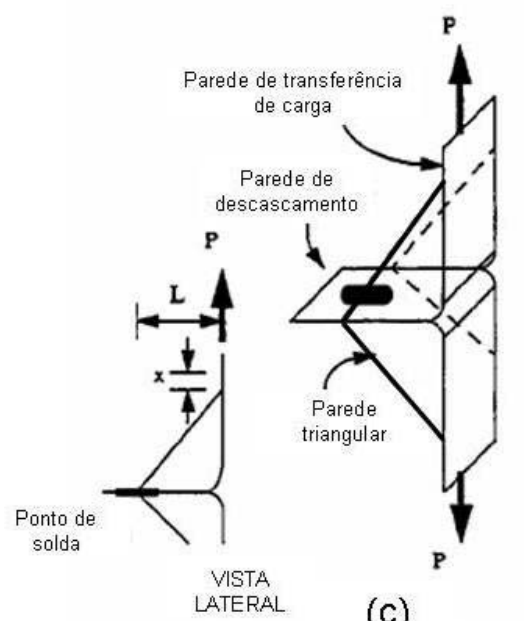

(c)

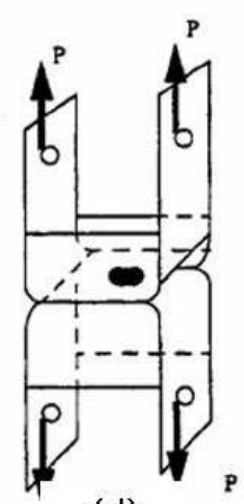

(d)

Figura 6.12: Corpos de Prova para falha por cisalhamento (a), rotação no plano (b), descascamento (c), e normal (d) (Wung, 2001)

Com o foco em determinar um critério de falha simples e que não limitasse uma aplicação industrial, Chao (2003) adotou uma distribuição de tensão simples baseada nos mecanismos de falhas identificados em testes Lap Shear e Cross Tension. Para os corpos de prova do teste Lap Shear, uma vez que a falha ocorre predominantemente pela atuação de uma carga de tração uniaxial e o ponto de solda é circular, uma distribuição harmônica da tensão normal ao redor do ponto de solda é adotada (figura 6.13), e pode ser descrita por:

$$
\sigma(\theta)=\sigma_{\max } \cos \theta
$$

O ângulo $\theta$ na figura varia de $-90^{\circ}$ a $90^{\circ}$ e $\sigma_{\max }$ é máxima tensão normal no ponto de solda que ocorre para $\theta=0^{\circ}$. Por simetria, pode ser feita a analogia para $\sigma_{\max }$ em $\theta=180^{\circ}$, com o ângulo $\theta$ variando de $90^{\circ}$ a $270^{\circ}$. 

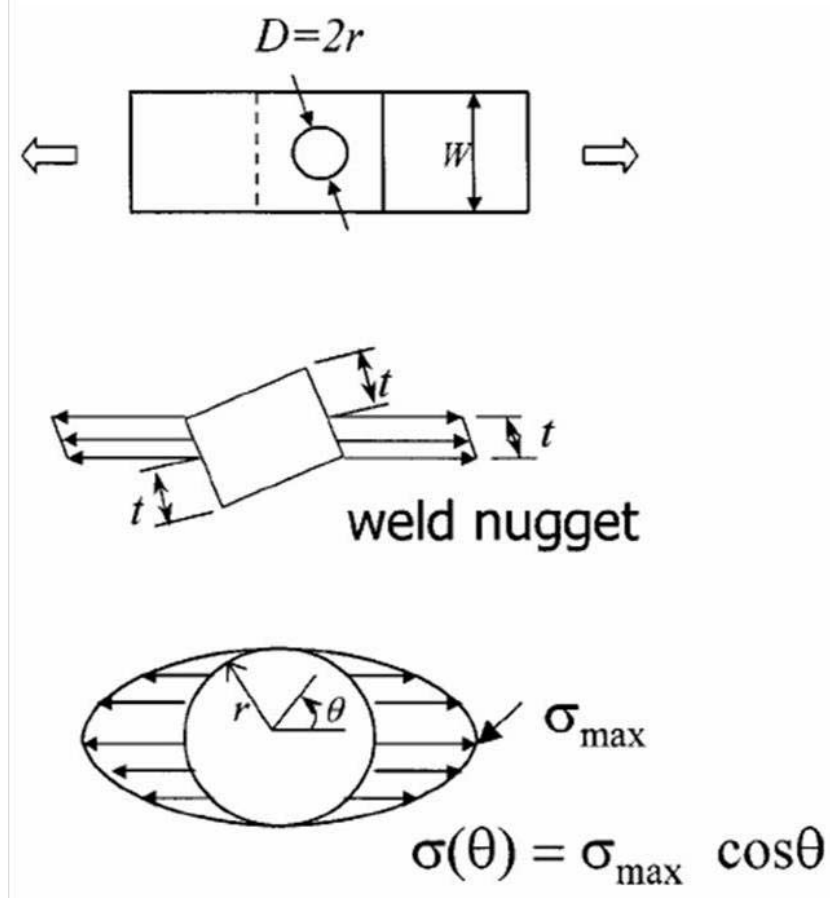

Figura 6.13: Distribuição de Tensões Normais ao redor do ponto de solda no teste Lap Shear (Chao, 2003)

Segundo Chao (2003), na condição de equilíbrio têm-se:

$$
P=\int_{-\pi / 2}^{\pi / 2} \sigma(\theta) \cdot \frac{d}{2} t \cdot \cos \theta \cdot d \theta=\frac{\pi}{4} t d \sigma_{\max }=0,785 t d \sigma_{\max }
$$

onde $P$ é a carga de tração aplicada no corpo de prova. Vale notar que esta equação relaciona a máxima tensão local na região do ponto de solda com a carga aplicada no teste. No início da fratura, a equação 6.3 se transforma em:

$$
P_{f}=0,785 t d \sigma_{f}
$$

onde $t$ é a espessura da chapa soldada ou metade da espessura do ponto de solda, $d$ é o diâmetro do ponto, $P_{f}$ é a força de falha e $\sigma_{f}$ é a tensão de falha do material sob tração.

No caso de corpos de prova sob força normal aplicada diretamente no ponto de solda, nos testes denominados Cross Tension, uma vez que a falha ocorre 
predominantemente pela atuação de uma carga de cisalhamento ao redor do ponto de solda circular, uma distribuição harmônica da tensão de cisalhamento ao redor do ponto de solda é adotada (figura 6.14), e pode ser descrita por:

$$
\tau(\theta)=\tau_{\max } \cos 2 \theta
$$

onde $\tau_{\max }$ é a máxima tensão de cisalhamento que ocorre em $\theta=0^{\circ}, 180^{\circ}$ e $\theta=90^{\circ}$, $270^{\circ}$ na outra chapa do corpo de prova.

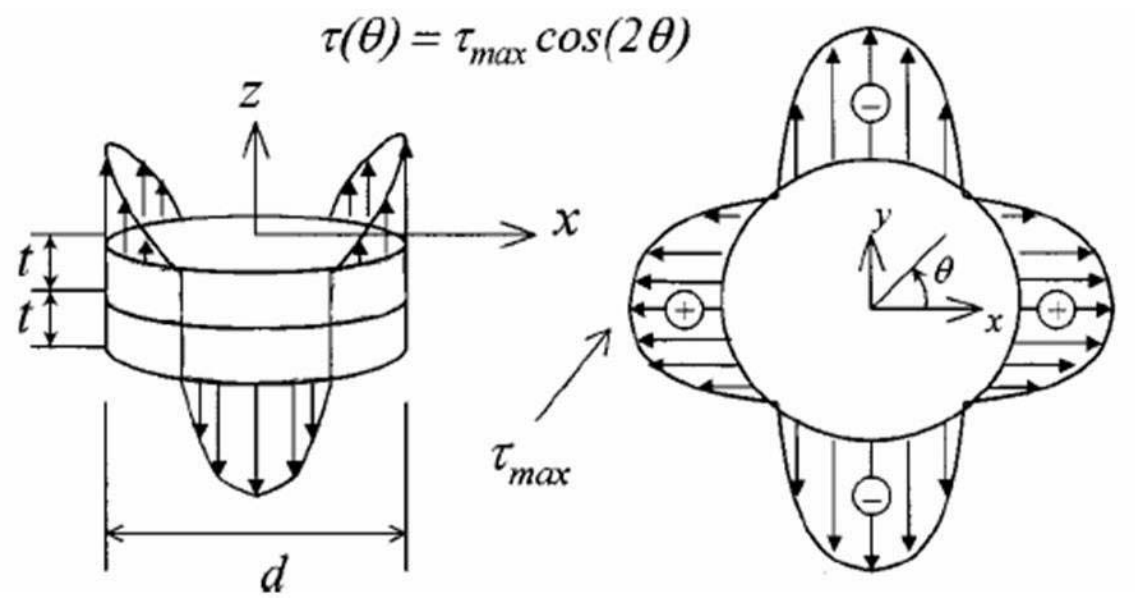

Figura 6.14: Distribuição de Tensões de Cisalhamento ao redor do ponto de solda no teste Cross Tension (Chao, 2003)

Na condição de equilíbrio, Chao (2003) propõe:

$$
P=2 \int_{-\pi / 4}^{\pi / 4} \tau(\theta) . r t d \theta=t d \tau_{\max }
$$

onde $P$ é a carga de tração aplicada no corpo de prova. No início da fratura, a equação 6.6 se transforma em:

$$
P_{f}=t d \tau_{f}
$$

onde $\tau_{f}$ é a tensão de falha do material sob ação de cisalhamento. 
Avaliando as forças de falha descritas nas equações 6.4 e 6.7 , pode-se notar que esta é proporcional à espessura da chapa e ao diâmetro do ponto de solda. Além disso, tensões de ruptura do material base também estão presentes nas mesmas equações. E ainda a partir critérios clássicos de ruptura, Chao (2003) relaciona estas duas equações sabendo que para materiais dúcteis, o critério de ruptura de Von Mises enuncia que $\tau_{f}=0,577 . \sigma_{f}$ e com o critério de ruptura de Tresca enuncia que $\tau_{f}=0,5 . \sigma_{f}$.

Dessa forma, as equações 6.4 e 6.7 passam a ser:

para Von Mises:

$$
\begin{aligned}
& P_{f}^{\text {CrossTension }}=0,735 P_{f}^{\text {LapShear }} \\
& P_{f}^{\text {CrossTension }}=0,64 P_{f}^{\text {LapShear }}
\end{aligned}
$$

As equações 6.8 e 6.9 relacionam a carga de falha dos pontos de solda nos testes de Cross tension e Lap Shear.

Outro critério de falha estudado e que está referenciado em trabalhos como os de Chao (2003), Lin et al (2002), Ruiz (2005), Nakano (2005), entre outros, é o critério apresentado por VandenBossche (1977).

O modelo estudado por VandenBossche (1977) leva em consideração uma aproximação de plasticidade do material para examinar a resistência dos pontos de solda em corpos de prova submetidos ao teste de cisalhamento Lap Shear.

Com a aplicação da força tracionando as extremidades do corpo de prova, ocorre a rotação do ponto de solda formando a rótula plástica (Plastic Hinge), ilustrada na figura 6.15. O modo de falha do ponto de solda depende das tensões relativas entre a interface do ponto e a ZTA, que podem ser avaliadas através do critério de Máxima Energia de Distorção de Henky - Huber - Von Mises (VANDENBOSSCHE, 1977) para o cálculo da tensão equivalente, que é então comparada com as tensões de ruptura. Para o entendimento da tensão na interface do ponto, um diagrama das forças atuantes nos corpos (figura 6.16) foi construído, mostrando a decomposição da força $F$ em carga de tração $P$ e carga de cisalhamento $V$. 
As expressões matemáticas do modelo analítico proposto estão apresentadas na sua forma final, sem a apresentação das deduções, que estão detalhadas em VandenBossche (1977).

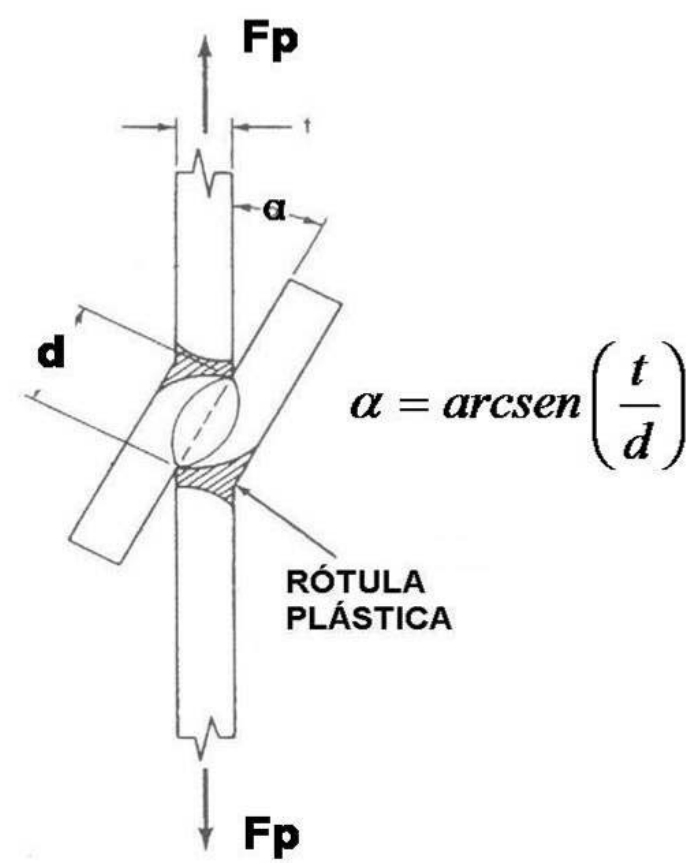

Figura 6.15: Esquema da Rótula Plástica com ação da força aplicada $F_{P}$ (VandenBossche, 1977)

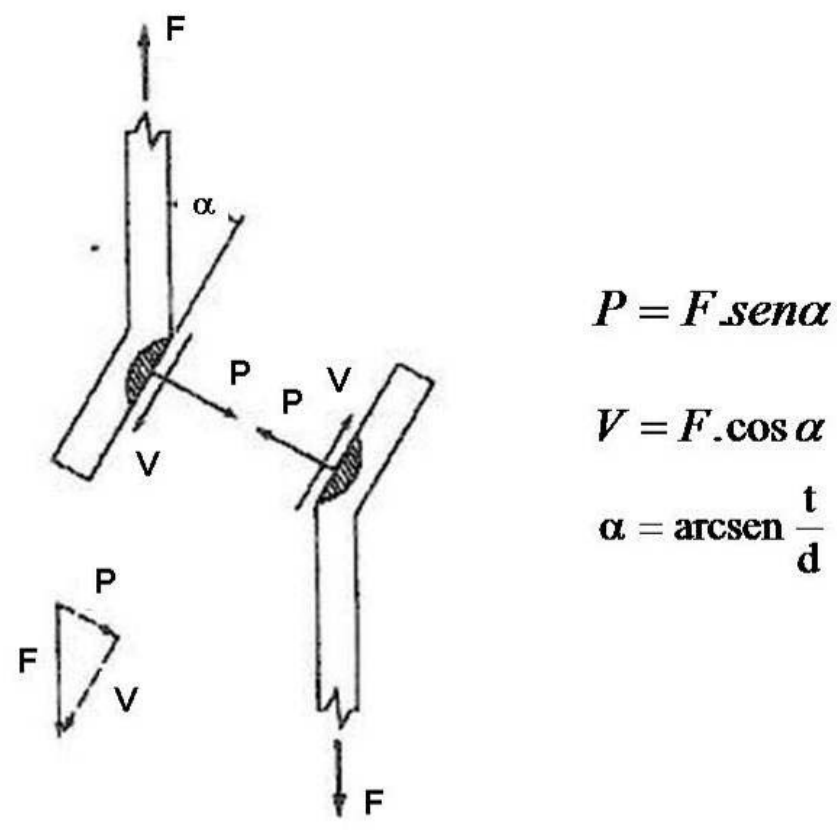

Figura 6.16: Diagrama de Corpo Livre no ponto de máxima rotação da solda (VandenBossche, 1977) 
Para a relação entre a espessura da chapa e o diâmetro do ponto expressa por $0<\mathrm{t} / \mathrm{d} \leq 1 / 3$, a tensão equivalente $\sigma_{e l}$ na interface da solda é:

$$
\sigma_{e l}=\frac{3 \cdot F}{d^{2}}
$$

Para o caso de falha na ZTA, certo volume de metal é empurrado para fora de uma ou das duas chapas, com a forma aproximada de um cilindro, conforme foi utilizado nos cálculos e esquematizado na figura 6.17:

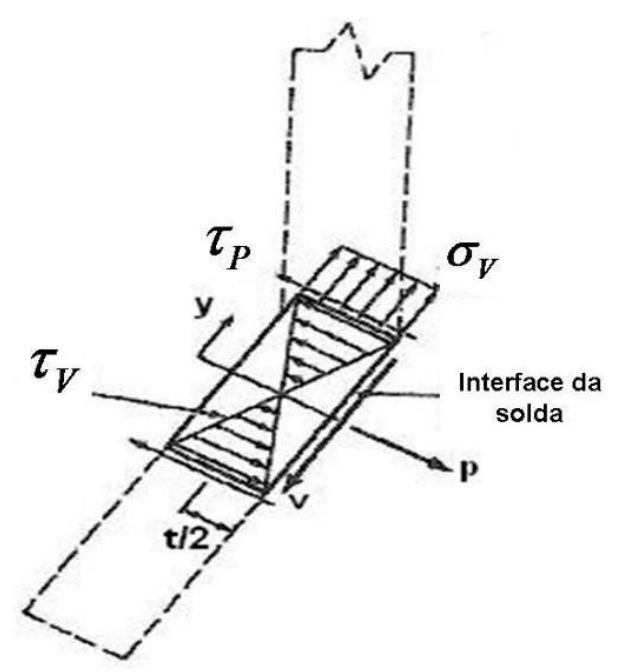

6.17: Distribuição de tensões na ZTA (VandenBossche, 1977)

A tensão na ZTA é dada por:

$$
\sigma_{e Z T A}=\frac{F}{d^{2}} \cdot\left(\frac{d}{t}+\frac{1}{2}\right)
$$

O critério da Máxima Energia de Distorção prevê que a falha ocorrerá quando a tensão equivalente em um ponto determinado exceder o limite de escoamento do critério. Dependendo da escolha do limite, e se ele ocorre na interface ou na ZTA, as equações 6.12 e 6.13 a seguir, podem ser utilizadas para prever onde a falha ocorrerá primeiro: 


$$
\begin{gathered}
\sigma_{e \text { interface }}=\frac{3 \cdot S y_{M B} \cdot w \cdot t}{2 \cdot d^{2}} \\
\sigma_{e \mathrm{Z} T A}=\frac{S y_{M B} \cdot w \cdot t}{2 \cdot d^{2}} \cdot\left(\frac{d}{t}+\frac{1}{2}\right)
\end{gathered}
$$

onde $S y_{M B}$ é a tensão de escoamento do metal base e $w$ é a largura do corpo de prova.

Substituindo $\sigma_{e l}$ por $S y_{M S}$ (tensão de escoamento do metal de solda) e $\sigma_{e Z T A}$ por $S y_{Z T A}$ (tensão de escoamento na ZTA) e rearranjando os termos das equações, têm-se duas expressões (6.14 e 6.15) que relacionam a razão do diâmetro da solda / espessura da chapa com as propriedades independentes do corpo de prova, permitindo a definição dos seguintes critérios:

- Critério de falha para a interface da solda:

$$
\left(\frac{d}{t}\right)^{2}=\frac{3 \cdot S y_{M B} \cdot w}{2 \cdot S y_{M S} \cdot t}
$$

- Critério de falha para a ZTA:

$$
\frac{\left(\frac{d}{t}\right)^{2}}{\left(\frac{d}{t}+\frac{1}{2}\right)}=\frac{S y_{M B} \cdot w}{2 \cdot S y_{Z T A} \cdot t}
$$

Combinando as duas expressões 6.14 e 6.15, e usando a aproximação mostrada abaixo (6.16), resulta da faixa da relação $d / t$, dentro da qual a falha na interface não é possível e a ZTA é assegurada (6.17). 


$$
\begin{gathered}
\frac{\left(\frac{d}{t}\right)^{2}}{\left(\frac{d}{t}+\frac{1}{2}\right)}=\frac{d}{t}-\frac{1}{2} \\
\left(1,5 \cdot \frac{S y_{M B} \cdot w}{S y_{M S} \cdot t}\right)^{\frac{1}{2}}<\frac{d}{t} \leq \frac{S y_{M B} \cdot w}{2 \cdot S y_{Z T A} \cdot t}+\frac{1}{2}
\end{gathered}
$$

Tomando o lado esquerdo da expressão 6.17 como o mais importante, esta revela que há uma tendência de que a falha na interface pode ser suprimida. Assim, para evitar este modo de falha e garantir a falha na ZTA, pode-se definir uma relação d/t crítica:

$$
\left(\frac{d}{t}\right)_{c}=\left(1,5 \cdot \frac{S y_{M S} \cdot w}{S y_{M S} \cdot t}\right)^{\frac{1}{2}}
$$

VandenBossche (1977) concluiu então que caso o valor de $S y_{M S}$ seja constante ou uma função de $S y_{M B}$, então a razão crítica d/t deve ser diretamente proporcional ao limite de escoamento do metal base.

O diâmetro mínimo requerido para falha na ZTA é função também da resistência do metal, espessura e largura da junção, e isso resulta em uma equação que permite relacionar a razão diâmetro-espessura com a carga de ruptura de um ponto de solda.

$$
\frac{d}{t}=\left(0,54 \cdot \frac{S y_{M B}}{1,54 \cdot S y_{M B}+572 M P a} \cdot \frac{w}{t}\right)^{\frac{1}{2}}+3,0
$$

Por fim, VandenBossche (1977) enuncia a carga limite de falha para a solda que pode ser determinada pela relação:

$$
L=\frac{S y_{M B} \cdot w \cdot t}{2}
$$




\section{4 - aplicação do critério de determinação do diâmetro crítico do ponto de solda}

Neste estudo de correlação, conforme descrito no capítulo 4, os corpos de prova testados foram feitos com o material de acordo com a norma NBR 5906, e tem tensão de escoamento $\left(S y_{M B}\right)$ igual a 162,7 MPa. As chapas disponíveis para a confecção possuíam as espessuras de 0,8 e 1,2 mm. A largura da chapa $(w)$ para a chapa de 0,8 $\mathrm{mm}$ de espessura é de $50 \mathrm{~mm}$, e para a chapa de 1,2 $\mathrm{mm}$ é igual a 52 $\mathrm{mm}$.

Assim, de acordo com a equação 6.19 proposta por VandenBossche (1977), o diâmetro crítico para as duas espessuras dos corpos de prova seriam:

- Espessura da chapa $=0,8 \mathrm{~mm}$

$$
\begin{aligned}
& \frac{d c}{0,80}=\left[\frac{0,54 \cdot 162,7}{1,54 \cdot 162,7+572 \mathrm{MPa}} \cdot\left(\frac{50}{0,80}\right)\right]^{\frac{1}{2}}+3,0 \\
& d c=4,47 \mathrm{~mm}
\end{aligned}
$$

- Espessura da chapa $=1,2 \mathrm{~mm}$

$$
\begin{aligned}
& \frac{d c}{1,20}=\left[\frac{0,54 \cdot 162,7}{1,54 \cdot 162,7+572 \mathrm{MPa}} \cdot\left(\frac{52}{1,20}\right)\right]^{\frac{1}{2}}+3,0 \\
& d c=6,18 \mathrm{~mm}
\end{aligned}
$$

Os diâmetros dos pontos de solda nos corpos de prova foram adotados como a média das medidas tomadas em duas direções e são: $6,0 \mathrm{~mm}$ para os corpos de prova com 0,8 $\mathrm{mm}$ de espessura, e 6,5 $\mathrm{mm}$ para os corpos de prova com 1,2 $\mathrm{mm}$ de espessura. Ambos estão acima do limite do diâmetro crítico calculado, garantindo analiticamente a falha na ZTA, o que foi comprovado nos testes Lap Shear e de força normal aplicada diretamente no ponto de solda, descritos no capítulo 5. 


\section{CAPÍTULO 7 CONCLUSÕES}

O estudo de correlação do comportamento das juntas soldadas a ponto, ainda que submetidas a uma pequena variação de tipos de cargas neste estudo, mostrouse eficaz na representação do ponto de solda feita por elementos finitos sólidos (hexaedros) e na representação do material da solda com critério de falha pela força máxima suportada pela junta soldada.

As diferenças dos resultados das avaliações virtuais, no caso da representação da solda por um elemento sólido, para os testes físicos foram da ordem de $1 \%$ para o teste Lap Shear e de $4 \%$ no caso do teste de força normal aplicada diretamente no ponto de solda. Já para a representação por elemento de viga, as diferenças ficaram da ordem de $20 \%$ no teste Lap Shear, e $30 \%$ no teste de força normal aplicada diretamente no ponto de solda.

Pensando em precisão e eficiência, e caracterizando eficiência por tempo de processamento e tamanho do modelo, a utilização de elementos mais simples é fundamental. Assim, apesar do elemento de viga ter apresentado resultados inferiores aos encontrados para as simulações com elemento sólido quando correlacionados aos resultados dos testes em laboratório, uma maior investigação do comportamento deste elemento pode ser compensadora principalmente na sua utilização em modelos grandes de impacto veicular, que conta com milhares de nós e elementos.

A modelagem dos pontos de solda utilizada neste estudo, com independência da malha de elementos finitos, ou seja, sem a necessidade de fazer a ligação por nós, pois esta é feita através do contato, reduz significativamente o tempo necessário para a representação dos muitos pontos de solda presentes num modelo de impacto veicular.

O efeito do refinamento da malha apenas aumentou a rigidez, resultando em menor deslocamento do corpo de prova. Nenhuma mudança significativa é notada para a força máxima suportada pela solda.

A combinação entre critérios de falha utilizando o critério da força máxima no caso da falha na interface do ponto e o critério de deformação para a falha do 
material nas adjacências da ZTA pode ser utilizada para diferenciar os tipos de falha do ponto de solda.

Quando o comportamento elasto-plástico dos materiais é considerado no modelo de elementos finitos, e este é mais realista quando comparado ao comportamento apenas elástico que também é investigado na literatura, o comportamento da solda se mostrou bastante representativo, com diferenças entre as forças máximas da ordem de $4 \%$ para a representação da solda por elementos sólidos. E levando em consideração uma aplicação prática, pode-se julgar que o resultado é suficientemente bom. Assim, a inclusão de outros fatores, tais como a modelagem da ZTA, a qual "encarece" o processo em tempo de modelagem e cálculo, além do tamanho do modelo, não deve afetar qualitativamente esta conclusão.

Não é vantajoso dentro da indústria, onde a premissa do departamento de cálculo estrutural é a correlação dos resultados das simulações com os testes físicos, investir na representação de modelos complexos como a ZTA, uma vez que os parâmetros do processo de soldagem são bastante conhecidos e controlados, e simulações estocásticas podem ser realizadas quando há a necessidade de conhecer o comportamento da junta soldada sob variação desses parâmetros.

Ao contrário, o processo de modelagem e simulação dos pontos de solda deve ser robusto o suficiente para que o "cliente", ou seja, a engenharia de produtos, tenha confiança nos resultados, e o desenvolvimento do projeto do veículo caminhe no futuro para uma validação que ocorra com veículos já da produção, eliminando a necessidade da realização dos testes em protótipos durante o desenvolvimento, gerando assim significativa redução nos custos do projeto. 


\section{CAPÍTULO 8 \\ RECOMENDAÇÃO PARA TRABALHOS POSTERIORES}

Para complementar os estudos aqui apresentados e permitir uma compreensão mais abrangente do comportamento mecânico de juntas soldadas a ponto, os tópicos listados abaixo sugerem outros estudos que podem ser investigados por testes em laboratório e também por análises de elementos finitos:

- Estudos com mais de duas chapas, uma vez que a montagem de 3 chapas soldadas juntas acontece com bastante freqüência em carrocerias;

- Combinação entre espessuras e materiais de propriedades mecânicas diferentes das chapas, uma vez que neste estudo essa variação não foi considerada;

- Investigação em dois níveis diferentes, sendo o primeiro a avaliação de componentes e posteriormente a avaliação de um veículo completo;

- Avaliação de outros tipos de materiais metálicos como os aços de alta resistência e o alumínio;

- Combinação de cargas de cisalhamento e tração em diferentes proporções, o que pode ser conseguido com a aplicação de carga entre os componentes soldados variando o ângulo entre $0^{\circ}$ e $90^{\circ}$;

- Avaliação de juntas soldadas sujeitas a cargas dinâmicas de impacto, onde a taxa de deformação do material pode alterar a propriedade mecânica dos mesmos;

- Estudos em corpos de prova soldados por outros processos, tais como solda MIG e Laser, buscando a correlação dos resultados dos testes físicos vs. virtuais. 


\section{CAPÍTULO 9 \\ REFERÊNCIAS BIBLIOGRÁFICAS}

BATHE, K. J. Finite Element Procedures. Upper Saddle River, New Jersey (EUA): Prentice Hall, 1996; 1037 p.

BELYTSCHKO, T., LIU, W. K., MORAN, B. Nonlinear Finite Elements for Continua and Structures. Chichester (Inglaterra): John Wiley \& Sons Ltd, 2000; 665 p.

CHAO, Y. Ultimate Strength and Failure Mechanism of Resistance Spot Weld Subjected to Tensile, Shear, or Combined Tensile/Shear Loads. Journal of Engineering Materials and Technology, 2003; vol. 125, pp. 125-132.

CHENG, C-S. The Assessment of a Combined Methodology for Spot Weld Failure Modeling. SAE, 2004-01-0690, 2004; 6 p.

COMBESCURE, A. DELCROIX, F., CAPLAIN, L., ESPANOL, S. AND ELIOT, P. A Finite element to simulate the failure of weld points on impact. International Journal of Impact Engineering, 2003; vol. 28, pp. 783-802.

COOK, R. D. Finite Element Modeling for Stress Analysis. Madison, Wisconsin (EUA): John Wiley \& Sons, INC., 1995; 320 p.

Current and future developments of LS-DYNA $-4^{\text {th }}$ European Conference. Livermore, California (EUA): Livermore Software Technology Corporation - LSTC, 1999.

DENG, X., CHEN, W., SHI, G. Three-dimensional finite element analysis of the mechanical behavior of spot welds. Finite Elements in Analysis and Design, 2000; pp. 17-39.

DONG, P. A Framework for Modeling Spot Welds in Finite Element Analysis of Auto-Body Structures. SAE, 1999-01-3191, 1999; 7 p.

General Motors. Worldwide Engineering Standards - Materials Specification Metals (Low Carbon Steel) GMW2, 2004; 11 p. 
HALLQUIST, J. LS-DYNA Theoretical Manual. Livermore, California (EUA): Livermore Software Technology Corporation - LSTC, 1998. 498 p.

HALLQUIST, J. LS-DYNA Keyword user's Manual (Nonlinear Analysis of Structures) - Version 950. Livermore, California (EUA): Livermore Software Technology Corporation - LSTC, 1999. 1130 p.

HALLQUIST, J. LS-DYNA Keyword user's Manual - Version 970. Livermore, California (EUA): Livermore Software Technology Corporation - LSTC, 2003. 1564 p.

HALLQUIST, J. Getting Started with LS-DYNA. Livermore, California (EUA): Livermore Software Technology Corporation - LSTC, 2002. 17 p.

HAMZE, R., DUVAL, L. R. Mechanical Behavior Model of Resistance Spot Weld Joints for Body Structure Crash Simulation. SAE, 1999-01-3189, 1999; 7 p.

HEUBRANDTNER, T., RANGGER, G., SCHERJAU, D. Advanced Spotweld Failure Modeling Based on Trefftz Formulation. LS-DYNA Anwenderforum, Bamberg, 2005; pp. B-I-13 - 22.

Hypermesh 7.0 - Hypermesh version 7.0 - User's Manual, Altair Computing. Inc., 2005.

Hypergraph to Crashworthiness- Hypermesh version 7.0 modules - User's Manual, Altair Computing Inc., 2005.

Hyperview to Crashworthiness - Hypermesh version 7.0 modules - User's Manual, Altair Computing. Inc., 2005.

LEE, Y., WEHNER, T., LU, M., MORRISSETT, T., PAKALNINS, E. Ultimate Strength of Resistance Spot Welds Subjected to Combined Tension and Shear. Journal of Test and Evaluation, 1998; vol. 26, pp. 213-219.

LIN, S. -H., PAN, J., WU, S. -R, TYAN, T. AND WUNG, P. Failure loads of spot welds under combined opening and shear static loading conditions. International Journal of Solids and Structures, 2002; pp. 19-39.

LS-DYNA SUPPORT. LS-DYNA user's guide. Livermore, California (EUA). 78 p. Disponivel em <http://www.dynasupport.com/Support/tutorial/users.guide/>. Acesso em 01 nov. 2006. 
MACKIN, T. J. ME 346 - Failure Mechanisms in Engineering Materials. UrbanaChampaign: University of Illinois (EUA), 2000. Notas de aula da disciplina de pós graduação do Departamento de Engenharia Mecânica, ME 346.

MADASAMY, C., TYAN, T. AND FARUQUE, O. Finite Element Modeling of Spot Weld Connections in Crash Applications. SAE, 2004-01-0691, 2004; 8 p.

MADASAMY, C., TYAN, T., FARUQUE, O. AND GUIMBERTEAU, T. Determination of Spot Weld Modeling Parameters from Test Data for Finite Element Crash Simulation. SAE, 2004-01-0692, 2004; $10 \mathrm{p}$.

MARYA, M., HECTOR, L. G., WANG, K., GAYDEN, X. Q. Tensile-Shear Forces and Fracture Modes in Single and Multiple Weld Specimens in Dual-Phase Steels. Journal of Manufacturing Science and Engineering, 2006; vol. 128, pp 287298.

MENDES, C. Contribuição ao Desenvolvimento de Projeto de Carrocerias Automotivas Utilizando Adesivo Estrutural Para Junção de Chapas Metálicas. 2005. 150 p. Dissertação (Mestrado) - Escola Politécnica da Universidade de São Paulo, São Paulo, 2005.

NAKANO, R. Influência da Taxa de Deformação na Falha de Uniões por Solda a Ponto. 2005. 75 p. Dissertação (Mestrado) - Escola Politécnica da Universidade de São Paulo, São Paulo, 2005.

NIMBALKAR, R. Finite Element Model of a Transit Bus. 2003. 186 p. Master of Science Thesis - The Florida State University FAMU-FSU College of Engineering, Florida (EUA), 2003.

PALUSZNY, A. State-of-the-Art Review of Automobile Structural Crashworthiness. Southfield, Michigan (EUA): American Iron and Steel Institute, 1992. $71 \mathrm{p}$.

RUIZ, D. Contribuição ao Desenvolvimento de Processos de Montagem e Soldagem de Carrocerias Automotivas. 2005. 124 p. Dissertação (Mestrado) Escola Politécnica da Universidade de São Paulo, São Paulo, 2005.

SALVAGNI, R. B. PME 5201 - Análise de Vibrações Mecânicas pelo Método dos Elementos Finitos. São Paulo: Escola Politécnica da Universidade de São Paulo, 2002. Apostila para disciplina de pós graduação na área de Engenharia Mecânica, PME 5201 - Análise Estrutural em Engenharia Mecânica. 
SÁNCHEZ, C. Estudo de Impacto usando Elementos Finitos e Análise Nãolinear. 2001. 129 p. Dissertação (Mestrado) - Escola de Engenharia de São Carlos, Universidade de São Paulo, São Carlos, 2001.

SSAB TUNNPLÅT AB. Sheet Steel Handbook - Design and Fabrication in High Strength Sheet Steel. Borlänge (Suécia), 1996; 196 p.

VANDENBOSSCHE, D. J. Ultimate Strength and Failure Mode of Spot Welds in High Strength Steels. SAE, 770214, 1977. Detroit, MI (EUA), 1977.

XU, S. AND DENG, X. An Evaluation of Simplified Finite Element Models for Spot-Welded Joints. Finite Elements in Analysis and Design 40, 2004; pp. 11751194.

ZHANG, S. A Simplified Spot Weld Model for Finite Element Analysis. SAE, 2004-01-0818, 2004; $7 \mathrm{p}$.

ZHANG, S. Stress intensities at spot welds. International Journal of Fracture 88, 1997; pp. 167-185.

ZHANG, S. Recent Developments in Analysis and Testing of Spot Welds. SAE, 2001-01-0432, $14 \mathrm{p}$.

ZHOU, M., HU, S. J., AND ZHANG, H. Critical Specimen Sizes for Tensile-Shear Testing of Steel Sheets. Welding Research supplement, 1999; pp. 305-313.

ZUNIGA, S. M., SHEPPARD, S. D. Determining the Constitutive Properties of the Heat-Affected Zone in a Resistance Spot Weld. Modeling Simulation and Materials Science, 1995; vol. 3, pp. 391-416.

WANG, K. Modeling of Spot Weld Separation in LS-DYNA. General Motors Engineering Report, 2000; $15 \mathrm{p}$.

WITTEMAN, W. Improved Vehicle Crashworthiness Design by Control of the Energy Absorption for Different Collision Situations. 1999. 191 p. Doctoral Thesis - Eindhoven University of Technology, Eindhoven (Holanda), 1999.

WUNG, P. A Force-based Failure Criterion for Spot Weld Design. Experimental Mechanics, 2001; pp. 107-113. 


\section{ANEXO I \\ LS-DYNA - Lista de Unidades Consistentes}

Unidades consistentes de acordo com o manual do LS-DYNA (HALLQUIST, 2002)

\begin{tabular}{|l|c|c|c|}
\hline & (a) & (b) & (c) \\
\hline \hline Length unit & meter & millimeter & millimeter \\
Time unit & second & second & millisecond \\
Mass unit & kilogram & tonne & kilogram \\
Force unit & Newton & Newton & kiloNewton \\
Young's Modulus of Steel & $210.0 \mathrm{E}+09$ & $210.0 \mathrm{E}+03$ & 210.0 \\
Density of Steel & $7.85 \mathrm{E}+03$ & $7.85 \mathrm{E}-09$ & $7.85 \mathrm{E}-06$ \\
Yield stress of Mild Steel & $200.0 \mathrm{E}+06$ & 200.0 & 0.200 \\
Acceleration due to gravity & 9.81 & $9.81 \mathrm{E}+03$ & $9.81 \mathrm{E}-03$ \\
Velocity equivalent to 30 mph & 13.4 & $13.4 \mathrm{E}+03$ & 13.4 \\
\hline
\end{tabular}




\section{ANEXO II \\ Diferenças nos Parâmetros de Soldagem entre Aços de Baixo Carbono e Aços de Alta Resistência}

\begin{tabular}{|l|l|}
\multicolumn{1}{|c}{ Referência: SSAB TUNNPLÂT, 1996} \\
\hline \multicolumn{1}{|c|}{ Parâmetro de solda } & \multicolumn{1}{c|}{ Diferença substituindo aço de baixo carbono por aço de alta resistência } \\
\hline Tempo de Soldagem & Normalmente não há diferença \\
\hline Corrente & $\begin{array}{l}\text { Redução da corrente para aços sem revestimento. Para aços revestidos, não } \\
\text { importando qual o tipo do aço, a corrente necessária é maior do que para aços sem } \\
\text { revestimento }\end{array}$ \\
\hline Força do eletrodo & A força do eletrodo deve ser aumentada em no máximo $50 \%$ \\
\hline Tempo de Resfriamento & $\begin{array}{l}\text { Pode ser crítico para altas taxas de resfriamento. Manter o tempo de resfriamento o } \\
\text { mais curto possível }\end{array}$ \\
\hline Eletrodos & Normalmente os mesmos eletrodos podem ser utilizados \\
\hline
\end{tabular}




\section{ANEXO III \\ CONSIDERAÇÕES PRELIMINARES E EQUAÇÕES GOVERNANTES \\ UTILIZADAS PELO LS-DYNA}

Considere o corpo mostrado na figura 2.2 mostrada na seção 2.1.2. Ele é objeto de estudo para se entender a deformação ao longo do tempo na qual um ponto em $b$ inicialmente em $x_{a}(\alpha=1,2,3)$ no sistema de coordenadas Cartesianas retangulares se move para um ponto $x_{i}(i=1,2,3)$ no mesmo sistema de coordenadas. Desde que a formulação Lagrangeana seja utilizada, a deformação pode ser expressa em termos de coordenadas $\mathrm{x}_{\alpha}$, e tempo $\mathrm{t}$ (HALLQUIST, 1998):

$$
x_{i}=x_{i}\left(X_{\alpha}, t\right)
$$

No tempo $t=0$ têm-se as seguintes condições iniciais:

$$
\begin{gathered}
x_{i}\left(X_{\alpha}, 0\right)=X_{\alpha} \\
\dot{x}_{i}\left(X_{\alpha}, 0\right)=V_{i}\left(X_{\alpha}\right)
\end{gathered}
$$

onde Vi define as velocidades iniciais.

A solução para a equação de momento (4) é procurada, satisfazendo as condições de contorno definidas por (5) no limite $\partial b_{1}$, os deslocamentos nas condições de contorno (6) no limite $\partial b_{2}$, a descontinuidade de contato (2.36) ao longo de um limite interior $\partial b_{3}$ quando $x_{i}^{+}=x_{i}^{-}$.

$$
\begin{gathered}
\sigma_{i j, j}+\rho f_{i}=\rho \ddot{x}_{i} \\
\sigma_{i j} n_{i}=t_{i}(t) \\
x_{i}\left(X_{\alpha}, t\right)=D_{i}(t) \\
\left(\sigma_{i j}^{+}-\sigma_{i j}^{-}\right) n_{i}=0
\end{gathered}
$$


Aqui, $\sigma_{i j}$ é a tensão de Cauchy, $\rho$ é a densidade instantânea, $f$ é a densidade de força do corpo, $\ddot{x}$ é a aceleração, as vírgulas denotam uma diferenciação covariante, e $n_{j}$ é um vetor normal direcionado para fora para o elemento de contorno de $\partial b$.

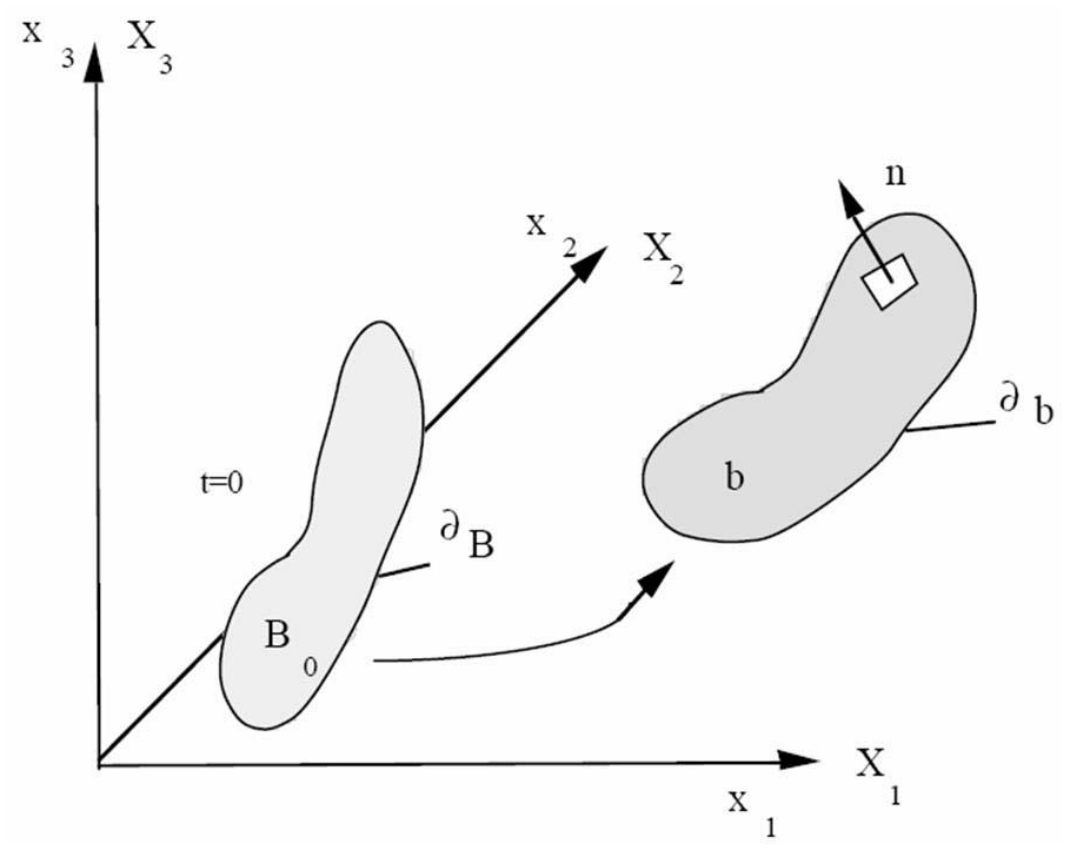

Figura 2.6: Esquema do Processo Iterativo de Integração no Tempo do LS-DYNA (LS-DYNA Theory Manual, 1998)

A conservação de massa é trivialmente expressa por:

$$
\rho V=\rho_{0}
$$

onde $\mathrm{V}$ é o volume relativo, que é o determinante da matriz gradiente de deformação, $F_{i j}$,

$$
F_{i j}=\frac{\partial x_{i}}{\partial X_{j}}
$$

e $\rho_{0}$ é a densidade de referência. A equação de energia 


$$
\dot{E}=V S_{i j} \dot{\varepsilon}_{i j}-(p+q) \dot{V}
$$

é integrada no tempo e usada para avaliação das equações de estado e o balanço de energia global. Na equação (10), $s_{i j}$ e p representam tensões e pressões conforme as relações abaixo:

$$
\begin{gathered}
s_{i j}=\sigma_{i j}+(p+q) \delta_{i j} \\
p=-\frac{1}{3} \sigma_{i j} \delta_{i j}-q=-\frac{1}{3} \sigma_{k k}-q
\end{gathered}
$$

onde q é a viscosidade, $\delta_{i j}$ é a variação de Kronecker ( $\delta_{i j}=1$ se i=j; ao contrário, $\left.\delta_{i j}=0\right)$ e $\dot{\varepsilon}_{i j}$ é o tensor de taxa de deformação. A taxa de deformação e a viscosidade não serão detalhadas nestas considerações introdutórias.

Pode-se escrever:

$\int_{V}\left(\rho \ddot{x}_{i}-\sigma_{i j, j}-\rho f\right) \delta x_{i} d v+\int_{\partial b_{1}}\left(\sigma_{i j} n_{j}-t_{i}\right) \delta x_{i} d s+\int_{\partial b_{3}}\left(\sigma_{i j}^{+}-\sigma_{i j}^{-}\right) n_{j} \delta x_{i} d s=0$

onde $\delta x_{i}$ satisfaz todas as condições de contorno em $\partial b_{2}$, e as integrações são sobre a geometria atual. A aplicação do teorema de divergência dá:

$$
\int_{V}\left(\sigma_{i j} \delta x_{i}\right)_{, j} d v=\int_{\partial b_{1}} \sigma_{i j} n_{j} \delta x_{i} d s+\int_{\partial b_{3}}\left(\sigma_{i j}^{+}-\sigma_{i j}^{-}\right) n_{j} \delta x_{i} d s
$$

e notando que

$$
\left(\sigma_{i j} \delta x_{i}\right)_{, j} \sigma_{i j, j} \delta x_{i}=\sigma_{i j} \delta x_{i, j}
$$

leva-se a forma fraca da equação de equilíbrio:

$$
\delta \pi=\int_{V} \rho \ddot{x}_{i} \delta x_{i} d v+\int_{V} \sigma_{i j} \delta x_{i, j} d v-\int_{V} \rho f_{i} \delta x_{i} d v-\int_{\partial b_{1}} t_{i} \delta x_{i} d s=0
$$


que é uma definição do Princípio do Trabalho Virtual.

Impondo a malha de elementos finitos interconectada nos pontos nodais em uma configuração de referência e monitorando partículas através do tempo, que é:

$$
x_{i}\left(X_{\alpha}, t\right)=x_{i}\left(X_{\alpha}(\xi, \eta, \zeta), t\right)=\sum_{j=1}^{k} \phi_{j}(\xi, \eta, \zeta) x_{i}^{j}(t)
$$

onde $\phi_{j}$ são as funções de forma (interpolação) das coordenadas paramétricas $(\xi, \eta, \zeta), \mathrm{k}$ é o número de pontos nodais que definem o elemento, e $x_{i}^{j}$ é a coordenada nodal do j-ésimo nó na i-ésima direção.

Somando os n elementos, pode-se aproximar de $\delta \pi$ com:

$$
\delta \pi=\sum_{m=1}^{n} \delta \pi_{m}=0
$$

e escrever:

$$
\sum_{m=1}^{n}\left\{\int_{v_{m}} \rho \ddot{x}_{i} \Phi_{i}^{m} d v+\int_{v_{m}} \sigma_{i j}^{m} \Phi_{i, j}^{m} d v-\int_{v_{m}} \rho f_{i} \Phi_{i}^{m} d v-\int_{\partial b_{1}} t_{i} \Phi_{i}^{m} d s\right\}=0
$$

onde

$$
\Phi_{i}^{m}=\left(\Phi_{1}, \Phi_{2}, \ldots, \Phi_{k}\right)_{i}^{m}
$$

Em notação matricial, a equação (19) se torna:

$$
\sum_{m=1}^{n}\left\{\int_{v_{m}} \rho N^{t} N a d v+\int_{v_{m}} B^{t} \sigma d v-\int_{v_{m}} \rho N^{t} b d v-\int_{\partial b_{1}} N^{t} t d s\right\}^{m}=0
$$

onde $\mathrm{N}$ é uma matriz de interpolação e $\sigma$ é o vetor de tensões

$$
\sigma^{t}=\left(\sigma_{x x}, \sigma_{y y}, \sigma_{z z}, \sigma_{x y}, \sigma_{y z}, \sigma_{z x}\right)
$$


B é a matriz deformações-deslocamentos, a é o vetor de aceleração nodal

$$
\left[\begin{array}{c}
\ddot{x}_{1} \\
\ddot{x}_{2} \\
\ddot{x}_{3}
\end{array}\right]=N\left[\begin{array}{c}
a_{x_{1}} \\
a_{y_{1}} \\
\vdots \\
a_{y_{k}} \\
a_{z_{k}}
\end{array}\right]=N a
$$

B é o vetor carregamento de forças do corpo, e t são os carregamentos de tração aplicados.

$$
b=\left[\begin{array}{l}
f_{x} \\
f_{y} \\
f_{z}
\end{array}\right], \quad t=\left[\begin{array}{l}
t_{x} \\
t_{y} \\
t_{z}
\end{array}\right]
$$

